\title{
Alan Fappi
}

\section{Efeitos do ácido graxo ômega-3 na prevenção da atrofia muscular induzida pela dexametasona}

Dissertação apresentada à Faculdade de Medicina da Universidade de São Paulo para obtenção do título de Mestre em Ciências.

Programa de Neurologia

Orientador: Prof. Dr. Edmar Zanoteli 


\section{Alan Fappi}

\section{Efeitos do ácido graxo ômega-3 na prevenção da atrofia muscular induzida pela dexametasona}

Dissertação apresentada à Faculdade de Medicina da Universidade de São Paulo para obtenção do título de Mestre em Ciências.

Programa de Neurologia

Orientador: Prof. Dr. Edmar Zanoteli

\section{SÃO PAULO}

2013 
Dados Internacionais de Catalogação na Publicação (CIP)

Preparada pela Biblioteca da

Faculdade de Medicina da Universidade de São Paulo

Creprodução autorizada pelo autor

Fappi, Alan

Efeitos do ácido graxo ômega-3 na prevenção da atrofia muscular induzida pela dexametasona / Alan Fappi. -- São Paulo, 2013.

Dissertação(mestrado)--Faculdade de Medicina da Universidade de São Paulo. Programa de Neurologia.

Orientador: Edmar Zanoteli.

Descritores: 1.Atrofia muscular/genética 2.Atrofia muscular/patologia 3.Atrofia muscular/induzido quimicamente 4.Glucocorticoides 5.Dexametasona/efeitos adversos 6.Músculo esquelético/efeitos de drogas 7.Ácidos graxos ômega-3/efeitos adversos 8.Ratos Wistar 9.Fatores de transcrição Forkhead 10.Ubiquitina-proteína ligases/genética 11.Reação em cadeia da polimerase em tempo real 12.Western Blotting 


\section{DEDICATÓRIA}

Dedico este trabalho àqueles que de alguma forma me auxiliaram para que eu continuasse em frente, buscando e alcançando o "sonho" acadêmico. Àqueles que mesmo sabendo das dificuldades que eu encontraria, me fizeram ver a oportunidade nas dificuldades, e não o oposto.

Dedico esse trabalho, em especial, aos meus pais, Srs. Eloi e Helena Fappi, que "construíram" em mim, diariamente, uma base estável de autoconfiança que me mantinha seguro meio às incertezas que existiam e hão de existir hoje e sempre. Para estes lhe digo: "Sou seu sangue, seu amor, a transcrição de suas vidas, dedico tudo a vocês". 


\section{AGRADECIMENTOS}

Ao meu orientador, Professor Dr. Edmar Zanoteli, um especial agradecimento por todo auxílio e respeito desde o primeiro dia de laboratório, obrigado por acreditar nos alunos, nas pessoas, e em mim. Sem que o senhor perceba está participando dos sonhos das pessoas, nas suas conquistas, como faz agora nessa etapa de minha vida, a você, "meu amigo", muito obrigado.

Ao Professor Dr. Gerson Chadi, por receber e acreditar sempre em novos alunos e profissionais, independente do que façam, contanto que estejam dispostos a fazer pesquisa. Obrigado por acreditar nas contribuições que eu poderia trazer ao "nosso" laboratório.

Aos amigos e companheiros de laboratório, agradeço o apoio, encorajamento, auxílio e por participarem se alguma forma para meu "crescimento profissional" jamais me esquecerei de vocês: Leandro N. Sanches, Thaísa Benatti, Kathe Coccuzi, Chrystian Junqueira Alves, Gabriela Pintar de Oliveira, Vanessa R. Rizzato, Juliana de Carvalho Neves, Thais Virgínia, Chary Eli, Dr ${ }^{\mathrm{a}}$ Jessica R. Maximino, Eliene, Tatiana Duobles, Juliana Scoriza, Francisco Marcos Alencar Silva, Tereza Florence Dinucci, Sarah de Souza Gomes, Gilmar Marques da Silva, Iolanda de Paula Oruê, Mariana Miranda, Paula Martho, Daniel Go Ishibira, Camila Veja, Vanessa Kummer e Helena Aquino.

Aos LIMs: Patologia (LIM 22), Neurologia (LIM15), Oncologia (LIM24) pela disponibilização de equipamentos e contribuição nesta pesquisa.

Agradeço a Deus pela dádiva da vida e por nos manter pensantes (existentes) neste solo fértil, onde a "nova" ciência nasce e a "velha" nova ciência morre a cada dia, nos permitindo planejar, agir - errando e acertando - e além de tudo, refletir sobre a intrigante perfeição da maquinaria humana, para que desta forma, seja cada vez mais possível, de fato, ajudar o próximo.

Um especial agradecimento à Marília N. Pontarolli, pelos incentivos, desincentivos, amor e companheirismo durante minha caminhada profissional e à Susana Sales Telles, por me apresentar formalmente ao mundo laboratorial: "se estou aqui hoje, devo parte disso a vocês, obrigado". 
Agradeço a CAPES e a FAPESP (2011/03862-8) pelo suporte financeiro (bolsa de auxílio) a mim provido, me permitindo, desta forma, cumprir todas as etapas de pesquisa me dedicando exclusivamente a isso. 
Epígrafe

"Não há fatos eternos, como não há verdades absolutas". Friedrich Nietzsche 
Esta dissertação está de acordo com as seguintes normas:

Universidade de São Paulo. Faculdade de Medicina. Divisão de Biblioteca e Documentação.

Guia de apresentação de dissertações, teses e monografias / elaborado por Anneliese Carneiro da Cunha, Maria Julia de A. L. Freddi, Maria Fazanelli Crestana, Marinalva de Souza Aragão, Suely Campos Cardoso, Valéria Vilhena. 3a ed. - São Paulo : Divisão de Biblioteca e Documentação - DBD/FMUSP, 2011. 92p.

Abreviaturas dos títulos dos periódicos de acordo com o List of Journals Indexed in Index Medicus 


\section{SUMÁRIO}

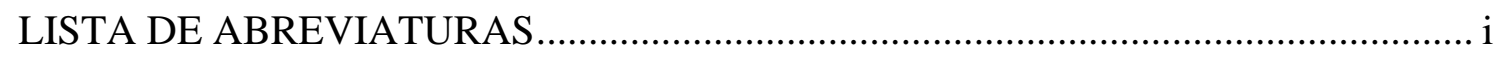

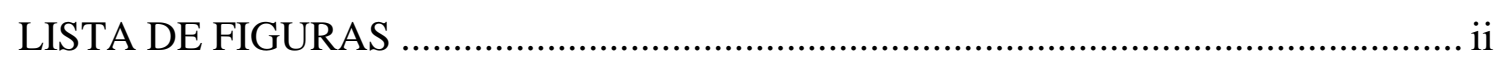

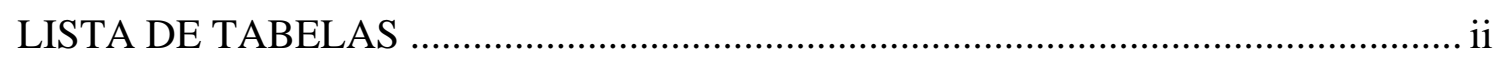

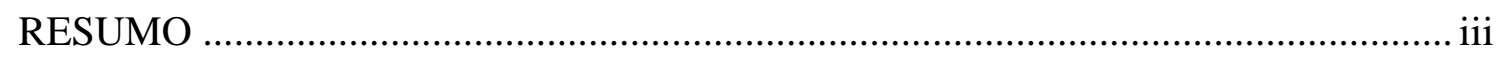

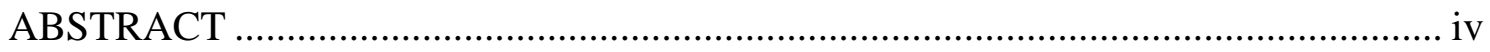

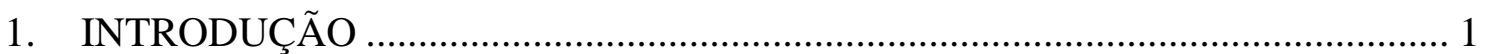

2. REVISÃO DA LITERATURA....................................................................... 2

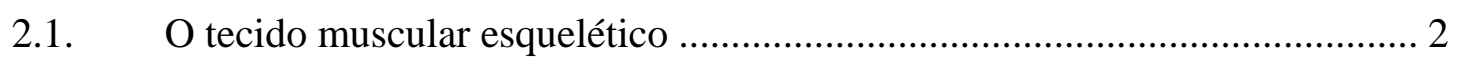

2.2. Contração muscular esquelética.................................................................. 4

2.3. Atrofia muscular esquelética........................................................................ 5

2.3.1. Sistema Ubiquitina Proteassoma (SUP) .................................................. 6

2.3.2. Atrofia relacionada à via IGF-1/PI -3K/Akt/mTOR …................................ 7

2.3.3. Fatores de transcrição NF-kB e TNF- $\alpha$ e a atrofia muscular ........................ 10

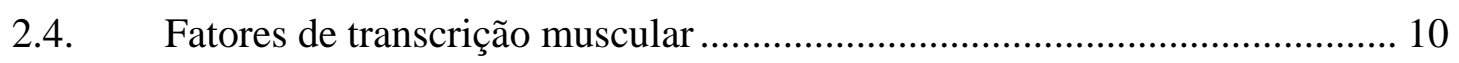

2.5. Glicocorticoides e a atrofia muscular esquelética ...................................... 12

2.6. Alvos potenciais no tratamento da atrofia muscular ................................. 14

2.7. Ácidos graxos e sua atuação na atrofia muscular....................................... 15

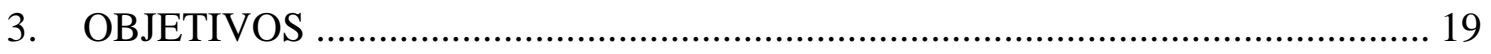

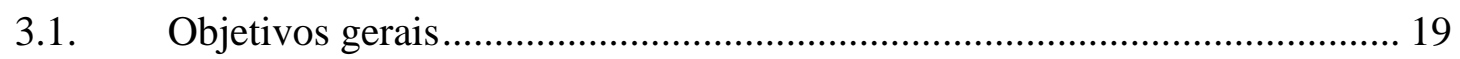

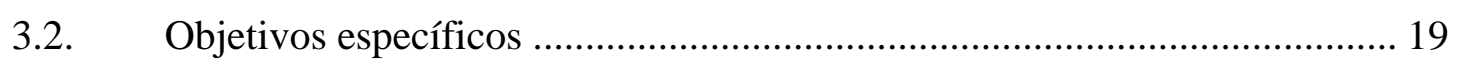

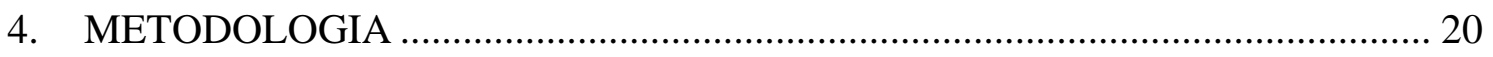

4.1. Animais do estudo e Estruturação ………................................................... 20

4.1.1. Suplementação com o Ômega-3 e indução da atrofia muscular .................. 20

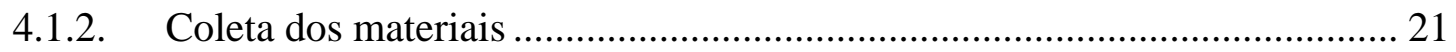

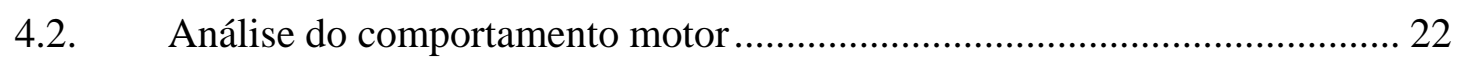

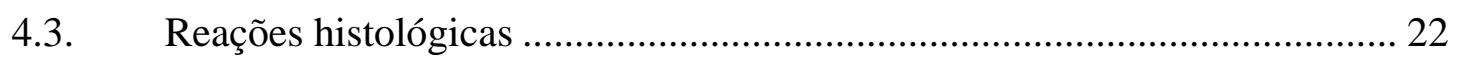

4.4. Coloração metacromatica de ATPase ......................................................... 22

4.5. Eletroforese SDS-PAGE (Western blotting) ............................................. 23

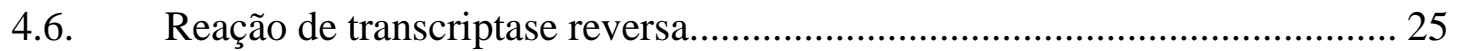

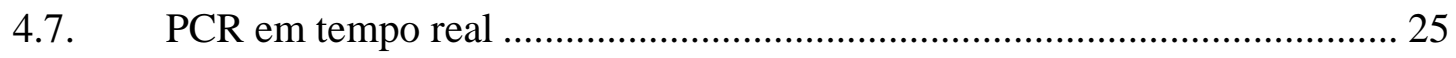




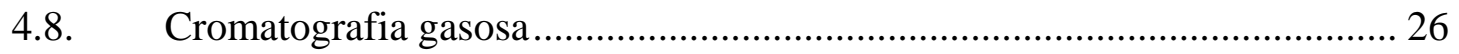

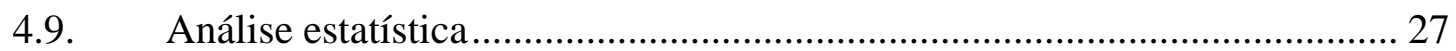

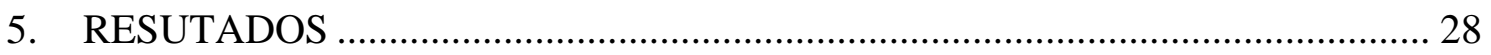

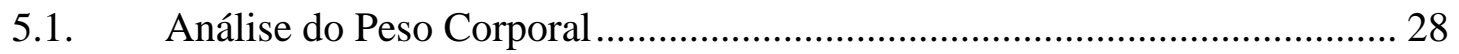

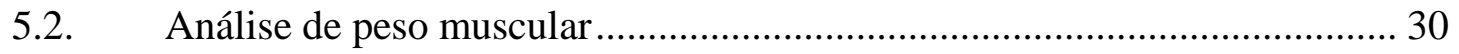

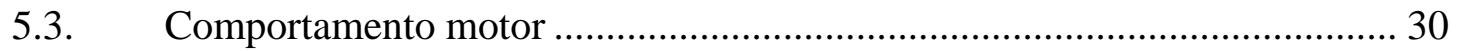

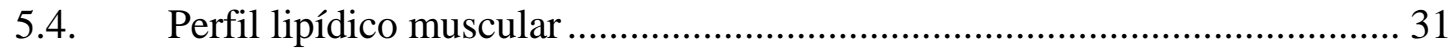

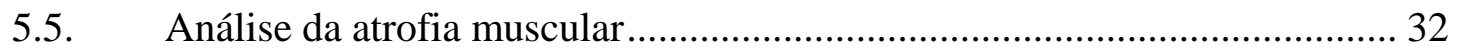

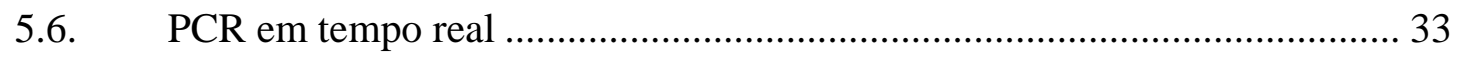

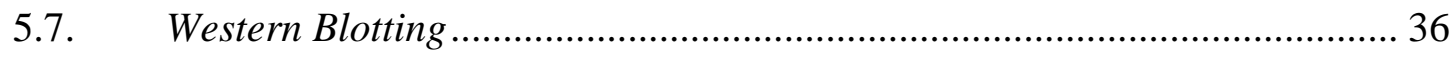

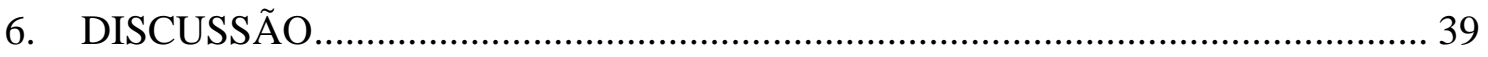

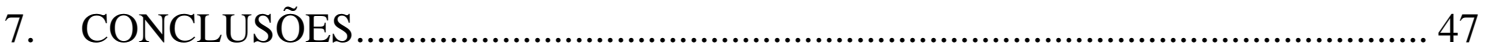

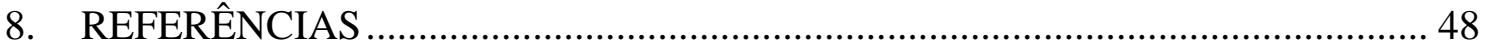

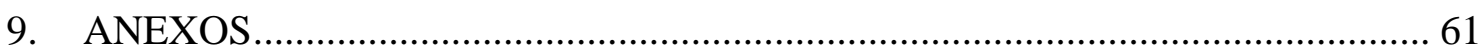

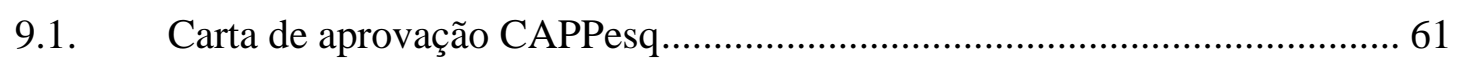




\section{LISTA DE ABREVIATURAS}

4EBP1

AIDS

Akt/PKB

DG

DHA

DMC

eIF-2B

EPA

FOXO

GA

GAD

GAPDH

GSK3- $\beta$

HMB

IGF-1

IKB

IKK

LDL

$M A F b x$

MRF

mTOR

MuRF

Myf5

$\mathrm{MyHC}$

MyoD

NF- kB

P70S6K

PGC1 $\alpha$

PI-3k

PPAR $\gamma$

REDD1 e 2

RNAm

SUP

TA

TGF- $\beta$

TNF- $\alpha$

$\omega-3$

$\omega-6$ do inglês, factor $4 E$ binding protein 1

do inglês, Acquired immune deficiency syndrome

do inglês, protein kinase- $B$

distroglicanas

do inglês, docosahexaenoic acid

distrofia muscular congênita

do inglês, eukaryotic initiation factor 2

do inglês, eicosapentaenoic acid

do inglês, forkhead box $O$

gastrocnêmio

glicoproteínas associadas à distrofina

do inglês, glyceraldehyde 3-phosphate dehydrogenase

do inglês, glycogen synthase kinase-3

do inglês, hydroxymethylbutyrate

do inglês, Insulin-like growth factor 1

do inglês, IkappaB

do inglês, IkappaB kinase

do inglês, low-density lipoprotein

do inglês, muscle atrophy f-box, sinônimo para atrogina-1

do inglês, myogenic regulatory factors

do inglês, mammalian target of rapamycin

do inglês, muscle ring finger

do inglês, myogenic factor 5

do inglês, myosin heavy chain

do inglês, myogenic differentiation

do inglês, nuclear factor-kappaB

do inglês, p70 ribosomal S6 Kinase

do inglês, peroxisome proliferator activated receptor gamma

coactivator alpha

do inglês, phosphatidylinositol 3-kinase

do inglês, peroxisome proliferatoractivated receptor $\gamma$

do inglês, Regulated in development and DNA damage responses 1

e 2

RNA mensageiro

sistema da ubiquitina proteassoma

tibialis anterior

do inglês, Transforming and Growth Factor- $\beta$

do inglês, Tumor necrosis factor alpha

Ômega-3

Ômega-6 


\section{LISTA DE FIGURAS}

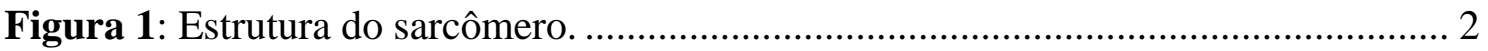

Figura 2: Propriedades contráteis das fibras musculares ............................................ 3

Figura 3: Sinalização do IGF-1 na atrofia muscular induzida por glicocorticoide ........ 14

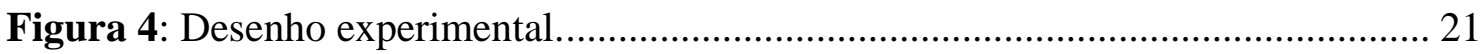

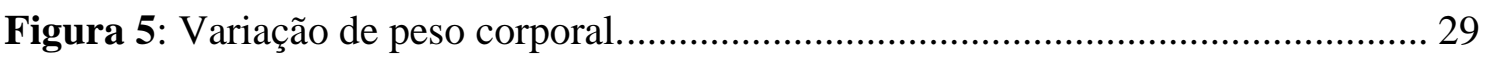

Figura 6: Porcentagem de perda de peso corporal..................................................... 29

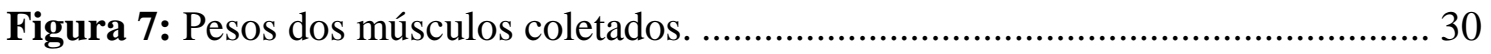

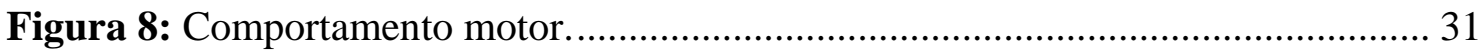

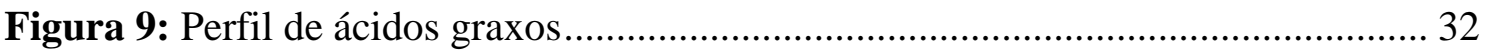

Figura 10: Cortes transversais de fibras musculares. ................................................. 33

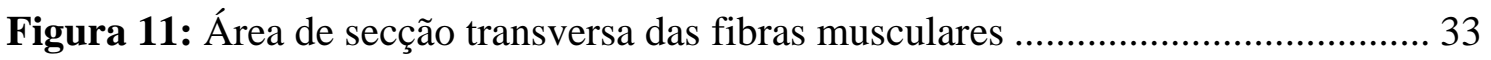

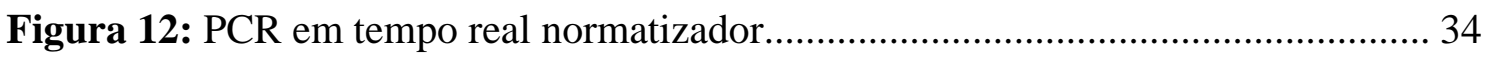

Figura 13: Expressão gênica de $M y o D$ e Miogenina ..................................................... 34

Figura 14: Expressão gênica de atrogina-1, MuRF e Miostatina................................. 35

Figura 15: Expressão gênica do REDD-1 e REDD2 .................................................. 36

Figura 16: Expressão proteica de Akt, GSK3 $\beta$, P-Akt e P- GSK3 $\beta$............................. 37

Figura 17: Expressão proteica de FOXO3a, mTOR, P-FOXO3a e P-mTOR............... 38

\section{LISTA DE TABELAS}

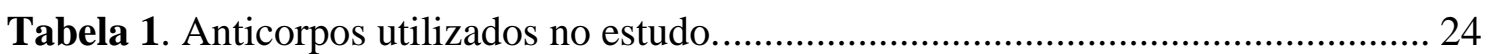

Tabela 2. Sequencias de oligonucleotídeos utilizados no estudo............................... 26 


\section{RESUMO}

Fappi A. Efeitos do ácido graxo Ômega-3 na prevenção da atrofia muscular induzida pela dexametasona [Dissertação]. São Paulo: Faculdade de Medicina, Universidade de São Paulo; 2013.

Várias condições podem estar associadas com a atrofia muscular, tais como inatividade, envelhecimento, septicemia, diabetes, câncer e uso de glicocorticoides. Todas estas condições levam a atrofia muscular através de mecanismos que incluem aumento da degradação proteica e/ou redução na síntese proteica, envolvendo pelo menos cinco sistemas: lisossomal, da calpaína, das caspases, metaloproteinases e o sistema ubiquitina-proteasoma (SUP). Glicocorticoides, tais como a dexametasona, acarretam atrofia muscular atuando em quase todos esses sistemas, com significante ativação do SUP e lisossomal, afetando uma importante via de trofismo muscular, a via do IGF-1/PI-3K/Akt/mTOR. Ácidos graxos poli-insaturados, como o Ômega-3 ( $\omega-3)$, têm sido utilizados de forma benéfica na atenuação da atrofia muscular que ocorre na septicemia e na caquexia associada ao câncer, no entanto, sua atuação sobre a atrofia muscular induzida por glicocorticoides ainda não foi avaliada. Objetivo: Avaliar se a suplementação do ácido graxo $\omega-3$ influenciaria o desenvolvimento da atrofia muscular induzida pela dexametasona em ratos. Metodologia: Vinte e quatro ratos Wistar suplementados e não suplementados com $\omega-3$ (40 dias) foram submetidos à administração de dexametasona subcutânea $(5 \mathrm{mg} / \mathrm{Kg} / \mathrm{dia})$ nos últimos 10 dias, formando assim quatro grupos: Controle (CT), dexametasona (DX), $\omega 3$ e dexametasona $+\omega 3(\mathrm{DX}+\omega 3)$. Através de estudo de comportamento motor, histológico, PCR em tempo real e Western Blotting foram avaliados respectivamente, o número de grandes e pequenos movimentos em campo aberto; a área de secção transversa das fibras musculares (fibras I, IIA e IIB); a expressão dos genes MyoD, Miogenina, MuRF-1, Atrogina-1 e Miostatina; e a expressão de proteínas relacionadas com a via do IGF-1/PI3K/Akt/mTOR: Akt, GSK3 $\beta$, FOXO3a e mTOR, totais e fosforiladas. Resultados: A dexametasona produziu diminuição na quantidade de pequenos movimentos, atrofia muscular em fibras do tipo IIB e diminuição na expressão de P-Akt, P-GSK3ß e P-FOXO3a/FOXO3a total. A suplementação com Ômega-3 não se mostrou eficaz na atenuação de tais alterações. Por outro lado, o Ômega-3 associado à dexametasona (grupo DX $+\omega 3$ ) induziu a maior expressão de atrogenes (MuRF-1 e atrogina-1) causando, adicionalmente, maior atrofia muscular em fibras do tipo I e IIA, além de menor expressão gênica de Miogenina. O Ômega-3 de forma isolada conduziu de forma significativa a maior expressão de Miostatina e MyoD, e de forma não significante elevou a expressão proteica de mTOR total e induziu menor ganho de peso corporal dos animais ao fim do estudo. Conclusão: A suplementação de Ômega-3 não foi capaz de atenuar as alterações comportamentais, atrofia muscular e perda de peso corporal causadas pela administração de dexametasona, levando por outro lado a maior atrofia das fibras musculares e aumento na expressão de atrogenes. Desta forma, este estudo sugere que suplementos alimentares usualmente considerados benéficos para saúde, tal como o ácido graxo Ômega-3, podem agir em interação com alguns medicamentos, como os glicocorticoides, potencializando seus efeitos colaterais.

Descritores: Atrofia muscular/genética; Atrofia muscular/patologia; Atrofia muscular/induzido quimicamente; Glucocorticoides; Dexametasona/efeitos adversos; Músculo esquelético/efeitos de drogas; Ácidos graxos ômega-3/efeitos adversos; Ratos Wistar; Fatores de transcrição Forkhead; Ubiquitina-proteína ligases/genética; Reação em cadeia da polimerase em tempo real; Western Blotting 


\begin{abstract}
Fappi A. Effects of omega-3 fatty acid in preventing dexamethasone-induced muscle atrophy [dissertation]. Sao Paulo: "Faculdade de Medicina, Universidade de São Paulo"; 2013.
\end{abstract}

Many conditions can be related to muscle atrophy, such as inactivity, aging, sepsis, diabetes, cancer, as well as, glucocorticoid treatment. All these conditions lead to muscle atrophy through mechanisms that include increase of protein degradation and/or decrease of protein synthesis involving at least five systems: lysossomal, calpain, caspases, metaloproteinases and ubiquitin proteasome system (UPS). Glucocorticoids, such as dexamethasone cause muscle atrophy acting in almost all of these systems, with a significant UPS activation and affecting an important pathway related to muscular trophism, IGF-1/PI-3k/Akt/mTOR pathway. Polyunsaturated fatty acids, such as Omega-3 ( $\omega-3)$, have been used beneficially to attenuation of muscle atrophy that occur in sepsis and cachexia related to cancer, however, its action in the glucocorticoid-induced muscle atrophy, has never been evaluated. Objective: Assess whether the $\omega-3$ supplementation would influence the development of dexamethasone-induced muscle atrophy in rats. Methods: Twenty four Wistar rats supplemented and non-supplemented with $\omega$ 3 (40 days) were submitted to dexamethasone administration $(5 \mathrm{mg} / \mathrm{kg} /$ day $)$ during the last 10 days, thus establishing 4 groups: control (CT), dexamethasone (DX), $\omega-3$ and dexamethasone $+\omega-3$ (DX+ $+\omega-3)$. The amount of large and small movements in open field; muscle fiber cross sectional areas (I, IIA and IIB); MyoD, Myogenin, MuRF-1, Atrogin-1 and Myostatin gene expression; and protein expression of Akt, GSK3 $\beta$, FOXO3a and mTOR, total and phosphorylated forms were assessed, respectively, by: motor behavior testing, histological reactions, Real-time PCR and Western Blotting analysis. Results: Dexamethasone administration induced significant decrease of small motor movements, atrophy in type IIB muscle fibers and decrease of P-Akt, P-GSK3 $\beta$ and P-FOXO3a/total FOXO3a expression. Omega-3 supplementation was not able to attenuate these changes. Instead, $\omega$ - 3 associated to dexamethasone (DX+ $\omega$-3 group) additionally induced higher muscle atrophy in type I, IIA muscle fibers, and reduced expression of Myogenin. The isolated use of Omega-3 led to a significant higher expression of Myostatin and $M y o D$, and a non-significant increase of total mTOR protein expression and less body weight gain at end of study. Conclusion: Supplementation of $\omega-3$ was not able to attenuate motor behavioral changes, muscle atrophy and loss of body weight caused by dexamethasone administration, leading on the other hand to higher muscle fibers atrophy and increase in atrogenes expression. Therefore, this study suggests that food supplements, usually considered benefic to the health, such as Omega-3 fatty acid, may interact with some medications, such as glucocorticoids, potentiating its side effects.

Descriptors: Muscular atrophy/genetics; Muscular atrophy/pathology; Muscular atrophy/chemically induced; Glucocorticoids; Dexamethasone/adverse effects; Muscle, skeletal/drugs effects; Fatty acids, omega-3/adverse effects; Rats, Wistar; Forkhead transcription factors; Ubiquitin-protein ligases; Real-time polymerase chain reaction; Blotting Western. 


\section{INTRODUÇÃO}

O tecido muscular esquelético é o mais abundante no corpo humano, correspondendo cerca de 30 a $40 \%$ da massa corporal de um ser humano adulto (Nader, 2005; Schiaffino \& Reggiani, 2011; Nedergaard et al., 2013). É um tecido que apresenta grande capacidade adaptativa as demandas funcionais, seja através de atrofia ou de hipertrofia musculares (Guyton, 2002; Schiaffino et al., 2013).

A atrofia muscular corresponde à perda da massa muscular decorrente de redução da área das fibras musculares e/ou redução da quantidade de suas fibras. Várias são as condições que podem estar associadas a este estado catabólico, incluindo aquelas ligadas a adaptações a condições fisiológicas como jejum prolongado, inatividade e envelhecimento, bem como em associação com condições patológicas tais como a septicemia, diabetes, caquexia, AIDS, câncer, microgravidade, lesão medular e doenças geneticamente herdadas, como as miopatias e neuropatias, além do uso de glicocorticoides (Voisin et al., 1996; Glass, 2003; Boonyarom \& Inui, 2006; Kandarian \& Jackman, 2006; Stewart \& Rittweger, 2006; Sandri, 2008; Pereira et al., 2011). Os glicocorticoides induzem atrofia muscular através de mecanismos diversos que incluem desde inibição da resposta à insulina e ao IGF-1, acarretando redução da síntese proteica, inibição da miogênese e aumento da atividade proteolítica mediada pela ativação das vias da SUP e lisossomal (Schakman et al., 2009; Pereira \& Freire de Carvalho, 2011; Schiaffino et al., 2013).

Os ácidos graxos poli-insaturados (PUFA's - poly unsaturated fatty acid) geram efeitos benéficos em diversos processos fisiológicos que incluem a função cognitiva, ação anti-inflamatória e imunossupressora, sendo seus principais representantes os ácidos graxos da família $\omega-3$ e $\omega-6$ (Diziezak, 1989; Calder, 1998; Leonard et al., 2004). Vários estudos têm demonstrado que a reposição de EPA (ácido eicosapentaenoico) e de $\omega$-3 é capaz de atenuar a atrofia muscular associada ao câncer, privação alimentar e septicemia (Smith et al., 2005; Khal \& Tisdale, 2008). No entanto, sua utilização com objetivos de prevenir ou aliviar a atrofia muscular induzida por glicocorticoides, como a dexametasona, ainda não foi testada. Considerando que os glicocorticoides são anti-inflamatórios utilizados no tratamento de diversas situações médicas, procuramos com este estudo determinar se a suplementação de Ômega-3 teria a propriedade de prevenir ou atenuar a atrofia muscular induzida pela administração de 
dexametasona. Por outro lado, tivemos como objetivo determinar mecanismos moleculares envolvidos na indução de atrofia muscular pela dexametasona e na atuação dos ácidos graxos na prevenção deste efeito colateral, o que certamente seria muito importante na identificação de possíveis alvos terapêuticos para prevenção da atrofia muscular.

\section{REVISÃO DA LITERATURA}

\subsection{O tecido muscular esquelético}

O tecido muscular esquelético é constituído de células multinucleadas de aspecto cilíndrico, com diâmetros que variam entre 10 e $80 \mu \mathrm{m}$, denominadas fibras musculares, ou miócitos, com os núcleos posicionados ao longo da periferia da fibra, subjacente à membrana plasmática, ou sarcolema. As fibras musculares são quase que completamente preenchidas por miofibrilas, e estas são constituídas por sarcômeros, (Figura 1), sendo esta a sua unidade contrátil (Guyton, 2002; Chargé \& Rudnicki, 2004; Floeter, 2009).

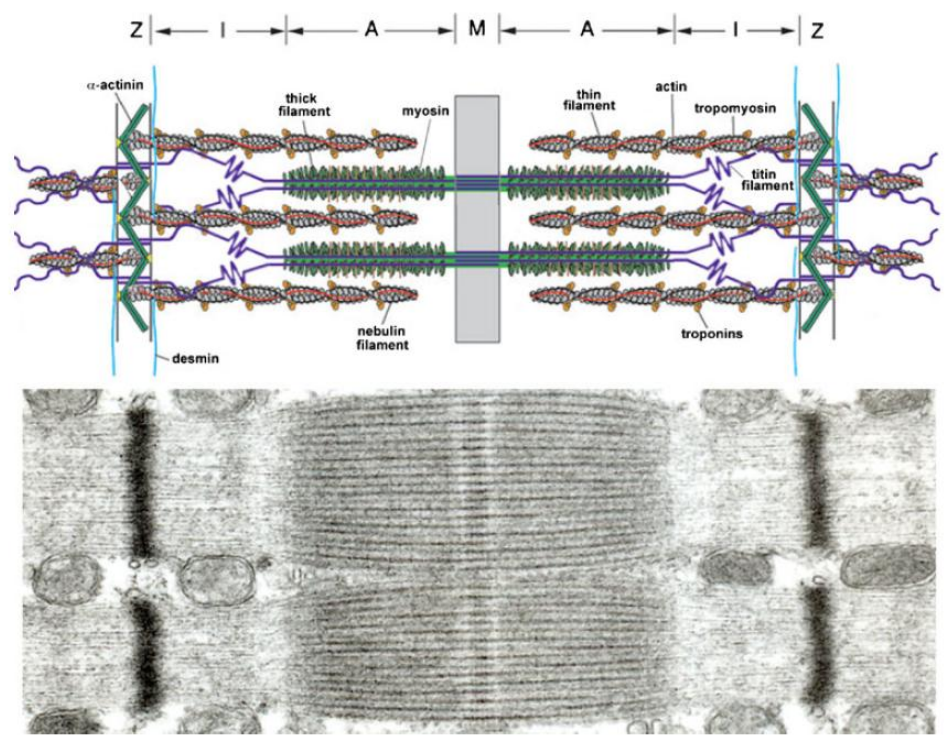

Figura 1: Estrutura do sarcômero. Ilustração superior representa as proteínas miofibrilares actina (actin) e miosina (myosin) juntamente com seus componentes na sua disposição longitudinal, com o filamento de titina, em lilás (titin filament), na banda $\mathrm{Z}$ do sarcômero. A imagem inferior mostra a fotografia de um sarcômero completo por microscopia eletrônica. Legenda: $Z=$ disco $Z ; M=$ banda $M$; $I=$ banda-I; $A=$ banda-A. Tradução: $\alpha$ actin= alfa actina; desmin= desmina; nebulin filament = filamento de nebulina; troponins $=$ troponinas; tropomyosin $=$ tropomiosina; thin filament $=$ filamento fino; thick filament $=$ filamento grosso (Ottenheijm et al., 2008). 
O tecido muscular mostra-se heterogêneo em razão de suas diferentes características fenotípicas, o que configura diferentes propriedades de contração muscular (Ciciliot et al., 2013). A primeira descrição fenotípica data de 1874, por LuisAntonie Ranvier (Ranvier, 1874), que estudou as propriedades elétricas da contração muscular, sendo melhor caracterizada em 1970 por Brooke \& Kaiser, ao notarem que as fibras quando coradas, por reações de ATPase miofibrilar, apresentavam um padrão em mosaico similar ao de um "tabuleiro de xadrez", com fibras escuras e claras, o que auxiliou posteriormente na determinação dos diferentes tipos de miosinas de cadeia pesada (MyHC - Myosin Heavy Chain), as proteínas contráteis do músculo, que determinam as propriedades da contração muscular (Figura 2) (Brooke \& Kaiser, 1970). Originalmente, as fibras musculares são classificadas em três tipos básicos: tipo I, tipo IIA e tipo IIB, além de uma forma adicional, híbrida, chamada de IIC, que pode se converter em outras formas. Atualmente, oito diferentes isoformas de MyHC estão bem caracterizadas: I, IIA, IIX, IIB, $\alpha$-cardiaca, embrionária; perinatal e extraocular (Soukup et al., 2009; Schiaffino e Reggiani, 2011). Em humanos há basicamente fibras musculares do tipo I, IIA e IIX, anteriormente classificada como IIB (Gundersen, 2011).

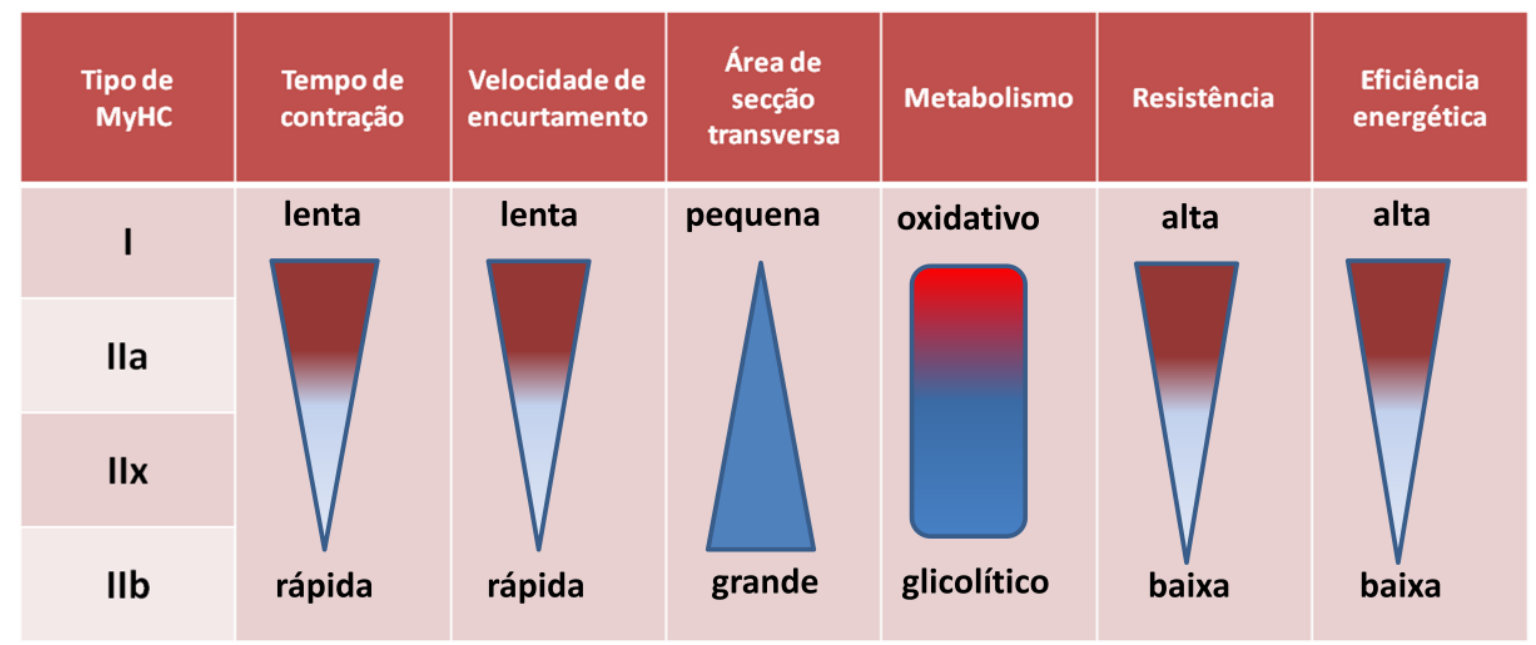

Figura 2: Propriedades contráteis dos diferentes tipos de fibras musculares (modificado de Gundersen, 2011). 


\subsection{Contração muscular esquelética}

O componente motor funcional do músculo é constituído de um neurônio motor e uma grande quantidade de fibras musculares, similares entre si, no entanto não idênticas, em razão das diferentes características e tipos de proteínas existentes, como a MyHC (Brooke \& Kaiser, 1970; Soukup et al., 2009; Schiaffino \& Reggiani, 2011). Além da diferença entre as propriedades fenotípicas e de contração das fibras, a sua distribuição, quanto aos tipos de fibras nos músculos do corpo, também se mostra variada. Por exemplo, em seres humanos, os músculos dos membros inferiores se mostram mais oxidativos e com contração mais lenta, comparados aos músculos presentes nos membros superiores (Schiaffino \& Reggiani, 2011).

A contração da fibra muscular acontece basicamente em razão do deslizamento entre os filamentos grossos (miosina) e finos (actina) dentro do sarcômero, sendo que é o modo de organização destes filamentos que dá ao músculo sua aparência estriada (Agarkova \& Perriard, 2005; Karpati et al., 2009). Tais filamentos, finos e grossos, são montados em paralelo através de duas estruturas transversais, o disco $\mathrm{Z}$ e a banda M, responsáveis, respectivamente, pelo ancoramento de filamentos finos antiparalelos e sarcômeros adjacentes, e pela regulação da organização e alinhamento adequado dos filamentos grossos durante a miogênese (Agarkova \& Perriard, 2005). De forma mais descritiva, os filamentos finos constituem-se de actina entrelaçada por tropomiosina e troponina, sendo esta última uma proteína de ligação com o cálcio, já os filamentos grossos consistem apenas em miosinas, formadas por uma cauda e uma cabeça globular (Karpati et al., 2009).

O aparato contrátil muscular é enriquecido por uma rede denominada "tríade" ou junções de liberação de cálcio, formada pelo retículo sarcoplasmático, que se posiciona estreitamente com inúmeras invaginações para dentro da fibra muscular chamado de túbulos-T (Karpati et al., 2009). Quando a contração muscular é iniciada, por um potencial de ação nervoso, o cálcio liberado pelo retículo sarcoplasmático dentro do sarcômero se liga à troponina entrelaçada à actina, que por sua vez expõe os sítios de ligação da actina com a miosina, viabilizando sua ligação. As cabeças das miosinas possuem atividade de ATPase e sítios de ligação, formando assim pontes cruzadas entre os sítios de ligação da actina e de suas cabeças. Durante a formação da ponte cruzada ocorre consumo de ATP, que ao ser hidrolisado produz quebra da ligação formada, liberando a cabeça da miosina para o próximo sítio de ligação de actina. A repetida 
formação e quebra de pontes cruzadas produzem o deslizamento entre os miofilamentos, com encurtamento sarcomérico e por fim a contração muscular (Karpati et al., 2009).

Entretanto, para uma adequada contração muscular é preciso que haja uma estabilização (ancoramento) do sarcômero. Desta forma, o sarcolema possui como revestimento externo um complexo proteico que facilita a ligação entre proteínas da matriz extracelular e a actina contrátil intracelular, denominada complexo de glicoproteínas associadas à distrofina (GAD), que além de atuar essencialmente na estabilização do sarcolema durante a contração muscular, atua também na organização de moléculas envolvidas com a sinalização celular (Guyton, 2002; Schachter et al., 2004; Reed, 2009). Defeitos na produção ou glicosilação (adição de açucares) destas proteínas resultam em instabilidade de contração, ou sarcolemal, com consequente lesão da fibra e morte celular. Os diferentes tipos de deficiencia proteica, por produção ou glicosilação, caracterizam diferentes formas de doenças geneticamente herdadas, como as doenças musculares congênitas (DMC), distrofias musculares de Duchenne e de Becker, e as distrofias musculares de cinturas (Reed, 2009; Bushby et al., 2010).

\subsection{Atrofia muscular esquelética}

A atrofia muscular ocorre através de mecanismos que incluem o aumento da degradação proteica e/ou redução da síntese proteica com redução da expressão gênica muscular e encolhimento das miofibras devido à perda da rede de proteínas, organelas e citoplasma (Voisin et al., 1996; Glass, 2003; Boonyarom \& Inui, 2006; Schiaffino et al., 2013). A aquisição, manutenção, ou perda de massa muscular dependem essencialmente da dinâmica de dois processos regulatórios que se opõem: síntese e degradação proteica muscular (Matsakas \& Patel 2009; Nader, 2005). Estudos têm identificado pelo menos cinco diferentes sistemas envolvidos no processo de atrofia muscular, os sistemas: lisossomal, da calpaína, caspases e apoptose, metaloproteinases e o sistema da ubiquitina-proteassoma (SUP) (Voisin et al., 1996; Glass, 2003; Kandarian \& Jackman, 2006). Dentre todos os sistemas envolvidos, o SUP, a qual participa de praticamente todas as formas de atrofia, e o autofagico lisossomal são os que geram maior contribuição (Hershko \& Ciechanover, 1998; Schiaffino et al., 2013). 


\subsubsection{Sistema Ubiquitina Proteassoma (SUP)}

O SUP caracteriza-se pela habilidade de reconhecer, ubiquitinar e marcar como alvo proteínas específicas para degradação, atuando em resposta a mudanças na atividade muscular (Verhees et al., 2011; Schiaffino et al., 2013). Proteínas degradadas pelo SUP são primariamente ligadas de forma covalente às cadeias de moléculas de ubiquitina, que marcam as proteínas e as direcionam para degradação nos proteassomas 26S (Hershko \& Ciechanover, 1998). A formação de um complexo ubiquitina-proteína envolve a participação de pelo menos três componentes: enzima ativadora de ubiquitina (E1), enzima conjugadora de ubiquitina (E2) e enzima ligadora de ubiquitina (E3). Em uma etapa inicial, ocorre a ativação da ubiquitina pela enzima E1, em seguida, a ubiquitina ativada é transferida para a enzima E2, liberando a enzima E1, após ubiquitinada, a enzima E2 liga-se à enzima E3 previamente ligada à proteínaalvo (substrato) em um complexo não covalente, de modo que a ubiquitina ativada seja transferida da E2 para o substrato. O complexo de ligação entre E2 e E3+substrato então se solta, liberando a enzima E2 e a proteína neste momento ubiquitinada. As etapas anteriores se repetem várias vezes, formando uma ou mais cadeias de ubiquitina na proteína-alvo. A especificidade do substrato é mediada por, pelo menos, três grupos de enzimas ligadoras E3: RING finger; homóloga ao domínio terminal carboxisil, E6AP (domínio HECT); e complexo de proteínas Skp1-Cul1-F-box (complexo SCF) (Powell, 2006).

Durante o processo de atrofia muscular, vários componentes do SUP são expressos mais intensamente, incluindo as E1, E2, E3s, 26S e ubiquitina (Medina et al., 1995). No entanto, ocorreu um grande avanço nas descobertas sobre o envolvimento do SUP no processo de atrofia muscular, com a identificação de dois genes de ligadoras E3 que se expressam significantemente em diferentes modos de atrofia muscular: MuRF1 (Muscle Ring Finger 1) e o MAFbx (Muscle Atrophy F-box), também conhecida como atrogina-1(Bodine et al., 2001a; Gomes et al., 2001).

Vários estudos têm demonstrado a importância de ligadoras E3 na fisiologia e remodelamento do sarcômero. A MuRF1, por exemplo, associa-se à titina - uma proteína sarcomérica gigante que participa da estabilização da linha M do sarcômero - e também à troponina-I, promovendo a ubiquitinação e degradação de ambas (McElhinny et al., 2004). Fielitz et al. (2007a) demonstraram que a MuRF3 interage e participa do processo de degradação da $\gamma$-filamina. Em outro estudo, os mesmos autores 
demonstraram que as ligadoras (E3) MuRF1 e MuRF3 atuam em cooperação na degradação da miosina de cadeia pesada (MyHC) $\beta$ e MyHC IIA via SUP. Camundongos com deficiência de ambas isoformas de enzimas E3 (MuRF1 e MuRF3) desenvolvem miopatia e cardiomiopatia hipertrófica caracterizadas pelo acúmulo de MyHC, fragmentação das fibras e diminuição do desempenho muscular (Fielitz et al., 2007b). Tal achado reforça o envolvimento de enzimas ligadoras E3 na renovação de proteínas sarcoméricas e ajuda a esclarecer aspectos patogênicos de miopatias com acúmulo de miosina.

Li et al. (2004) demonstraram que a atrogina-1 interage com a calcineurina-A e com a $\alpha$-actinina- 2 nas linhas $\mathrm{Z}$ das células cardíacas, além de atuar na ubiquitinação e degradação da calcioneurina-A, regulando o processo de hipertrofia cardíaca que ocorre em decorrência de diversos estímulos patogênicos. No entanto, algumas ligadoras E3 são expressas mais intensamente durante o processo de crescimento e regeneração muscular, e não na atrofia muscular, indicando que os processos de ubiquitinação e degradação proteica também ocorrem em condições de crescimento e maturação celular (Delaunay et al., 2008; Campos et al., 2010).

Algumas ligadoras E3 podem estar envolvidas em diferentes processos e modelos de atrofia muscular. A enzima ligadora E3 Nedd4-1, por exemplo, atuaria no processo de atrofia muscular por desuso, tendo ainda papel adicional na miogênese enquanto que a E3 Mull atuaria na atrofia induzida pelo jejum prolongado (Schiaffino et al., 2013). Recentemente, descobriu-se que a proteína Trim32 é uma ligadora E3, crucial para a degradação de filamentos finos (actina, troponina e tropomiosina), $\alpha$ actina e desmina (Kudryashova et al, 2012).

\subsubsection{Atrofia relacionada à via IGF-1/PI-3K/Akt/mTOR}

O IGF-1 (Insulin-like growth factor 1) é um fator de crescimento produzido, em sua maior parte, no fígado, que estimula o aumento da síntese proteica muscular e, consequentemente, de sua massa, além de diminuir os níveis de proteólise e apoptose nesse tecido (Schakman et al., 2011). Quando a ação do IGF-1 sobre o músculo é inibida, por exemplo, com o uso de glicocorticoides, há uma elevação nos níveis de degradação proteica e diminuição na síntese proteica, com consequente atrofia muscular (Schakman et al., 2011; Qin et al., 2012). 
O IGF-1 interage com proteínas intracelulares na fibra muscular, por meio de cascata de sinalização, como processo regulatório translacional. Após a ligação do IGF1 com o seu receptor, esses ligantes recrutam a atividade da proteína quinase PI-3K (fosfoinositídeo-3K) que, por sua vez, leva à formação de fosfatos fosfatidilinositol que se inter-relacionam até sua interação com o Akt, também conhecido como PKB (Protein Kinase-B), sendo então fosforilado. A ativação do Akt leva à consequente inibição e ativação de diversas proteínas relacionadas com a síntese e a degradação proteica, e com captação de glicose celular. O Akt quando fosforilado, leva à ativação do mTOR (mammalian target of rapamycin), relacionado com o aumento da síntese proteica e inibição de proteínas. Esses fatores conduzem ao aumento da degradação ou diminuição da síntese proteica, como o glicogênio sintetase $3 \beta$ (GSK3 $\beta$ ), acarretando aumento da massa muscular e favorecendo a hipertrofia (Jefferson et al., 1999; Bodine , 2001b; Léger et al., 2006; Gundersen, 2011).

A ação inibitória do Akt sobre o GSK3 $\beta$, supressor do fator de iniciação eucariótico 2B (eIF-2B), resulta em aumento da translação de RNAm, da capacidade de reciclagem dos ribossomos e, consequentemente, aumentando a síntese de proteínas em fases iniciais (Dufner et al., 1999; Verhees et al., 2011; Clemmons , 2009). A presença do GSK3 $\beta$, tal como recentemente demonstrado por Verhees et al. (2011) em modelo de atrofia com dexametasona, é fundamental para a expressão de genes das enzimas E3 do SUP, MuRF-1 e atrogina-1. O GSK3 $\beta$ também se relaciona com a síntese de glicogênio, tendo, sua alta expressão, sido relacionada com a intolerância à glicose e prejuízo sobre a ação da insulina (Dokken et al., 2005).

O mTOR quando ativado pelo Akt, forma um complexo chamado TORC1, que tem como função ativar a proteína de $70 \mathrm{kDa}$ S6 kinase (P70S6k), importante para a translação proteica, e inibir o 4EBP1 (factor $4 E$ binding protein 1), que atua inibindo fatores translacionais, favorecendo a síntese proteica (Bodine, 2001b; Clemmons, 2009).

Vários estudos utilizando diferentes modelos de indução de atrofia muscular in vitro e in vivo, têm demonstrado que a ativação do Akt previne os efeitos da atrofia muscular induzida por glicocorticoides, através da inativação dos FOXOs (Forkhead Box $O$ ) (Bodine, 2001b; Sandri et al., 2004; Schakman et al., 2008).

Os FOXOs constituem uma família de fatores de transcrição que, na forma ativa, não fosforilados, localizam-se predominantemente no compartimento nuclear, ligados 
ao DNA. Membros do FOXO (FOXO1, FOXO3a e FOXO4) regulam genes da via proteolítica do SUP, em particular os genes codificadores das enzimas E3, tais como o MuRF-1 e atrogina-1, bem como genes relacionados com a autofagia, reguladores do crescimento (Miostatina) e de degradação celular (catepsinas) (Sandri et al., 2004; Mammucari et al., 2007; Hasselgren et al., 2010). Os FOXOs 1 e 3a são responsáveis pela transcrição de atrogenes como $M U R F-1$ e atrogina-1, influenciando na degradação muscular pela maior ativação da SUP (Sandri et al., 2004; Stitt et al., 2004; Schakman et al., 2008). A inativação dos FOXOs pelo Akt ocorre através de interação com as proteínas 14-3-3, que sequestram e translocam os FOXOs para o citoplasma, onde são mantidos fosforilados e transcripcionalmente inativos (Birkenkamp \& Coffer, 2003; Sandri et al., 2004). Por outro lado, com a inativação do Akt, os FOXOs são translocados novamente para o núcleo, onde exercem sua atividade transcriptacional, ativando o processo de atrofia muscular, como ocorre, por exemplo, na atrofia induzida por glicocorticoides (Van Der Heide et al., 2004; Schakman et al., 2008).

Dois genes indutores de hipóxia, denominados Scylla e Charybdis, foram identificados em Drosophila como reguladores negativos da via TOR e do crescimento celular. Nos mamíferos esses genes são chamados REDD1 e REDD2 (Miyazaki \& Esser, 2009). A REDD1 (regulated in development and DNA damage responses 1) é um componente presente na resposta ao estresse e tem sua transcrição aumentada em casos de estresse energético, tratamento com glicocorticoides, e estresse oxidativo (Wang et al., 2006; Katiyar et al., 2009). Dentre suas funções, está a regulação, e principalmente, inibição do mTOR durante estresse por hipóxia, sendo sua função dependente de proteínas 14-3-3 e do complexo TSC (tuberous sclerosis complex). Sua degradação se dá via SUP por sinalização de enzima E3 específica (E3-CUL4ADDB1-ROC1-b-TRCP), sendo necessária sua degradação para restauração completa da atividade de mTOR (Katiyar et al., 2009).

A expressão de REDD2 é predominante no músculo esquelético, é considerado um regulador negativo da sinalização do mTOR no músculo, e atua independentemente da sinalização de Akt. É, entretanto, dependente da atividade da pequena proteína $G$ Rheb (Ras homolog enriched in brain), do complexo TSC1 e, de forma não completamente elucidada, das proteínas 14-3-3 (Miyazaki \& Esser, 2009). 
Alguns estudos têm mostrado que a miostatina, também conhecida como GDF8, membro da família de fatores de crescimento e transformação $\beta$ (TGF- $\beta$ Transforming and Growth Factor- $\beta$ ) é um importante regulador negativo da massa muscular, atuando por bloqueio da via IGF1/PI-3K/Akt/mTOR e ativando os FOXOs (McFarlane et al., 2006). A inibição da miostatina através da administração de folistatina ou, ainda, por nocaute gênico, em modelos experimentais, promove excessivo ganho de massa muscular resultante de hipertrofia e/ou hiperplasia de fibras musculares, entretanto, sem ganho de força equivalente (Lokireddy et al., 2011; Kalista et al., 2012; Winbanks et al., 2012; Grobet et al., 2003).

\subsubsection{Fatores de transcrição NF-kB e TNF- $\alpha$ na atrofia muscular}

O fator de transcrição NF-kB tem uma grande importância como mediadores da imunidade e inflamação, são também expressos no músculo e, aparentemente, mediam os efeitos de citoquinas inflamatórias, em particular da TNF- $\alpha$ e da interferon- $\gamma$, na atrofia muscular e caquexia (Cai et al., 2004). No estado inativo, o NF-kB é sequestrado no citoplasma por uma família de proteínas inibitórias chamadas IkB. Em resposta a o TNF- $\alpha$, o complexo IkB quinase (IKK) fosforila o IkB, o que resulta na sua degradação via SUP. Sem a inibição pelo $1 \mathrm{~KB}$, o NF-kB é então translocado para o núcleo, onde inicia transcrição gênica resultando em aumento da expressão de atrogenes (Cai et al., 2004).

O TNF- $\alpha$ e as citoquinas inflamatórias também causam resistência à insulina e supressão da via do IGF-1, o que mostra uma interligação entre essas duas vias no desenvolvimento de atrofia muscular (de Alvaro et al., 2004). O NF-kB pode, ainda, regular o processo de atrofia muscular através da degradação de fatores de transcrição, tal como o MyoD (Guttridge et al., 2000).

\subsection{Fatores de transcrição musculares}

Durante o desenvolvimento embrionário muscular, a especificidade das células precursoras mesodérmicas originárias dos somitos, em linhagem miogênica, requer aumento da expressão dos genes $M y o D$ e $M y f 5$, ativadores transcriptacionais da família dos fatores regulatórios miogênicos (MRF, do inglês Myogenic Regulatory Factors) (Chargé \& Rudnicki, 2004). Células proliferativas miogênicas positivas para MyoD e/ou Myf5 são chamadas de mioblastos. Mioblastos proliferativos saem do ciclo celular 
e se diferenciam em miócitos, os quais expressam MRF's tardios, miogenina, MRF4 e, subsequentemente, genes específicos musculares, tais como aqueles que codificam miosinas de cadeia pesada (MyHC) e creatinofosfoquinase (CPK). Finalmente, miócitos mononucleares se fundem para formarem células multinucleadas, que amadurecem em fibras musculares contráteis.

Durante o desenvolvimento muscular, uma subpopulação distinta de mioblastos não entra em diferenciação, porém se mantém associada à superfície das fibras em desenvolvimento, sendo denominadas células satélites quiescentes. Após a maturidade sexual, o músculo esquelético torna-se um tecido caracterizado por fibras musculares multinucleadas pós-mitóticas (Chargé \& Rudnicki, 2004).

O músculo esquelético tem uma capacidade de regeneração rápida e completa após dano muscular e, neste caso, eventos bioquímicos e moleculares recapitulam aqueles ocorridos durante o desenvolvimento embrionário (Chargé \& Rudnicki, 2004). Em um evento de dano muscular ocorre ativação de resposta inflamatória e proliferação celular da linhagem miogênica (células satélites). Após exposição a sinais químicos liberados na região do dano, as células satélites quiescentes passam para o estágio de células miogênicas precursoras, ou mioblastos. As células satélites podem ainda participar do processo de hipertrofia muscular (Pallafacchina et al., 2012).

Em nível molecular, a ativação das células miogênicas precursoras resulta na expressão de fatores de regulação muscular (MRF), Myf5 e MyoD, que ocorre já nas primeiras 12 horas após o dano muscular (Chargé \& Rudnicki, 2004). Já as células satélites quiescentes não expressam níveis detectáveis de MRFs. O MyoD tem importância fundamental na diferenciação das células satélites, enquanto que o Myf5 é importante na promoção de autorrenovação dessas células.

Após esse evento inicial, as células musculares recém formadas se diferenciam e se fundem, associando-se com as fibras lesadas para formar novas fibras musculares. Ocorre ativação dos genes Miogenina e MRF4 além de expressão de proteínas responsáveis pela parada do ciclo celular, como a p21 (Chargé \& Rudnicki, 2004). O programa de diferenciação celular é então completado com o início da expressão de proteínas musculares especificas - como as miosinas - e a fusão das células miogênicas precursoras com as células musculares lesadas. 


\subsection{Glicocorticoides e a atrofia muscular esquelética}

Os hormônios glicocorticoides são produzidos no córtex suprarrenal, dos quais os mais importantes para o organismo são o cortisol e a aldosterona. Tais hormônios regulam o metabolismo dos carboidratos e as funções hemodinâmicas, sendo essenciais para vida, sobretudo em situações de estresse (Alheira \& Brasil, 2005). Estão também, envolvidos em quase todas as funções celulares, moleculares e fisiológicas do organismo, e têm papel fundamental em processos biológicos importantes, tais como o crescimento, a reprodução, o metabolismo, as reações inflamatórias e imunológicas, bem como nas funções do sistema nervoso central, cardiovascular e renal. Os glicocorticoides representam um dos compostos terapêuticos mais utilizados na prática médica, e amplamente empregados no tratamento de doenças inflamatórias, autoimunes e linfoproliferativas (Nicolaides et al., 2010), além de serem universalmente utilizados no tratamento de doenças neuromusculares como as miopatias inflamatórias e na distrofia muscular de Duchenne (Reed, 2002).

Em nível celular, a ação dos glicocorticoides é mediada por uma proteína intracelular - o receptor de glicocorticoide $(R G)$ - que, ao fazer ligação com o corticoide, é translocado ao núcleo, onde se liga ao elemento de resposta ao glicocorticoide no DNA, realizando a transcrição de genes específicos. O RG pertence a uma superfamília de receptores nucleares esteroides/tireoide/ácido retinoico, sendo classificado como um fator de transcrição ligante-dependente, expresso no meio intracelular, que media a ação dos glicocorticoides e influencia funções fisiológicas essenciais para a vida (Gower, 1993;Nicolaides et al., 2010).

O uso de anti-inflamatórios glicocorticoides, tais como a dexametasona, predinisolona e predinisona, acarretam reações adversas - dependendo da dose e do tempo de uso - em diversos sistemas do organismo, tais como: gastrointestinal, dermatológico, neurológico, endocrinológico, oftalmológico, cardiovascular e musculoesqueléticos. Os principais efeitos adversos sobre a musculatura esquelética incluem: fraqueza e atrofia muscular, osteoporose, necrose asséptica da cabeça do fêmur e do úmero, fratura patológica dos ossos longos e ruptura de tendões (Fujisawa, 2011).

Os efeitos deletérios dos glicocorticoides sobre a musculatura esquelética foram primeiramente descritas por Harvey Cushing em 1932, na síndrome de Cushing, que se caracteriza por fadiga, fraqueza e atrofia muscular. O uso de glicocorticoides é a causa mais comum de miopatia induzida por droga, apresentando incidência de $60 \%$ 
(Cushing, 1932; Pereira \& Freire de Carvalho, 2011). Nesse tipo de atrofia, as fibras musculares mais afetadas são as do tipo II (contração rápida), particularmente as fibras do tipo IIB ou IIX, com pouco ou nenhum efeito sobre as fibras do tipo I (contração lenta). Os indivíduos idosos e os portadores de câncer são particularmente mais suscetíveis ao desenvolvimento de miopatia por glicocorticoides (Sandri et al., 2006; Matsakas \& Patel, 2009; Schakman et al., 2009; Pereira \& Freire de Carvalho, 2011; Schiaffino \& Reggiani, 2011).

A atrofia das fibras do tipo II induzida por glicocorticoides tem sido descrita há vários anos. Kelly \& Goldspink (1982) demonstraram a ocorrência de atrofia do músculo tibial anterior e da musculatura lisa de ratos submetidos à dosagem de $2,5 \mathrm{mg} / \mathrm{kg} / \mathrm{dia}$ de dexametasona, por 5 dias. Uma das possíveis explicações para a maior sensibilidade das fibras do tipo II aos glicocorticoides é a baixa expressão de PGC1 $\alpha$ nesse tipo de fibra, uma proteína coativadora da família de PPAR $\gamma$ (peroxisome proliferator activated receptor $\gamma$ ). Essa proteína age no músculo esquelético como sensor para a contração muscular, induzida pelo sistema nervoso através da sinalização do cálcio. Quando os seus níveis se encontram reduzidos, como demonstrado no estudo de Sandri et al. (2006) e de Qin et al. (2010), há maior expressão de fatores de transcrição FOXO3a no músculo esquelético, favorecendo o desenvolvimento da atrofia.

Os efeitos musculares dos glicocorticoides estão associados, também, com as repercussões relacionadas ao hipercortisolismo, como inibição do transporte de aminoácidos ao músculo, inibição da resposta à insulina e ao IGF-1 (Figura 3), acarretando na redução da síntese proteica. Outros efeitos descritos se relacionam com a inibição da miogênese e aumento da atividade proteolítica, mediada, principalmente, pela ativação das vias da SUP e lisossomal (Schakman et al., 2009; Pereira \& Freire de Carvalho, 2011; Schiaffino et al., 2013).

Em nível molecular, os glicocorticoides induzem à atrofia muscular, ao menos em parte, pela regulação de fatores de transcrição, atrogenes e catepsinas (Komamura et al., 2003; Schakman et al., 2009). Há um aumento nos níveis proteicos de GSK3 $\beta$ (Verhees et al., 2011) e REDD1, que reduz a atividade do mTOR (Wang et al., 2006). Segundo Gilson et al. (2007), a miostatina e a calpaína também estariam envolvidas no processo de perda da massa muscular induzida pelos glicocorticoides. A miostatina, após sua ligação com um receptor específico (receptor de activina tipo IIb), acarreta 
ativação dos fatores de transcrição $S m a d 2$ e Smad3. Esses fatores se translocam para o núcleo, interagindo com coativadores ou cosupressores nucleares que regulam a transcrição de genes relacionados com a degradação proteica (Rebbapragada et al., 2003; Zhu et al., 2004).

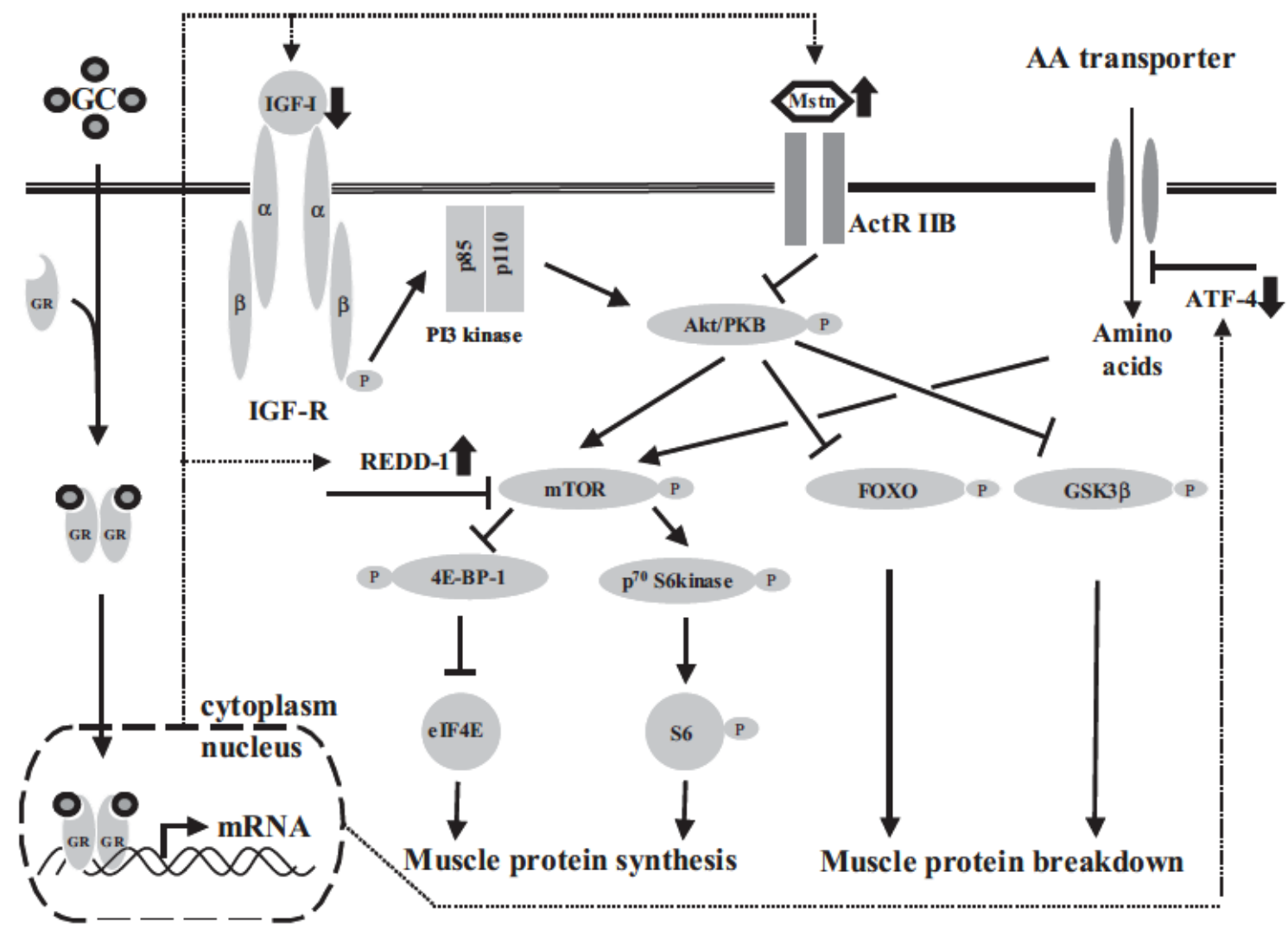

Figura 3: Esquema representativo da sinalização envolvida na atrofia muscular induzida por glicocorticoide. A atrofia muscular por glicocorticoides está associada com alterações na produção de IGF-1 e miostatina, dois fatores de crescimento que exibem efeitos opostos sobre a massa muscular, conduzindo a inibição da síntese e aumento da degradação proteica. Legenda: $\mathrm{GC}$ = glicocorticoide circulante; GR = receptor de glicocorticoide; ATF-4 = activating transcription factor 4; Mstn = Miostatina; ActT IIb = receptor para Miostatina; AA transporter = Transportador de aminoácidos. Tradução: Amino acids= amino ácidos; Muscle protein synthesis = Sínteses de proteínas musculares; Muscle protein breakdown = degradação de proteínas musculares; cytoplasm = citoplasma; nucleus = núcleo (Schakman et al., 2009).

\subsection{Alvos potenciais no tratamento da atrofia muscular}

Conhecendo os mecanismos envolvidos na atrofia muscular, o principal objetivo terapêutico seria o de modular alvos intracelulares indutores da atrofia muscular, tais como os fatores de transcrição FOXO ou da via NF-kB além de promover inibição direta da via SUP (Tisdale, 2006). 
Devido ao proeminente efeito na caquexia, drogas capazes de inibir a atividade do NF-kB têm sido testadas. Dentre elas, as drogas HMB (metabólito da Leucina), ibuprofeno e resveratrol são bons candidatos para uso clínico (Wyke et al., 2004). A talidomida atua na inibição de TNF- $\alpha$, aumentando a degradação do seu RNAm (Gordon et al., 2005). Os derivados da xantina, como a pentoxifilina e a torbafilina (HWA 448), através da inibição da expressão do TNF- $\alpha$, têm se mostrado eficazes na prevenção da atrofia muscular na caquexia (Combaret et al., 1999; Combaret et al., 2002). Vários estudos têm demonstrado que $\beta-2$ agonistas, como clembuterol (Yimlamai et al., 2005), fenoterol (Ryall et al., 2004) e formoterol (Busquets et al., 2004) possuem efeitos potenciais na prevenção da atrofia muscular. Essas drogas anabólicas parecem eficazes devido ao controle da ativação da SUP.

A suplementação alimentar com leucina, um aminoácido essencial, seria capaz de atenuar a degradação proteica via redução da ativação da SUP (Combaret et al., 2005) e, também, de aumentar a síntese proteica, através de ativação de sua translação (Yoshizawa et al., 1999). A leucina participaria, ainda, da regulação do sistema lisossomal, já que a sua deficiência acarreta ativação da autofagia do sistema lisossomal em cultura de células musculares (Mordier et al., 2000). No entanto, Nicastro et al. (2012) mostraram que a suplementação de leucina associada à dexametasona piorou a resposta à insulina e não preveniu a atrofia muscular observada nos animais. A creatina tem se mostrado eficaz na atenuação da atrofia muscular induzida por corticoides (Menezes et al., 2007).

A testosterona mostrou-se eficaz na prevenção da perda muscular induzida por glicocorticoide, atuando na inibição da atividade do REDD1 sobre o mTOR, na regulação do FOXO1 e PGC-1 $\alpha$ (Qin et al., 2010; Wu et al., 2010) e na inibição da degradação associado a um estímulo da síntese proteica via IGF-1/PI-3K/Akt/mTOR (Zhao et al., 2008; Jones et al., 2010). Finalmente, é importante ressaltar que o exercício físico é um método eficiente no controle da atrofia muscular, pois leva, em particular, a uma redução da ativação dos atrogenes e aumento da produção de IGF-1 (Jones et al., 2004).

\section{7. Ácidos graxos e sua atuação na atrofia muscular}

Os principais tipos de ácidos graxos, ou gorduras, são os ácidos graxos saturados, monoinsaturados e poli-insaturados. Dois tipos de ácidos graxos poliinsaturados, não produzidos pelo nosso organismo, sendo, portanto, classificados como 
ácidos graxos essenciais, formam a base para a produção de duas famílias de ácidos

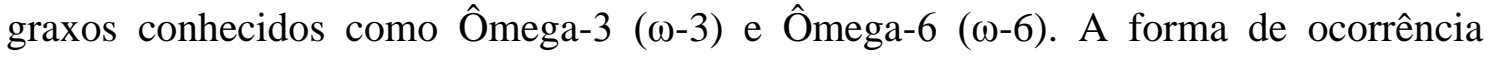
natural dos ácidos graxos de forma insaturada é chamada de "cis". Contudo, tais gorduras também podem adquirir formas diferentes, com estruturação mais saturada, sendo então denominadas "trans", podendo - esta forma - ocorrer naturalmente ou no processamento de alguns alimentos, trazendo um impacto negativo à saúde humana (Department of Health, 1994; Najbjerg et al., 2011).

As gorduras trans formam um soluto leve em temperatura ambiente e causam a elevação de LDL (low-density lipoprotein) no sangue humano, aumentando o depósito de colesterol nas artérias, elevando, assim, o risco de doenças arteriais coronarianas (Reisner et al., 2011). O consumo regular de $\omega$-3 está relacionado com maiores níveis de HDL (high-density lipoprotein), melhora nos níveis de triglicérides e em demais fatores associados com risco cardiovascular (Sun et al., 2003).

Os ácidos graxos poli-insaturados (PUFA's - poly unsaturated fatty acid) são subdivididos em grupos ou famílias, dependendo do estado de saturação das suas moléculas, sendo seus principais representantes os da família $\omega-3$ e $\omega-6$, cuja designação está relacionada pela insaturação do terceiro e sexto carbono metil-terminal respectivamente. $\mathrm{Na}$ família $\omega-3$, os principais ácidos graxos, são o ácido eicosapentaenoico (EPA) (C20:5 n-3) e o ácido docosaexaenoico (DHA) (C22:6 n-3), encontrados em sementes oleaginosas (canola, soja, linhaça), em vegetais (algas, microalgas e fito plânctons) e em animais de origem marinha (peixes e crustáceos) e sintetizados a partir do ácido $\alpha$-linolênico (ALA) (Diziezak, 1989; Calder, 1998). O ácido linoleico (AL) é o representante mais importante da família $\omega-6$, sendo encontrado nos óleos vegetais como o de girassol, algodão, milho e soja, dando origem ao ácido araquidônico (AA) e ao EPA quando metabolizado (Diziezak, 1989; Leonard et al., 2004).

Os PUFAs também servem como precursores de eicosanoides, reguladores de crescimento e hormônios, gerando efeito em diversos processos fisiológicos como a função cognitiva, ação anti-inflamatória e imunossupressora (Leonard et al., 2004). O $\omega-3$, ao ser incorporado à membrana celular, atuaria modulando diferentes sistemas celulares, tais como sinalização, expressão gênica e função estrutural das membranas (Surette, 2008). Um destes efeitos é modulado através do controle da expressão do NF- 
$\mathrm{kB}$ e fatores de transcrição, desta forma participando do processo de crescimento e atrofia celulares (Magee et al., 2008).

Atualmente, o consumo de PUFA, principalmente EPA e DHA, têm sido recomendado, e seus benefícios sobre a memória e o sistema cardiovascular são mundialmente conhecidos (Delgado-Lista et al., 2012). Os $\omega-3$ e $\omega-6$ constituem cerca de $30-35 \%$ do total de ácidos graxos cerebrais, sendo o DHA o ácido graxo mais abundante no cérebro humano, seguido do AA (Youdim, 2000).

Os primeiros benefícios do consumo de $\omega$-3 (EPA e DHA) foram relatados em esquimós da Groenlândia, os quais em razão do alto consumo de alimentos marinhos, apresentavam menores índices de doenças arteriais coronarianas, asma, diabetes tipo $1 \mathrm{e}$ esclerose múltipla (Simopoulos, 2009). Demais benefícios já relatados dos PUFAs incluem ação anti-inflamatória (Kang et al., 2010), melhora da resposta à insulina (Elmore et al., 1999; Haugaard, 2006; Haugaard, Vaag et al., 2009), alívio de doenças inflamatórias intestinais, artrite reumatoide e psoríase (Simopoulos, 2002), e melhora de quadros depressivos e demenciais (Freeman et al., 2006; Lin \& Su, 2007; Bourre, 2005).

Os ácidos graxos mostram auxiliar na redução da atrofia muscular diminuindo a atividade de componentes da via SUP, tal como observado na caquexia decorrente de câncer e sepsis (Whitehouse et al., 2001). Alguns estudos têm demonstrado que a reposição de EPA e de $\omega-3$ auxiliam na atenuação da atrofia muscular associada ao câncer, privação alimentar e septicemia (Smith et al., 2005; Khal \& Tisdale, 2008). No entanto, a sua utilização com foco na atrofia muscular induzida por glicocorticoides, como a dexametasona, ainda não foi testada, e os mecanismos moleculares com as quais os ácidos graxos atuariam prevenindo contra a atrofia muscular ainda não são bem conhecidos. 


\section{Justificativa}

Considerando que os glicocorticoides são anti-inflamatórios utilizados no tratamento de diversas situações médicas e visto o papel benéfico do Ômega-3 na atrofia muscular observada em demais condições patológicas como no câncer, julgamos importante determinar se a ingestão de Ômega-3 concomitante ao uso de glicocorticoides teria a propriedade de prevenir a atrofia muscular induzida por esse tipo de medicamento. A determinação de mecanismos moleculares com as quais a dexametasona acarreta atrofia muscular e os ácidos graxos atuariam na prevenção desse efeito colateral seria importante na identificação de possíveis alvos terapêuticos. 


\section{OBJETIVOS}

\subsection{Objetivos gerais}

- Avaliar se a suplementação do ácido graxo $\omega-3$ influenciaria o desenvolvimento da atrofia muscular induzida pela dexametasona em ratos.

\subsection{Objetivos específicos}

- Avaliar os efeitos da dexametasona sobre o peso corporal, área de secção transversa dos principais tipos de fibras musculares, comportamento motor, expressão gênica de fatores de transcrição muscular e atrogenes (atrogina $1 e$ $M u R F-1)$ e expressão proteica de componentes da via IGF-1/Akt/mTOR na musculatura esquelética de ratos.

- Avaliar os efeitos do $\omega-3$ sobre o peso corporal, a área de secção transversa dos principais tipos de fibras musculares, comportamento motor, expressão gênica de fatores de transcrição muscular e atrogenes (atrogina 1 e MuRF-1) e expressão proteica de componentes da via IGF-1/Akt/mTOR em ratos submetidos à administração de dexametasona. 


\section{METODOLOGIA}

\subsection{Animais do estudo e Estruturação}

Foram utilizados vinte e quatro animais Wistar machos, com idade entre 10 e 12 semanas, pesando entre 300 e 400 gramas. Todos os experimentos foram realizados de acordo com as normas que estabelecem os procedimentos para uso científico de animais no país (lei 11.794 de 8 de outubro de 2008), sendo realizados no Laboratório de Investigação Médica 45 (LIM45) da Faculdade de Medicina da Universidade de São Paulo (FMUSP). Os animais foram mantidos em gaiolas contendo no máximo cinco animais cada e mantidos em ciclo de $12: 12$ horas luz/escuro a $25^{\circ} \mathrm{C}$, com acesso livre a água e comida. Este estudo foi avaliado e aprovado pela Comissão de Avaliação de Projetos de Pesquisa da FMUSP (CAPPesq) em 06/09/2010, sob o número 1187/09 (Anexo 1).

O período experimental in vivo que incluiu a administração da dexametasona e do Ômega-3 aos animais, a coleta de dados iniciais (peso corporal e análise de comportamento motor), e a coleta e estocagem do material de estudo (músculos esqueléticos), foi realizado pelo investigador principal do estudo e orientador desta dissertação, Dr. Edmar Zanoteli. O aluno Alan Fappi, foi responsável pelos experimentos subsequentes, que incluíram as análises dos dados prévios coletados, análises histológicas e os estudos de expressão proteica e gênica.

\subsubsection{Suplementação com o Ômega-3 e indução da atrofia muscular}

Os animais foram separados em dois grupos iniciais, sendo doze animais suplementados com $\omega-3$ (extrato de ácidos graxos poli-insaturados, ácido eicosapentaenoico - EPA e ácido docosahexanoico - DHA), marca Proepa ${ }^{\circledR}$ (laboratório Aché), administrado via gavagem na dosagem de $100 \mathrm{mg} / \mathrm{Kg} / \mathrm{dia}$, de segunda-feira a sábado, por um período de 40 dias. Outros doze animais foram usados como controle e receberam a mesma quantidade da solução veículo, pela mesma via, porém sem $\omega-3$. As cápsulas de Proepa ${ }^{\circledR}$ foram dissolvidas em água destilada e Tween20, sob agitação contínua, imediatamente antes da administração.

Para indução de atrofia muscular, dexametasona (Decadron injetável, 4mg/mL, laboratório Aché) foi administrada na dose de $5 \mathrm{mg} / \mathrm{kg} / \mathrm{dia}$, via subcutânea, nos últimos 10 dias da suplementação com $\omega$-3, em 6 animais suplementados com $\omega$-3 e em 6 não 
suplementados (Figura 4). Nos demais animais $(\mathrm{n}=12)$ foi administrada via subcutânea o mesmo volume em solução salina, obtendo-se, portanto, 4 grupos de 6 animais cada:

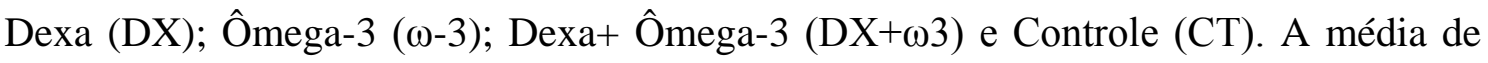
peso inicial dos animais foi de 356,33 \pm 4,7g (CT); 345,5 \pm 8,8g ( $\omega-3) ; 342,4 \pm 7,6 \mathrm{~g}$ $(\mathrm{DX})$ e $334,0 \pm 5,5 \mathrm{~g}(\mathrm{DX}+\omega 3)$. Os animais foram pesados nos dias 1, 10, 20, 30 32, 34, 36 e 40.

\section{Desenho experimental}

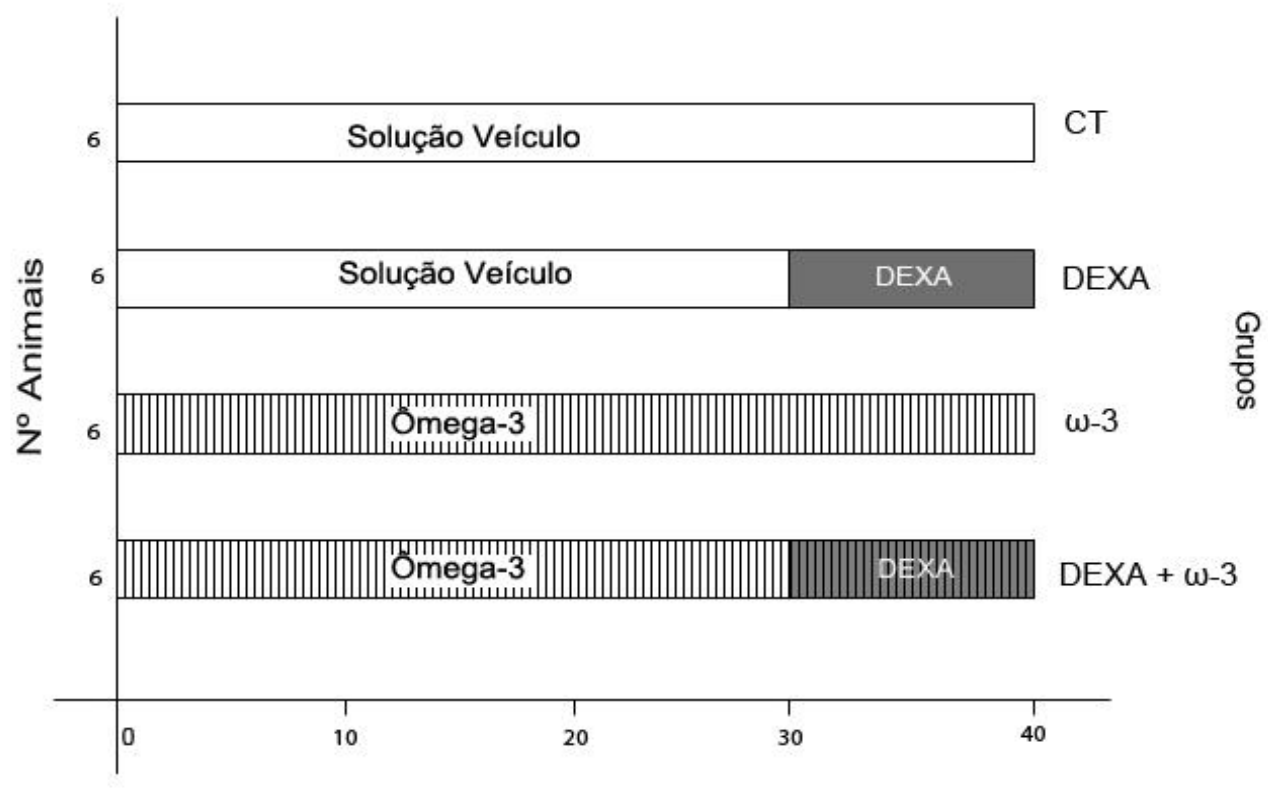

Dias de estudo

Figura 4: Esquema representativo do desenho experimental realizado para a suplementação de $\omega-3$ e administração da dexametasona.

\subsubsection{Coleta dos materiais}

Ao final do período de 40 dias, os animais foram pesados e eutanasiados por administração de pentobarbital sódico $(30 \mathrm{mg} / \mathrm{Kg})$ por via intraperitoneal, e os músculos gastrocnêmios (GA) e tibiais anteriores (TA) foram coletados e pesados. A metade proximal dos músculos do hemicorpo direito dos animais foi montada coronalmente em fragmento de cortiça com tissue tek e congelada em isopentano previamente resfriado em nitrogênio líquido para posterior análise histológica. A porção distal dos mesmos músculos, bem como os músculos TA e GA esquerdos, foram congelados em nitrogênio liquido e estocados a $-80^{\circ} \mathrm{C}$ para extração de RNA total e proteínas. 


\subsection{Análise do comportamento motor}

Ao fim dos 40 dias do estudo, os vinte e quatro animais passaram por análise do comportamento motor em campo aberto, realizado através de gravação da atividade motora, foi baseado em três variáveis: quantidade de pequenos movimentos, grandes movimentos e a quantidade de intervalos sem movimentos. Utilizou-se um sensor de movimentos Infrared (Coulbourn Instruments, USA), como descrito por Alves et al. (2011). A sala de experimentação foi mantida escura, em temperatura e umidade controlada, e os ratos foram individualmente alocados em caixas de polietileno (37 x 17 x $30 \mathrm{~cm}$ ) as quais continham um sensor de movimento acoplado à tampa, com registros sendo efetuados a cada 2 minutos pelo período de 30 minutos. Ao final do teste os dados foram transferidos para um software externo, sendo analisada a quantidade de pequenos e grandes movimentos. Considera-se "pequeno movimento", de acordo com os registros de gravação do software, como a média de tempo em segundos durante o qual o animal se movimentou num intervalo superior a 0,01 até 0,1 segundo, e "grande movimento" como movimentos com intervalo de tempo superior a 1 segundo.

\subsection{Reações histológicas}

Fragmentos dos músculos TA e GA foram seccionados coronalmente em Criostato, marca Leica CM3000, de forma sequencial, a uma temperatura de $-23^{\circ} \mathrm{C}$, sendo escolhida para secções espessuras entre 8 e 10 micrometros. As lâminas com os fragmentos musculares foram submetidas às colorações histológicas de hematoxilina e eosina (HE) e metacromática de ATPase.

\subsubsection{Coloração metacromática de ATPase}

Para avaliação e cálculo das áreas das fibras musculares de acordo com seus subtipos optou-se pelo método metacromático de coloração de ATPase (mATPase), (Ogilvie e Feeback, 1990), que avalia o grau de inibição da atividade da ATPase miofibrilar, permitindo a distinção de 4 tipos de fibras musculares (I, IIA, IIB e IIC). Resumidamente, as lâminas com os cortes musculares congelados são secas e colocadas em solução de préincubação contendo água destilada $(475 \mathrm{ml})$, acetato de potássio $(2,45 \mathrm{~g})$ e cloreto de cálcio $(1.30 \mathrm{~g})$, em pH 4.5 (ajustado com ácido acético glacial), por 2 minutos em temperatura ambiente, sendo então realizado 3 lavagens de 2 minutos cada com Tampão de Tris com água destilada $(950 \mathrm{ml})$, Trizma base (12.10g), cloreto de cálcio (2.60g), em pH 7.8 (ajustado com $\mathrm{HCl}$ ). Em seguida as lâminas são incubadas 
em temperatura ambiente, por 25 minutos, em solução com água destilada (30 ml), cloreto de potássio $(185 \mathrm{mg})$, sal dissódico de ATP (76 mg), cloreto de cálcio 0.18M (5 $\mathrm{ml}$ ), Sigma 221 buffer (1.5 M 2-amino-2methyl1-propanol) (3.35 ml), em pH 9.4 (ajustado com $\mathrm{HCl}$ ). As laminas são lavadas sequencialmente com mergulhos em três mudanças de solução de $1 \%$ de cloreto de cálcio em água destilada e em seguida coradas em solução com $1 \%$ de azul de toloudina aquosa por 10 seg., sendo imediatamente lavadas em água destilada numa sequencia de três beakers, para remover o excesso de corante. As laminas passam então por desidratação em bateria de alcoóis (etanol 95\% e absoluto), clareamento em xilol (5 minutos) sendo então montadas para histologia com Entellan ${ }^{\circledR}$ (Merk Millipore). Foram utilizados cortes em que as fibras encontravam-se em posição coronal. Após a realização da técnica, as fibras coradas foram fotografadas a 20X, em fotomicroscópio marca Olympus AX70 (Olympus Melville, NY, USA), para o cálculo da área de secção transversa das fibras, que foi realizada por meio do programa Image $J$ (National Institutes of Health). Após configuração inicial do software, de acordo com manual do fabricante, as fibras musculares selecionadas por subtipos, tiveram seu sarcolema tracejado para o cálculo da área transversa. Foram mensuradas entre 300 e 400 fibras musculares por fragmento muscular de cada animal, sendo calculada a média em $\mu \mathrm{m}^{2}$ das áreas obtidas de acordo com a classificação das fibras, em tipos I, IIA e IIB.

\subsection{Eletroforese SDS-PAGE (Western blotting)}

Fragmentos do músculo GA de cada animal foram homogeneizados em homogeneizador Potter em 10 X seu peso em volume de tampão de lise RIPA (50 mM Tris, $\mathrm{pH}$ 7.5, $150 \mathrm{mM} \mathrm{NaCl}, 1 \mathrm{mM}$ EDTA and 1\% Nonidet P40), acrescidos de coquetel de inibidores de proteases e fosfatases (Sigma-Aldrich; P5726 e A-1153, respectivamente), seguido de centrifugação a $13.000 \mathrm{~g}$ por 5 minutos à $4{ }^{\circ} \mathrm{C}$, sendo o sobrenadante reservado para uso. A concentração de proteína de cada amostra foi determinada pelo método de Bradford, utilizando albumina sérica bovina na realização de curva de diluição padrão. Quantidades iguais de proteínas $(25$ - 100ug) foram acrescidas de tampão de eletroforese e DTT $0.1 \mathrm{M}$, fervidas a $95{ }^{\circ} \mathrm{C}$ por 5 minutos e mantidas no gelo por 5 minutos, sendo então aplicadas em gel SDS-PAGE (8-10\% de Acrilamida) e submetidas à eletroforese com voltagem de 100 a $120 \mathrm{~V}$, por 1 a 2 horas, em aparato de eletroforese marca BioRad. As proteínas foram então transferidas para 
membrana de PVDF ou Nitrocelulose (voltagem de 100V por 1-3hs) e posteriormente incubadas em tampão de bloqueio TBS-T (50 mM Trizma base, pH 7.5, $150 \mathrm{mM} \mathrm{NaCl}$ e $0.1 \%$ Tween 20), contendo $5 \%$ de leite desnatado, por pelo menos 1 hora em temperatura ambiente para bloquear sítios inespecíficos. Em seguida, as membranas foram incubadas em tampão de bloqueio contendo o anticorpo primário por aproximadamente 20 horas em temperatura de $4{ }^{\circ} \mathrm{C}$. Após três lavagens de 10 minutos com TBS-T, as membranas foram incubadas com tampão de bloqueio contendo anticorpo secundário conjugado com peroxidase (horseradish peroxidase conjugated) anticamundongo (Santa Cruz Biotechinology, SC-2031), ou anticoelho (KPL, 04-1506), nas concentrações de [1:6.000] e [1:10.000] mg/ml, respectivamente, por $1 \mathrm{hr}$ em temperatura ambiente. Após nova lavagem com TBS-T (3 vezes de 10 minutos cada), as membranas são reveladas após incubação com reagente quimioluminescente (Western Enhancing Chemiluminescence Reagent Plus, ECL kit, Perkinelmer, EUA) por 1 minuto em agitação manual, e em seguida é realizada, durante $30 \mathrm{seg}$. a 2 minutos, exposição a filme radiográfico (Hyperfilm ECL, Amersham Biosciences) conforme instruções do fabricante.

Para verificar a homogeneidade das amostras transferidas, as membranas foram coradas com Comassie Brilhant Blue. Com o objetivo de normatizar a quantidade de proteínas do tecido muscular aplicadas ao gel e determinar os valores a serem analisados, por razão de proteína alvo/normatizador em cada amostra, utilizou-se o marcador $\alpha$-tubulina. Os anticorpos primários utilizados bem como a sua concentração são apresentados na tabela 1. A análise densitométrica das bandas de proteínas marcadas nas membranas foi realizada utilizando o programa Image $J(\mathrm{NIH})$.

Tabela 1. Anticorpos utilizados no estudo.

\begin{tabular}{|c|c|c|c|}
\hline Antígeno & Hospedeiro & Empresa/ código & Concentração \\
\hline Akt & Coelho IgG & Cell Signaling / 4691 & {$[1: 2000]$} \\
\hline$P$-Akt & Coelho IgG & Cell Signaling / 4060 & {$[1: 2000]$} \\
\hline mTOR & Coelho & Cell Signaling / 2972 & [1:500] \\
\hline P-mTOR & Coelho & Cell Signaling / 2971 & {$[1: 500]$} \\
\hline GSK3及 & Coelho IgG & Cell Signaling / 9315 & {$[1: 2000]$} \\
\hline$P-G S K 3 \beta$ & Coelho IgG & Cell Signaling / 9322 & {$[1: 2000]$} \\
\hline P-p70S6 & Coelho IgG & Cell Signaling / 9205 & [1:1000] \\
\hline FOXO3a & Coelho IgG & Cell Signaling / 2497 & {$[1: 1000]$} \\
\hline P-FOXOЗа & Coelho & Cell Signaling / 9566 & {$[1: 500]$} \\
\hline$\alpha$-tubulina & Camundongo & Hybridoma bank/ AA4.3 & {$[1: 30.000]$} \\
\hline
\end{tabular}




\subsection{Reação de transcriptase reversa}

O RNA total dos fragmentos musculares de GA foi extraído usando o reagente TRIZOL (Invitrogen) em homogeneizador tipo Dounce. A integridade e a quantidade de RNA de cada amostra foram avaliadas por eletroforese em gel de agarose e por medida espectrofotométrica em absorbâncias a 260 e 280 nm, na qual amostras com razão $\mathrm{A}_{260}: \mathrm{A}_{280}$ menor que 1,8 foram descartadas. Realizou-se a quantificação de RNA através de espectrofotômetro NanoDrop 1000 e posteriormente avaliou-se a viabilidade do RNA através do uso do equipamento 2100 bioanalyzer, RNA 6000 Pico LabChip (Agilent). Foram utilizadas amostras com valor de integridade de RNA de RIN $\geq 5$. O RNA foi tratado com DNase I (Ambion), usando instruções do fabricante, com o objetivo de remover DNA genômico contaminante.

Para a síntese de DNA complementar (cDNA), seguiu-se com as seguintes etapas: $1 \mu \mathrm{g}$ (1000ng) de RNA total extraído foi diluído em água DEPC para volume final de 19,25 $\mu \mathrm{l}$. Em seguida as amostras foram mantidas em gelo para adição do mix contendo $5 \mu \mathrm{L}$ de tampão Rt Buffer 10x, 10 $\mu \mathrm{L}$ de $d N T P s$ 10mM mix, (Madison, WI), $11 \mu \mathrm{L}$ de $\mathrm{MgCl}^{2} 25 \mathrm{mM}, 2,5 \mu 1$ de Random hexamers e foram então incubadas com enzimas RNAase in $(1 \mu \mathrm{l})$ e Multiscribe $(1,25 \mu \mathrm{l})$. Em seguida os mixs foram distribuídos entre as amostras para volume final de $50 \mu 1$, homogeneizadas e colocadas em termociclador, marca (Eppendorf), para realização da transcrição reversa em ciclagem pré-determinada.

\subsection{PCR em tempo real}

A reação de PCR em tempo real foi realizada para estudar a expressão gênica dos fatores de transcrição musculares MyoD, Miostatina, Miogenina, REDD-1 e REDD2 e dos atrogenes atrogina-1 e MuRF1. Foram utilizadas amostras dos músculos GA dos animais. A amplificação por PCR foi efetuada utilizando-se 50ng de cDNA adicionado à $25 \mu \mathrm{L}$ de SYBR® Green PCR master mix (Fermentas), contendo 800 à 900nM de primers (senso e antissenso), em placas de 96 poços - Fast MicroAmp ${ }^{\circledR}$ Optical (Applied Biosystems). O volume de solução final foi de $25 \mu \mathrm{L}$, em duplicata, e foram analisadas no equipamento Step One Plus (Applied Biosystems, EUA). As condições da PCR em tempo real incluíram desnaturação inicial a $95{ }^{\circ} \mathrm{C}$ por 10 minutos, seguidos de 45 ciclos de desnaturação a $95^{\circ} \mathrm{C}$ por 15 segundos e 1 minuto entre $54-63^{\circ} \mathrm{C}$ para pareamento e extensão. Os dados referentes aos RNAm do estudo foram normalizados através de subtração dos valores referentes ao GAPDH (gliceraldeído-3- 
fosfato-desidrogenase) e comparados entre si por normalização logarítmica $\left(2^{-\Delta \Delta \mathrm{CT}}\right)$. Foram aceitas replicatas de amostras que apresentavam desvio padrão de até 0,6. As sequencias de oligonucleotídeos utilizados são apresentadas na tabela 2.

Tabela 2. Sequencias de oligonucleotídeos utilizados no estudo.

\begin{tabular}{ccccc}
\hline Gene & p.b & Forward & Reverse & Referência \\
\hline Miogenina & 196 & CACATCTGTTCGACTCTCTTCT & ACCTTGGTCAGATGACAGCTTTA & (Chen D et al., 2010) \\
Myostatin & 118 & CCAAGAGGTCCCGGAGAGAGAC & GCAATAATCCAGTCCCATCCAAAG & (Moore et al., 2008) \\
MURF-1 & 194 & TCGACATCTACAAGCAGGAA & CTGTCCTTGGAAGATGCTTT & (Pires et al., 2010) \\
atrogina-1 & 262 & TGAAGACCGGCTACTGTGGAGAGAC & TTGGGGTGAAGTGAGACGGAGCAG & (Pires et al., 2010) \\
REDD-1 & 136 & CACCGGCTTCAGAGTCATCA & CGGGTCTCCACCACAGAAAT & $\begin{array}{c}\text { (Murakami et al., } \\
\text { 2011) }\end{array}$ \\
REDD-2 & 129 & CTTCAGCGTCTGGTGAAATCC & ATGCTGGCCGTGTTCTACTG & (Murakami et al., \\
MyoD & 167 & TGTAACAACCATACCCCACTCTC & AGATTTTGTTGCACTACACAGCA & (Dasarathy et al., \\
2004)
\end{tabular}

\subsection{Cromatografia gasosa}

Para análise do perfil de ácidos graxos totais e PUFA no tecido muscular dos animais, foi realizada a técnica de cromatografia gasosa no Laboratório de Lípides da Faculdade de Ciências Farmacêuticas da Universidade de São Paulo (FCF-USP). A extração foi realizada pela técnica de Bligh \& Dyer (1959) de acordo com Iverson et al. (2001). Resumidamente, 125mg de amostras dos músculos GA foram homogeneizadas (Ultra-turrax, IKA T10 Basic) com uma mistura contendo clorofórmio $(125 \mu \mathrm{L})$ e metanol $(200 \mu \mathrm{L})$. A solução foi novamente homogeneizada com clorofórmio/metanol em solução salina de $(0,88 \%$ NaCL). A emulsão final foi centrifugada a $13,000 \mathrm{~g}$ por 5 minutos a $25^{\circ} \mathrm{C}$. A fase superior foi removida e a fase inferior evaporada sob vapor de nitrogênio. As amostras de gordura foram então derivadas usando a técnica de esterificação, descrita por Shirai et al. (2005), e suas composições foram determinadas em cromatógrafo a gás (Agilent 7890 AGC System, Agilent Technologies Inc., Santa Clara,USA). Utilizou-se coluna capilar fundida de sílica (J\&W DB-23 Agilent 122-236; 60m x 250 mm de diâmetro interno) para injeção das amostras. Hélio de alta pureza foi aplicado em fluxo de $1 \mathrm{ml} /$ minutos, com injeção de separação de 50:1. A programação de temperatura da coluna foi a seguinte: inicial a $80{ }^{\circ} \mathrm{C}$, taxa de aquecimento $5{ }^{\circ} \mathrm{C} /$ minutos até $175{ }^{\circ} \mathrm{C}$, seguido de outro gradiente de 3 ${ }^{\circ} \mathrm{C} /$ minutos para $230{ }^{\circ} \mathrm{C}$, e mantido nesta temperatura por $5 \mathrm{mim}$. A temperatura do 
injetor e detector foram $250^{\circ} \mathrm{C}$ e $280^{\circ} \mathrm{C}$, respectivamente. Os ácidos graxos foram identificados por comparação do tempo de retenção comparados com quatro misturas purificadas de padrões de retenção de ácidos graxos metil ésteres (Sigma Chemical Co.: 4-7801; 47085-U; 49453-U e 47885-U). Os resultados foram expressos em \% de ácidos graxos totais.

\subsection{Análise estatística}

Todos os dados obtidos foram analisados através de modos estatísticos não paramétricos do teste t ou análise de variância (ANOVA) de uma (One-Way) ou duas vias (Two-Way) dependendo do tipo de análise, sendo os testes realizados descritos no momento da apresentação de cada resultado juntamente com o $\mathrm{N}$ médio (número de indivíduos) para cada grupo de análise. Foram aceitas como variações significativas aquelas em que a diferença entre os grupos resultou em um $P$ menor ou igual a 0,05 . Os resultados estão apresentados em média aritmética \pm erro padrão da média. As análises estatísticas foram realizadas utilizando-se o programa Graph Pad Prism, versão 5.00 de 2007, para Windows (Graph Pad Software, San Diego, Califórnia, EUA). 


\section{RESUTADOS}

\subsection{Análise do Peso Corporal}

A administração da dexametasona induziu grande perda de peso corporal nos animais do estudo. Um dos animais do grupo DX morreu ao $5^{\circ}$ dia da administração da droga.

O gráfico com o peso dos animais durante o período experimental, e o gráfico com o peso corporal pré e pós o período de 10 dias de administração da dexametasona, mostraram que a administração deste glicocorticoide é de fato um grande indutor de perda de peso corporal, e que a administração prévia e concomitante do $\omega$-3 não foi eficaz em atenuar a perda de peso (Figuras 5). Todos os animais, independente do grupo a qual pertenciam, apresentaram ganho de peso progressivo e proporcional até o $30^{\circ}$ dia de estudo, compatível com o crescimento natural dos animais, sem que houvesse diferença entre os grupos. Foram observadas diferenças significativas de perda de peso dos grupos a partir do $32^{\circ}$ dia de estudo, ou seja, dois dias após a administração da dexametasona.

O grupo de animais que recebeu a dexametasona, bem como o grupo que recebeu o $\omega 3$ associado à dexametasona apresentaram grande perda de peso, com diferença de $-18,53 \%$ (grupo DX) e -19,76\% (grupo DX $+\omega 3$ ) ao $32^{\circ}$ dia de estudo em comparação ao grupo CT. Tal diferença de peso nestes grupos progrediu até o final do estudo ( $40^{\circ}$ dia), mostrando diminuição de peso similares em comparação ao grupo CT,

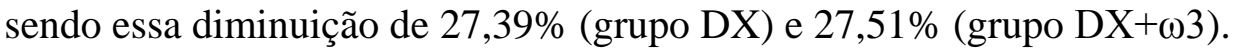

A porcentagem de ganho ou de perda de peso corporal dos animais pôde ser estimada ao comparar as médias de peso inicial e final de cada grupo durante o período experimental. $\mathrm{O}$ grupo CT, que apresentava média inicial de 356,33 $\pm 4,7 \mathrm{~g}$, completou o estudo pesando 427,66 $\pm 11,8 \mathrm{~g}$, o que representou um ganho de 20,01\% na média de peso. Observou-se de maneira similar, um ganho de peso no grupo $\omega$-3, porém de maneira menos expressiva, com média de peso inicial de $345,5 \pm 8,8 \mathrm{~g}$ e média final de $396,0 \pm 16,4 \mathrm{~g}$, ganho correspondente de $14,61 \%$. Por outro lado, os animais dos grupos DX e DX $+\omega 3$ mostraram redução na média de peso corporal final, com perda de $8,54 \%$ no grupo DX (média de peso inicial de 339,5 $\pm 6,8 \mathrm{~g}$ e final de $310,5 \pm 5,6 \mathrm{~g}$ ), e perda de $9,88 \%$ no grupo $\mathrm{DX}+\omega 3$ (média de peso inicial de $334,00 \pm 5,52 \mathrm{~g}$ e final de $301,0 \pm$ $9,8 \mathrm{~g})$. 


\section{Peso corporal}

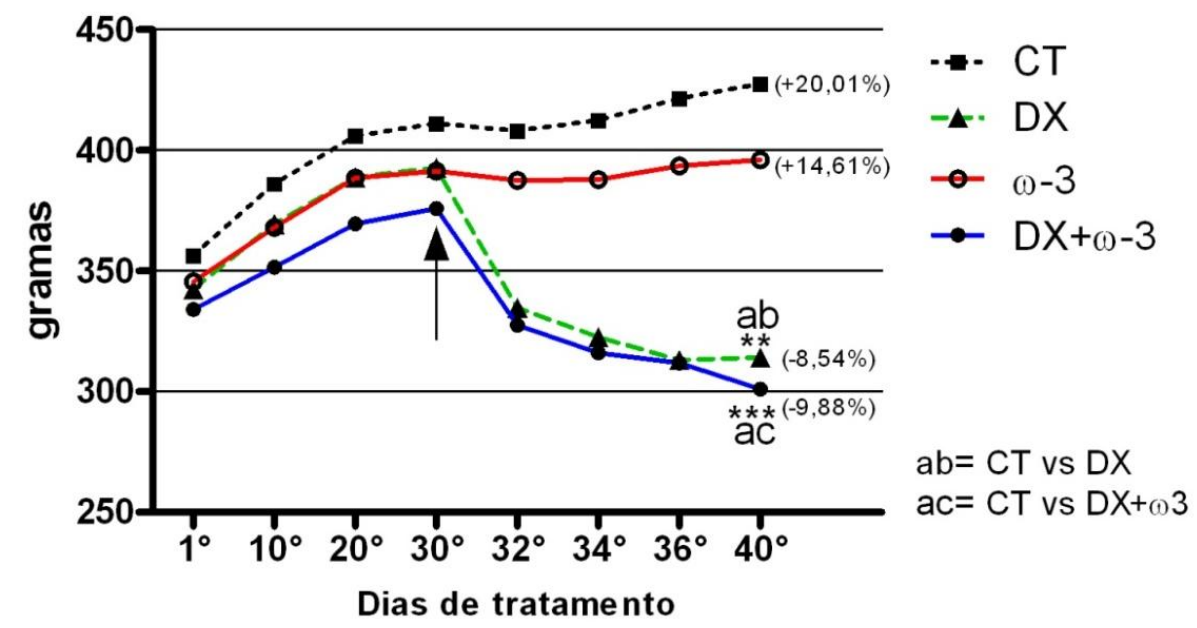

Figura 5: Variação de peso corporal dos animais no decorrer do estudo e a porcentagem de ganho de peso entre o inicio e final do estudo. A seta indica o momento inicial da administração da dexametasona. Teste estatístico de Friedman para medidas repetidas com pós-teste de Dunn's; $* *=P<0,01 ; * * *=P<0,001 ; \mathrm{N}$ total $=6$ animais/grupo.

As médias de peso corporal no momento da administração da dexametasona e dez dias após sua administração foram comparadas (Figura 6). A porcentagem de perda de peso corporal nos 12 animais que a receberam a dexametasona foi de 21,75\% (grupo DX) e de 19,91\% (grupo DX+ 13 ).

\section{Peso corporal pré \\ e pós administração de Dexametasona}

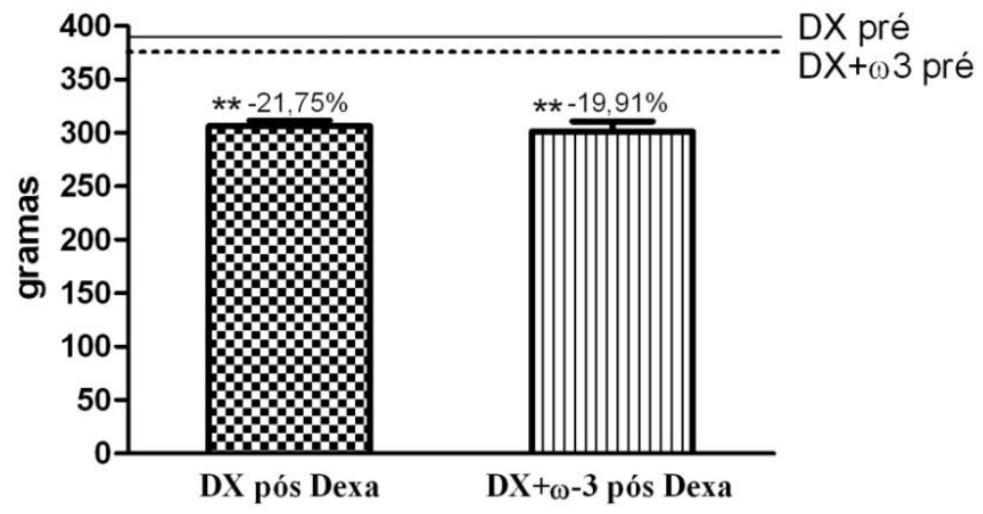

Figura 6: Porcentagem de perda de peso corporal dos animais no momento e após 10 dias da administração da dexametasona. Linhas representam momento inicial da administração da droga: linha pontilhada $=$ grupo $\mathrm{DX}+\omega 3$; linha contínua: grupo $\mathrm{DX} . * *=P<0,01$; Teste estatístico de Mann Whitney; $\mathrm{N}$ total $=6$ animais/grupo. 


\subsection{Análise de peso muscular}

Após a eutanásia dos animais os músculos GA e TA foram extraídos e pesados (Figura 7). Os animais dos grupos $\mathrm{DX}$ e $\mathrm{DX}+\omega 3$ mostraram importante redução no peso dos músculos GA e TA em comparação com o grupo CT. Não houve diferença entre as médias dos pesos musculares dos grupos CT e $\omega 3$, ou entre os grupos DX e $\mathrm{DX}+\omega 3$.

\section{Peso do músculo Gastrocnêmio}

A

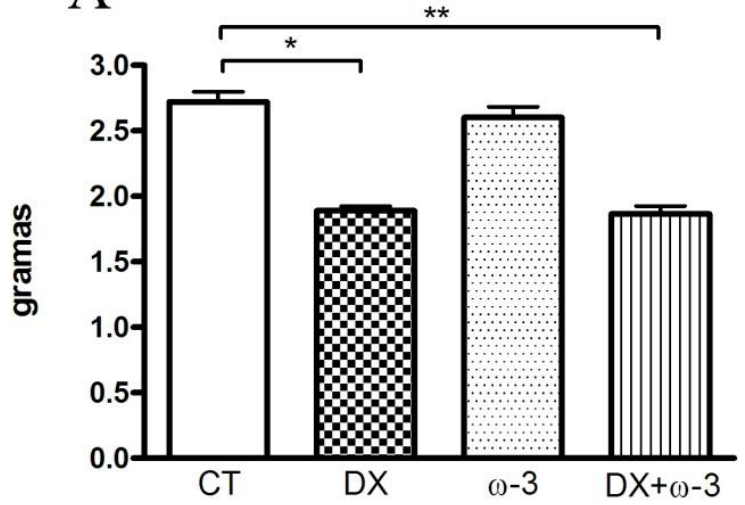

Peso do músculo

Tibial Anterior

$\mathrm{B}$

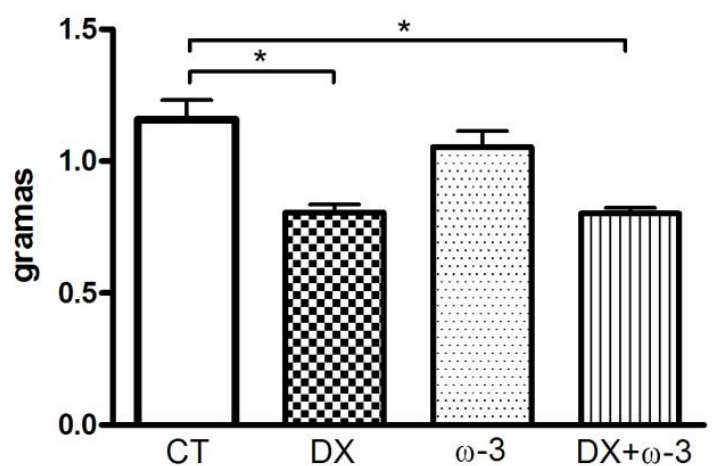

Figura 7: Pesos em gramas dos músculos coletados no momento da eutanásia. $*=P<0,05$; $* *=P<0,01$; Teste estatístico não paramétricos de Kruskal-Wallis seguido do pós teste de Dunn's; $\mathrm{N}$ total $=6$ animais/grupo.

\subsection{Comportamento motor}

A análise da quantidade de pequenos e grandes movimentos, realizados pelos animais ao último dia de estudo, mostrou não haver diferença significativa na quantidade de grandes movimentos entre os grupos (Figura 8A). No entanto, foi observado que a administração do glicocorticoide induziu, tanto os animais do grupo $\mathrm{DX}$, quanto do grupo $\mathrm{DX}+\omega 3$, a uma significativa diminuição na quantidade de pequenos movimentos em comparação ao grupo CT (Figura 8B). O grupo $\omega 3$ também apresentou diminuição no número de pequenos movimentos em comparação com o CT, no entanto, sem significância estatística. A média de pequenos movimentos no grupo CT foi de 400 repetições num intervalo de 30 minutos, enquanto que o grupo DX mostrou metade desse valor $(P<0,05)$. Diminuição similar foi observada no grupo $\mathrm{DX}+\omega 3$ em comparação ao grupo CT. 


\section{Análise Comportamental Infra-red}
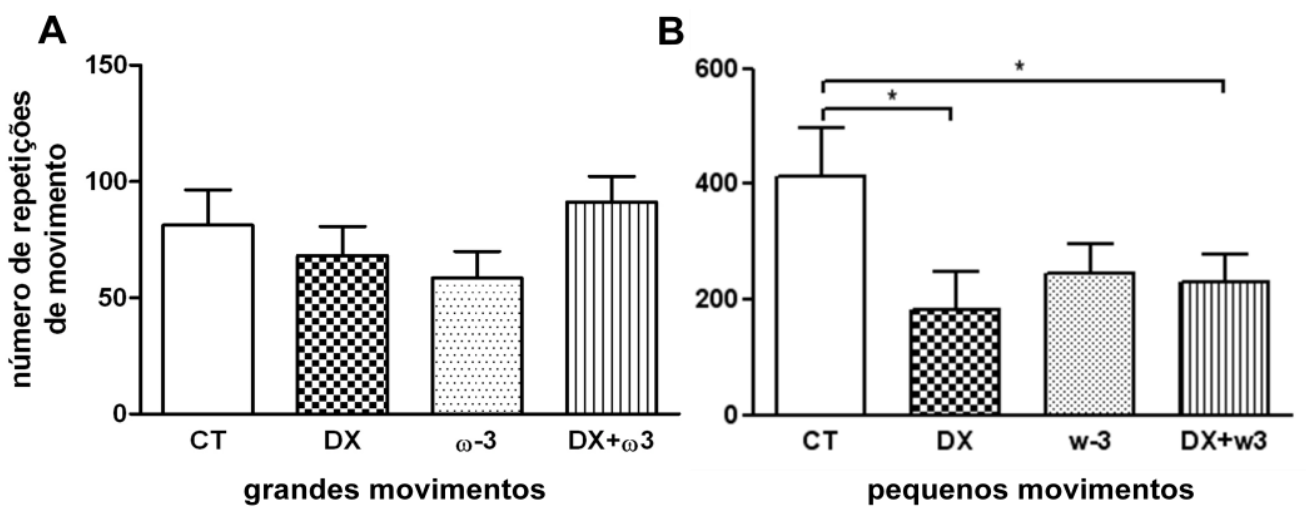

Figura 8: Quantidade de grandes e pequenos movimentos registrados pelo infrared. Teste estatístico de Mann Whitney. ${ }^{*}=P<0,05 ; \mathrm{N}$ total $=6$ animais/grupo.

\subsection{Perfil lipídico muscular}

A análise da porcentagem total de gorduras saturadas e do PUFA mostrou que o grupo $\omega 3$ elevou em 9,17\% a quantidade de PUFA e diminuiu em 12,63\% a quantidade de gordura em seus músculos em comparação ao grupo CT $(P=0,06$ para ambas comparações). O mesmo aumento na quantidade de PUFA, bem como a diminuição na

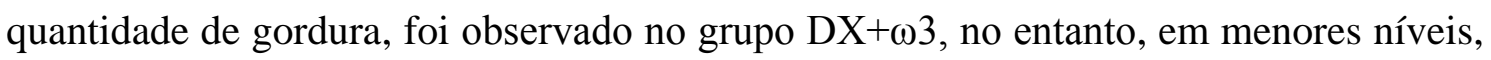
com aumento de 6,00\% nos níveis de PUFA e diminuição de 8,21\% nos níveis de gordura (figura 9A). Analisando as formas isoladas de PUFA nos grupos suplementados em comparação ao grupo CT, observou-se um aumento na quantidade de ácido linoleico em ambos os grupos suplementados com $\omega$-3, de forma significativa no grupo $\mathrm{DX}+\omega 3(P<0,05)$, e com tendência à aumento no grupo $\omega 3(P=0,06)$ (figura 9B). O ácido araquidônico mostrou-se em quantidades significantemente menores em ambos os grupos suplementados $(P<0,05$ para ambos) (figure 9C), e o ácido $\alpha-$ linoleico mostrou-se em quantidades significantemente maiores no grupo $\omega 3(P<0,05)$, com tendência a elevação no grupo $\mathrm{DX}+\omega 3(P=0,06)$ (figura 9D). 


\section{A Nível de PUFA e gordura}
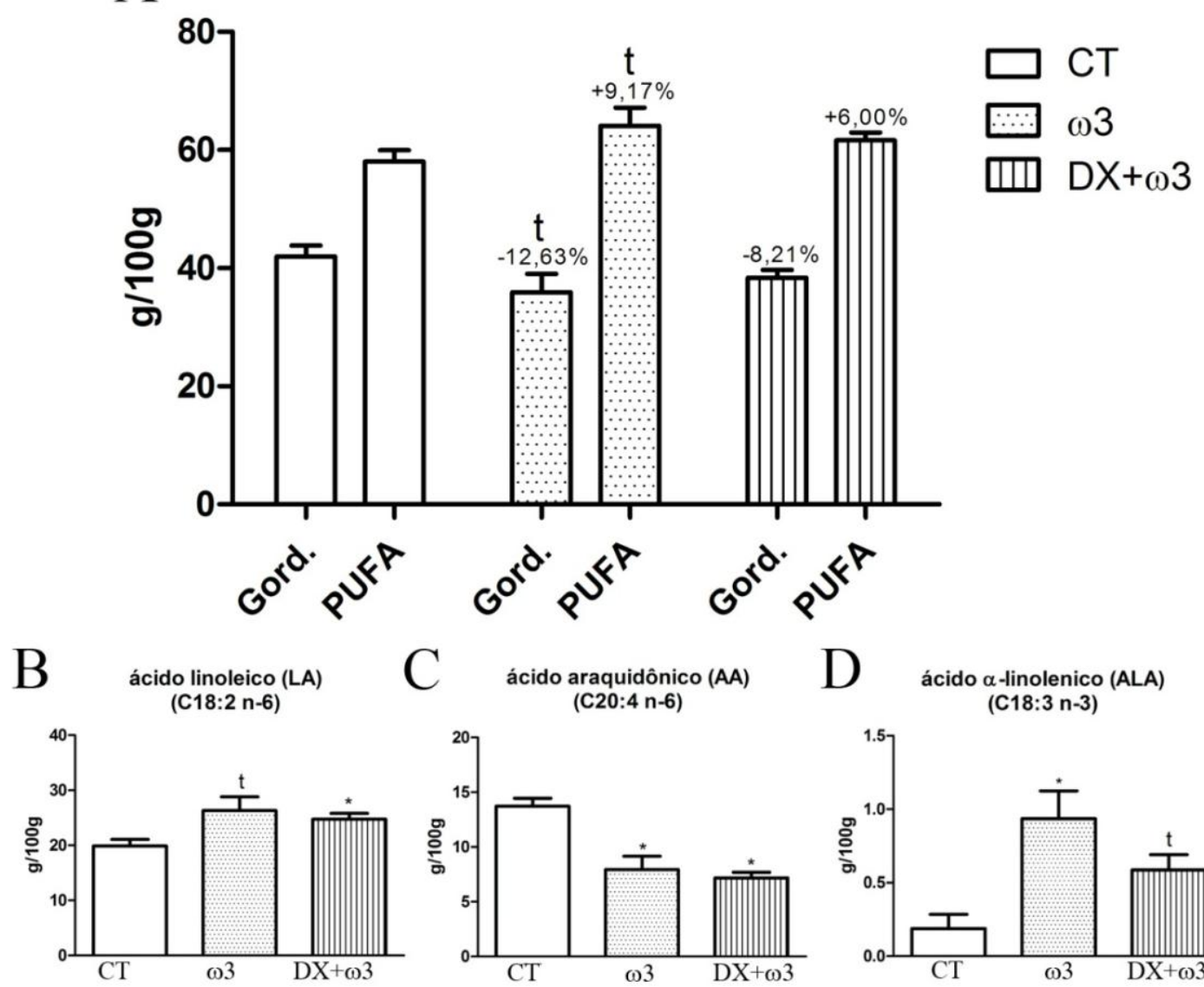
$\mathrm{C}$ ácido araquidonico (AA)

D ácido $\alpha$-linolenico (ALA) (C18:3n-3)
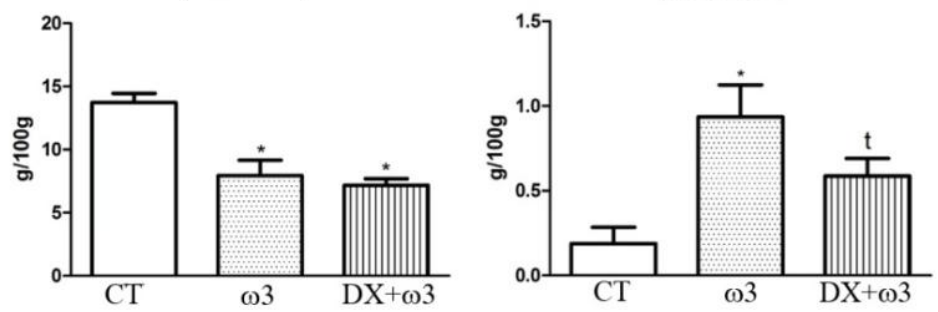

Figura 9: Cromatografia gasosa muscular de GA. (A) Porcentagem de Gordura saturada e de PUFA de acordo com os grupos de estudo. Valores acima das colunas indicam porcentagem de aumento ou de diminuição dos PUFAs e ou gorduras em comparação o observado no grupo CT. (B, C e D): Porcentagem dos ácidos: linoleico, araquidônico e $\alpha$-linolênico, respectivamente. Resultados estatísticos apresentados são em função da comparação dos grupos suplementados em comparação ao grupo CT. ${ }^{*}=P<0,05 ; \mathrm{t}(P=0,06)$. Teste de Anova de duas vias (A) e Mann Whitney (B, C e D); $\mathrm{N}=3$ animais/ grupo.

\subsection{Análise da atrofia muscular}

O cálculo da área de secção transversa das fibras musculares foi realizado por meio do programa Image $J$ após coloração das fibras musculares de TA pela técnica de mATPase (Figura 10). O resultado da análise comparativa das áreas de cada tipo de fibra entre os grupos, mostrou importante atrofia muscular nas fibras do tipo IIB nos animais que receberam dexametasona isoladamente $(25,03 \%$ de redução da área) ou concomitante com o $\omega-3$ (32,71\%) em comparação ao grupo CT ( $P<0,05$ para ambos). Adicionalmente, os animais que receberam dexametasona associada ao $\omega$-3 também apresentaram atrofia muscular significativa nas fibras do tipo I (14,58\% de redução de área) e IIA (20,53\% de redução de área) em comparação com o grupo CT ( $P<0,05$ para 
ambos) (Figura 11). A administração isolada do $\omega$-3 não induziu atrofia muscular em nenhum dos tipos de fibras.
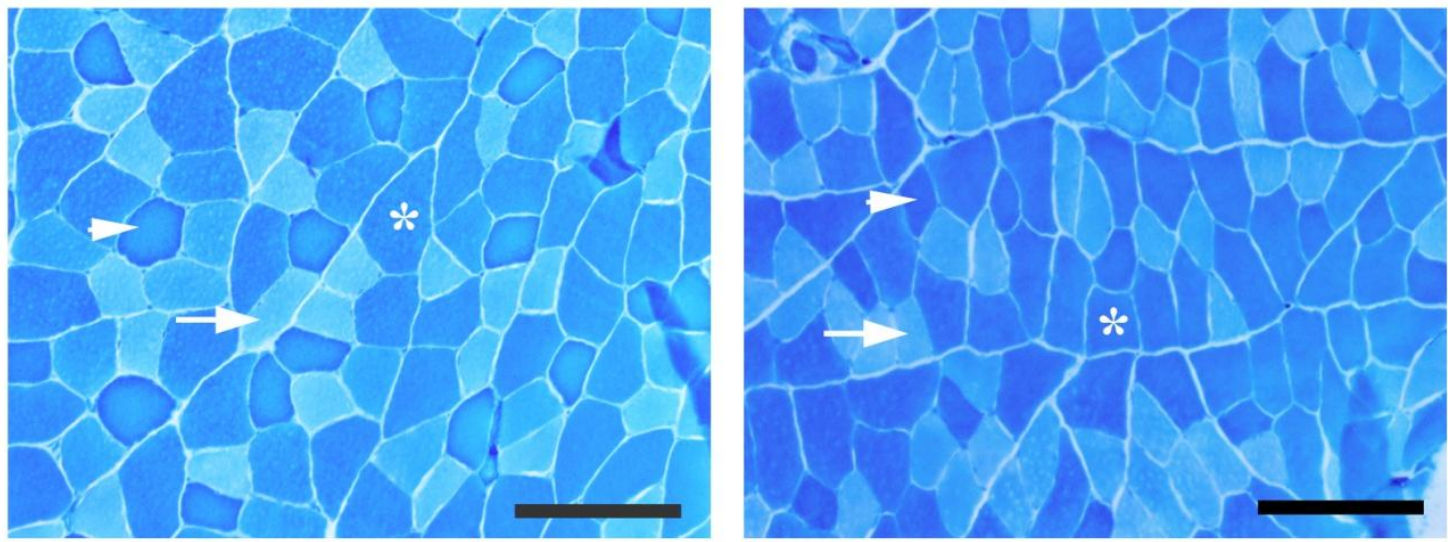

Figura 10: Cortes transversais de fibras musculares do músculo TA após técnica de mATPase (20X). À esquerda animal pertencente ao grupo CT e à direita animal pertencente ao grupo $\mathrm{DX}+\omega 3$ apresentando atrofia nos três tipos de fibras musculares. Fibra tipo I (cabeça de seta); fibras tipo IIA (seta); fibras tipo IIB (*); barra $(100 \mu \mathrm{m})$.

\section{Área de secção transversa}

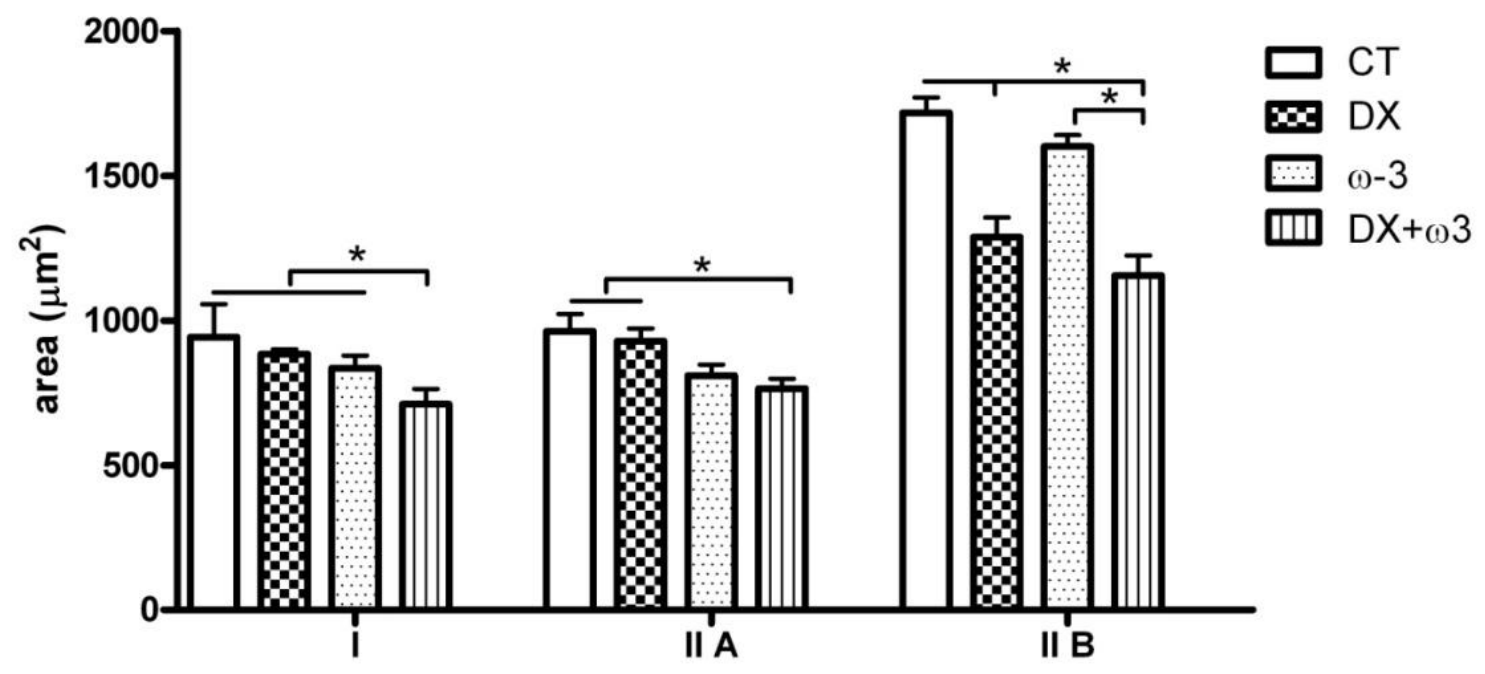

Tipo de fibra

Figura 11: Gráfico representativo da área média das fibras musculares de acordo com tipo de fibra e o grupo de estudo. Teste estatístico de Kruskal-Wallis seguido de pós teste de Dunn's realizado para cada variável. $*=P<0,05 ; \mathrm{N}$ total $=6$ animais/grupo.

\subsection{PCR em tempo real}

Para estudo de expressão gênica por PCR em tempo real (RT-PCR), fez-se inicialmente uma análise da expressão do gene normatizador $(G A P D H)$ entre os grupos (Figura 12). A análise estatística deste normatizador mostrou não haver diferença 
significativa entre os grupos, sendo, portanto, escolhido para normatizar os demais testes.

\section{Expressão relativa de GAPDH}

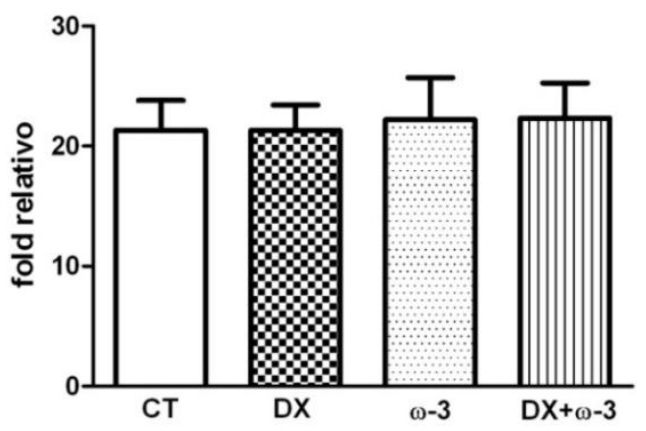

Figura 12: Fold relativo do normatizador. Teste estatístico não paramétrico de Kruskal-Wallis seguido do pós-teste de Dunn's. $\mathrm{N}$ total $=6$ animais/grupo.

Seguindo para as demais análises, o gene $M y o D$ mostrou-se com aumento de expressão no grupo $\omega-3$, e com diminuição no grupo $\mathrm{DX}+\omega 3$ comparados com o grupo CT, entretanto de forma não significativa para ambos. Tais alterações só se mostraram significantes quando comparados, entre si, os grupo $\omega 3$ e $\mathrm{DX}+\omega 3$ (Figura 13A). A expressão gênica de Miogenina mostrou-se com diminuição significativa no grupo $\mathrm{DX}+\omega 3$ em comparação ao grupo CT $(P<0,05)$, e com diminuição não significava nos demais grupos (Figura 13B).
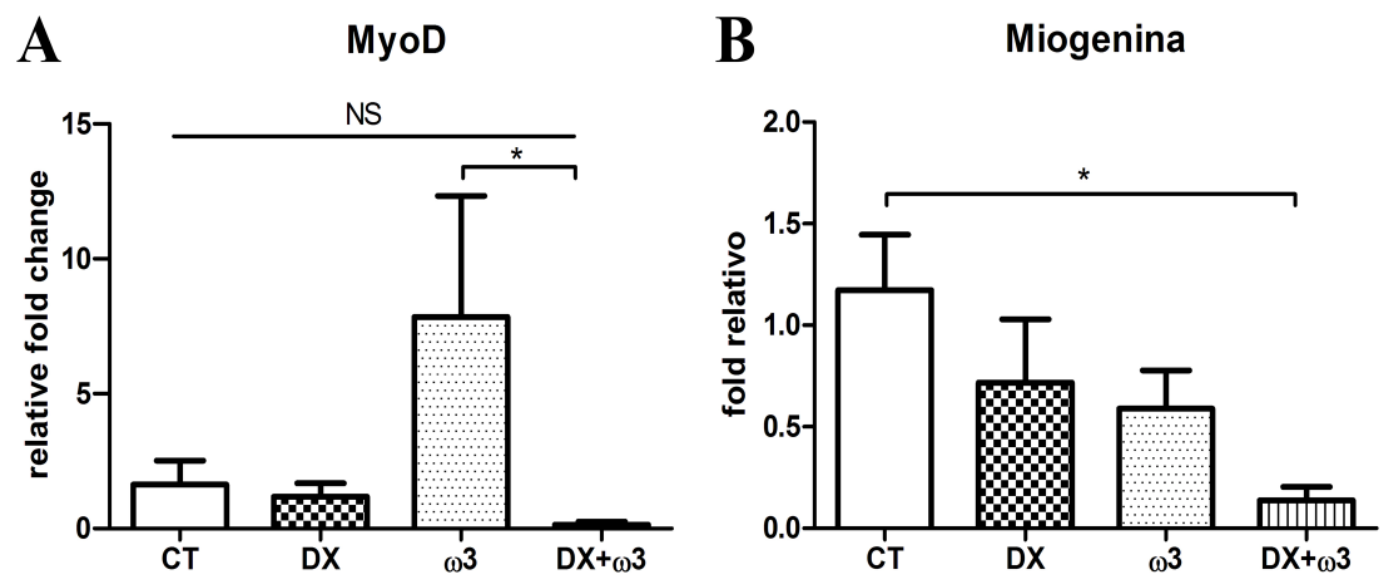

Figura 13: Expressão relativa de $M y o D / G A P D H(\mathbf{A})$ e Miogenina/GAPDH (B). NS = não significativo $(P=0,19) .{ }^{*}=P<0,05$; Teste estatístico não paramétrico de Mann-Whitney; $\mathrm{N}$ médio $=5$ animais/grupo.

A expressão dos genes da atrogina- 1 e $M u R F-1$ encontraram-se elevadas no grupo $\mathrm{DX}+\omega 3$ em comparação ao grupo CT. A expressão da atrogina-1 mostrou-se 
significantemente maior $(P<0,05)$ (Figura 14A), enquanto que a expressão do $M u R F 1$ mostrou-se com tendência de aumento $(P=0,09)$ (Figura 14B). Este aumento, nas expressões de atrogina-1 e $M u R F-1$ no grupo $\mathrm{DX}+\omega 3$, foi significativo em relação as expressões obtidas no grupo $\omega 3(P<0,05)$.

Com relação à Miostatina, regulador negativo do crescimento muscular, observou-se nos animais do grupo DX uma tendência de aumento na sua expressão em comparação com o grupo CT, no entanto, sem significância estatística, ao contrário do grupo que recebeu isoladamente o $\omega 3$, que apresentou aumento significante da expressão relativa deste gene em relação ao grupo CT $(P<0,01)$ (Figura 14C). Não houve diferença significativa na expressão da Miostatina no grupo DX ou DX+ $\omega 3 \mathrm{em}$ relação aos demais grupos.

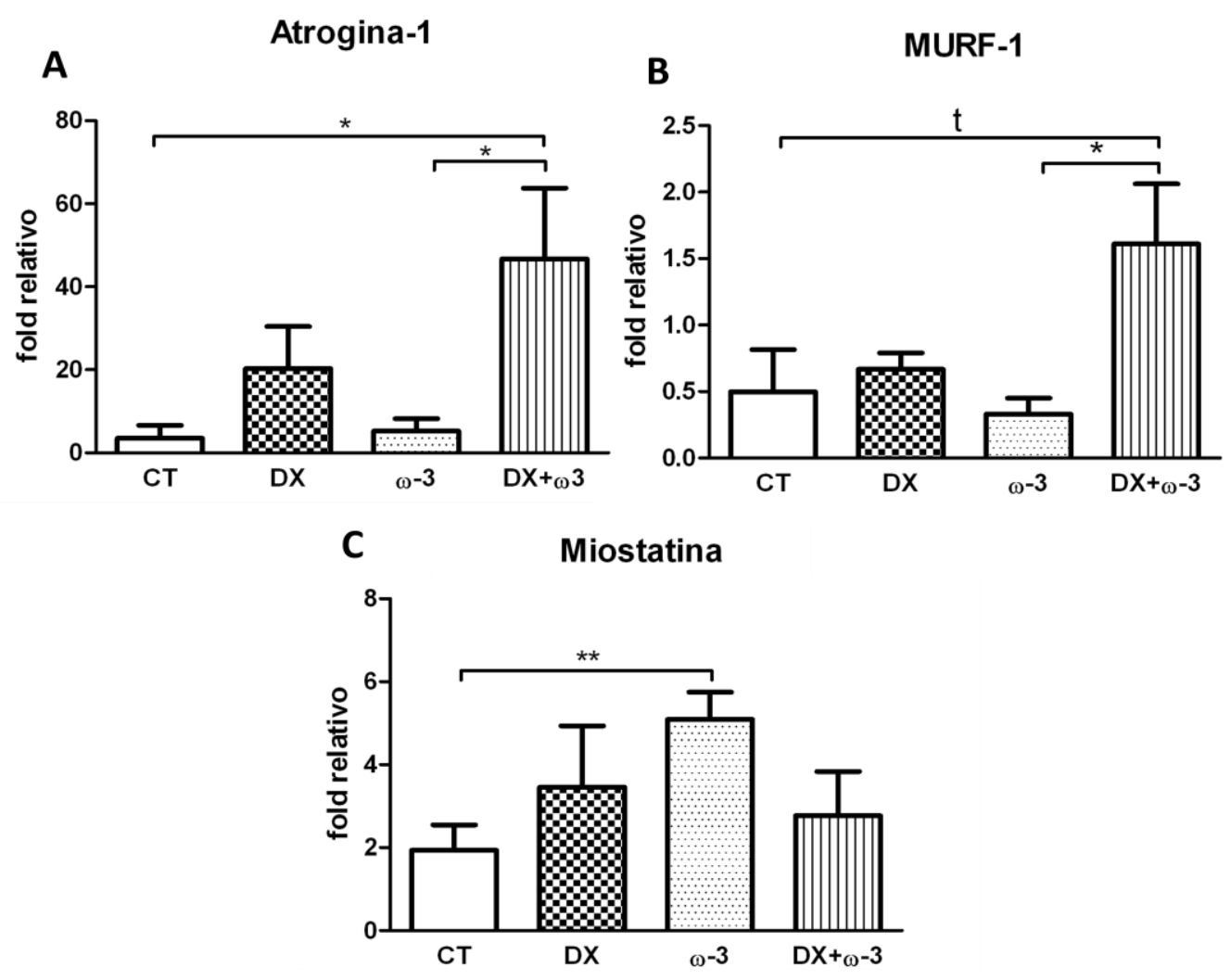

Figura 14: Expressão relativa de atrogina-1/GAPDH (A), $M u R F / G A P D H$ (B) $e$ Miostatina/GAPDH (C). Testes estatísticos de Mann Whitney. t $(P=0,09) ; *=P \leq 0,05 ; * *=P$ $<0,01 ; \mathrm{N}$ médio $=5$ animais/grupo.

A expressão de REDD1 não mostrou diferença estatisticamente significante entre os grupos (Figura 15A). Quanto à expressão do gene REDD-2, foi observado um aumento da expressão relativa no grupo que recebeu a dexametasona isoladamente, no entanto, sem significância estatística (Figura 15B). 

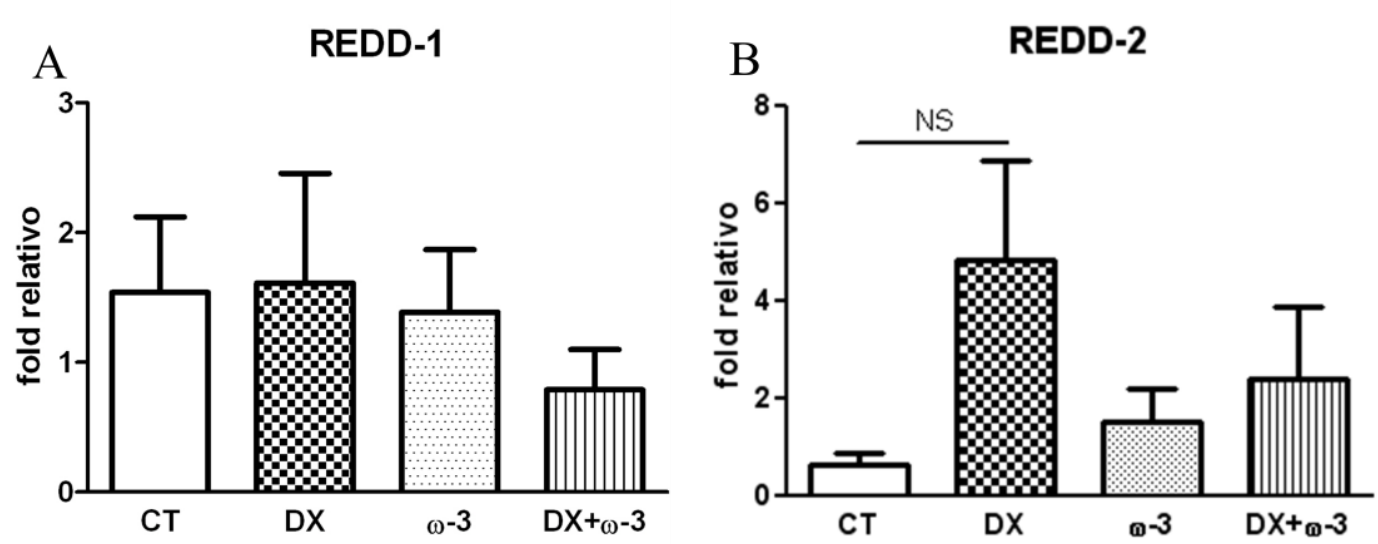

Figura 15: Expressão relativa do $R E D D-1 / G A P D H$ e $R E D D 2 / G A P D H$. Teste estatístico de Mann-Whitney. NS= não significativo $(P=0,17) ; \mathrm{N}$ médio 5 animais/grupo.

\subsection{Western Blotting}

A expressão de Akt total se mostrou com diminuição no grupo DX, e com ligeira elevação no grupo $\omega 3$ em relação ao grupo CT, no entanto, sem diferença estatística para ambas as análises (Figura 16 A). Já expressão do Akt na sua forma fosforilada (PAkt), bem como na razão P-Akt/Akt total, mostrou-se com diminuição significativa no grupo DX (-78,6\% na expressão de Akt total) em comparação com o grupo CT (p<0,05), não havendo diferença entre os demais grupos (Figura $16 \mathbf{C ~ e ~ E ) . ~}$

A expressão de GSK3 $\beta$ (Figura 16 B, D e F) mostrou-se similar à expressão observada no Akt em ambas as formas (total e fosforilada) no grupo DX em relação aos demais grupos, entretanto de forma não significante, havendo diminuição de 67,23\% na expressão de P- GSK3 $\beta(P=0,11)$, e com tendência a diminuição na relação P-GSK3 $\beta$ / GSK3 $\beta$ total $(P=0,07)$ em comparação com o grupo CT. Em ambas as expressões proteicas, de Akt e GSK3- $\beta$ (fosforiladas e totais), o grupo DX $+\omega 3$ apresentou um valor intermediário entre o valor expresso no grupo DX e no grupo $\omega 3$, com menor expressão em relação ao grupo CT em ambas as análises, no entanto, de forma não significante.

A expressão proteica do fator de transcrição de enzimas do SUP, o FOXO3a, mostrou-se com tendência de elevação, em sua forma total, no grupo DX $(P=0,07)$, aumento de 154,27\% em relação ao grupo CT (Figura 17 A), e mostrou tendência a diminuição na sua forma inativa $(\mathrm{P}-\mathrm{FOXO})(P=0,06)$ com diminuição de 64,62\% em relação ao grupo CT (Figura 17 C). A razão de P-FOXO3a/ FOXO3a total mostrou-se significantemente menor neste mesmo grupo em comparação ao grupo CT $(P<0,05)$ (Figura 17 E). Ambos os grupos, $\omega 3$ e DX+ $+\omega 3$, mostraram diminuição na razão P- 
Foxo3a/FOXO3a total em comparação ao grupo CT, no entanto, sem significância estatística.

A

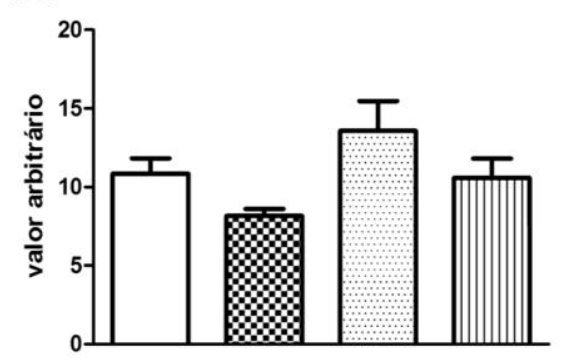

$\mathrm{C}$

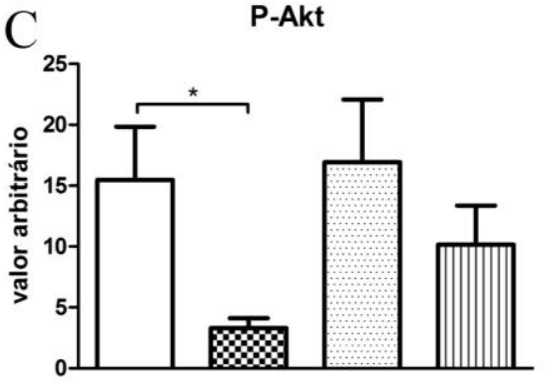

$\mathrm{E}$

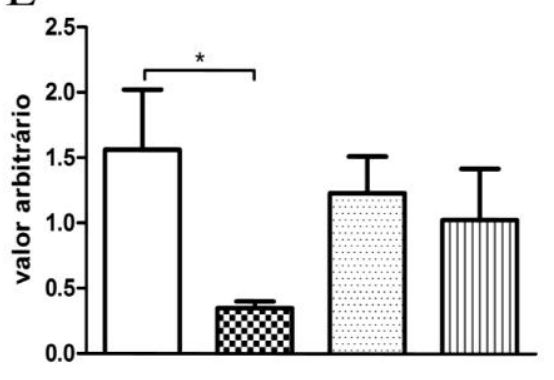

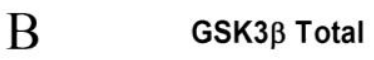
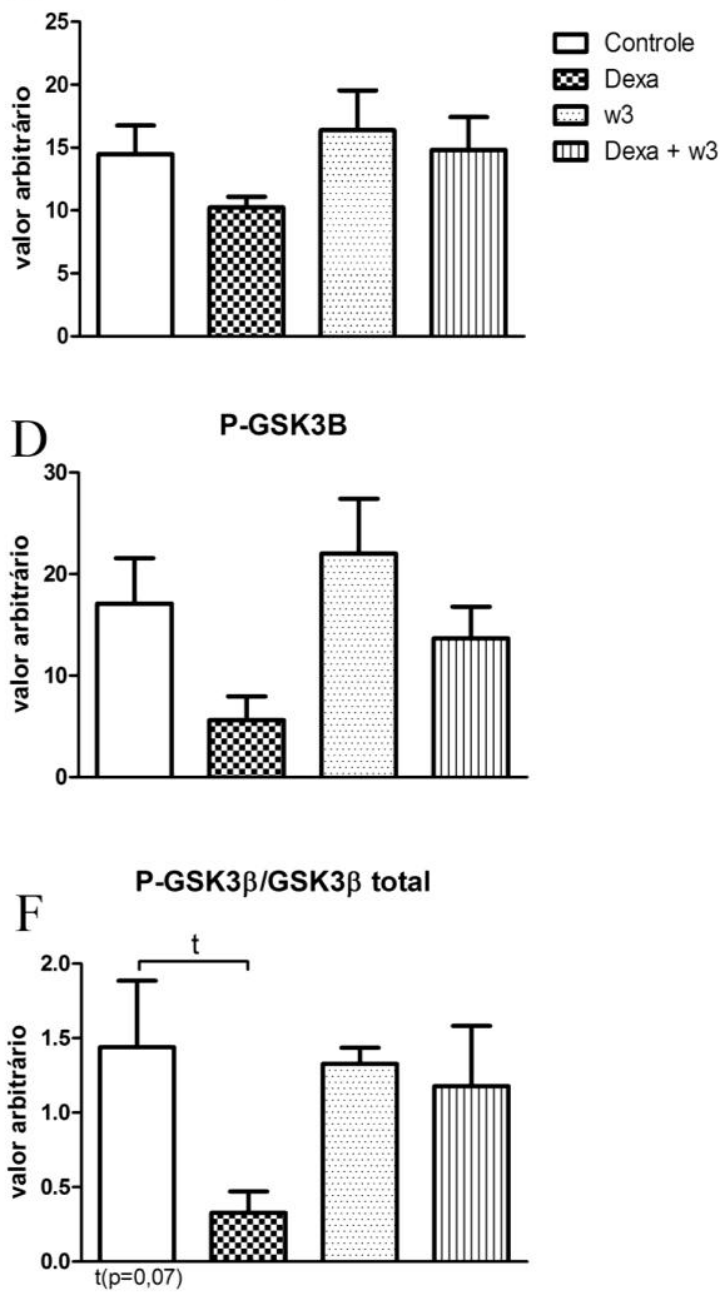

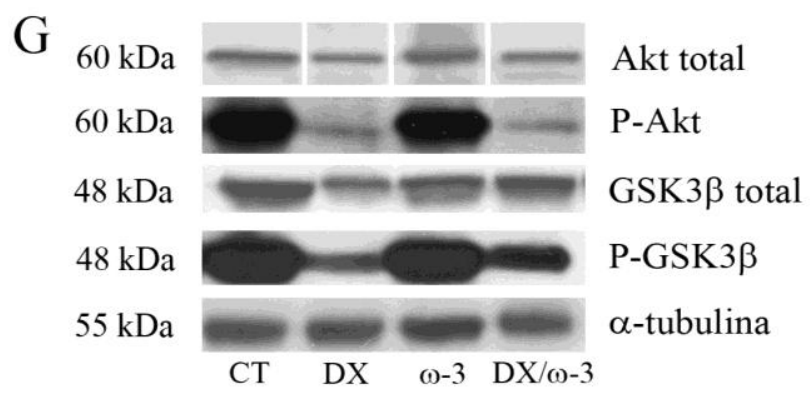

Figura 16: Expressão relativa das formas total e fosforilada de Akt (A e C) e GSK3 $\beta$ (B e D) e razão de expressão da forma fosforilada/total de Akt (E) e GSK3 $\beta$ (F). Na Figura G estão apresentadas imagens representativas de WB das reações de Akt total, P-Akt, GSK3 $\beta$ total, PGSK3 $\beta$ e $\alpha$-tubulina (normatizador); ${ }^{*}=P<0,05 ; \mathrm{t}(P=0,07) ; \mathrm{N}$ médio $=5$ animais/grupo.

Notou-se um aumento na expressão relativa de mTOR total e P-mTOR no grupo $\omega 3$ em relação aos demais grupos, no entanto, de forma não significativa (Figura 17 B, D e F). 


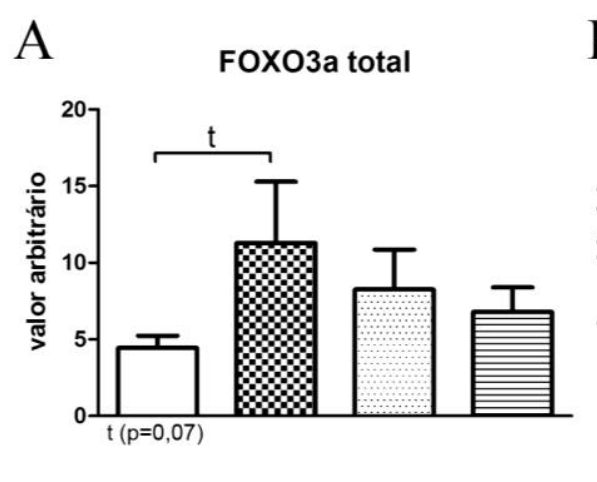

B mTOR total
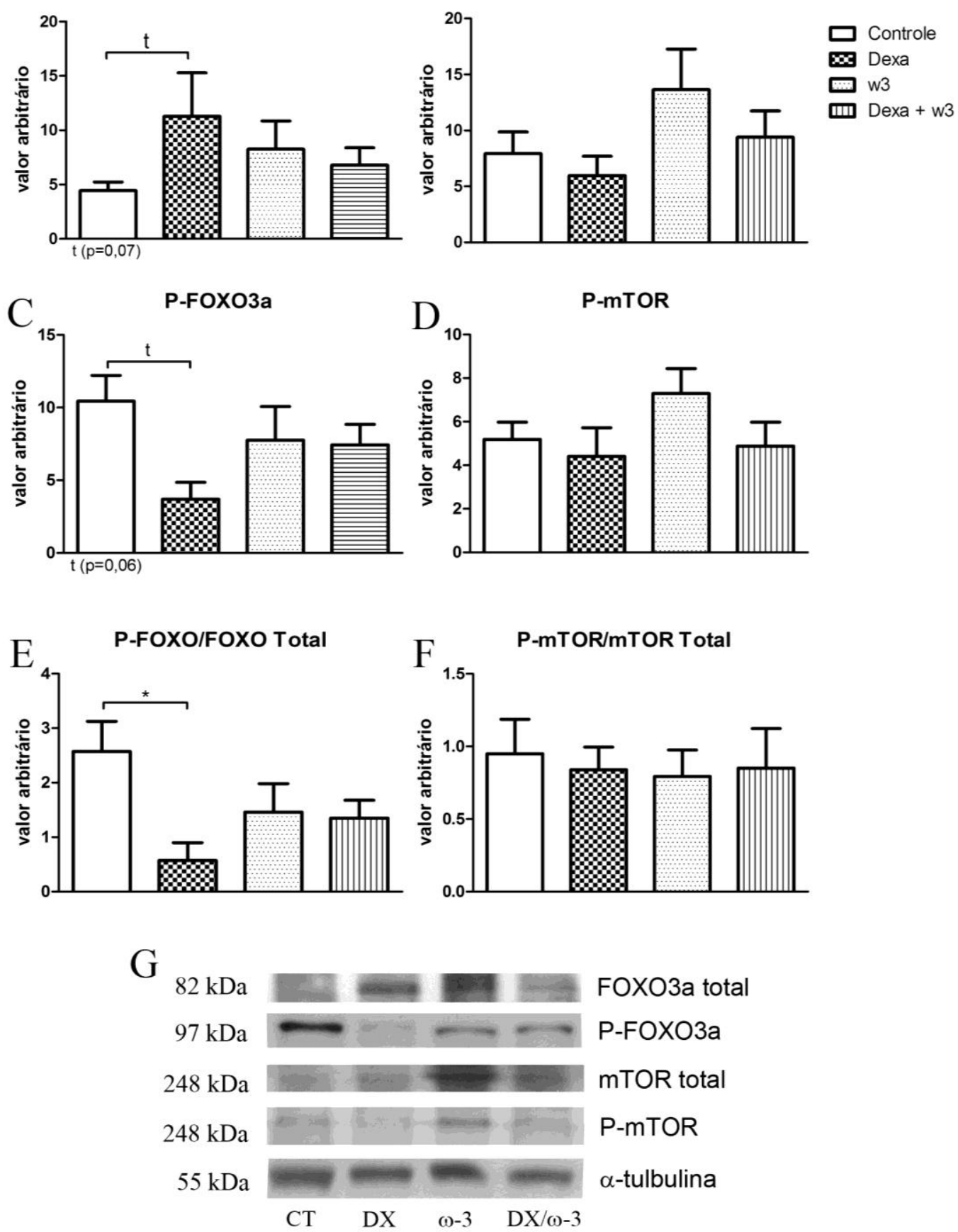

FOXO3a total

P-FOXO3a

mTOR total

P-mTOR

$\alpha$-tulbulina

Figura 17: Expressão relativa das formas totais e fosforiladas de FOXO3a (A e C) e mTOR (B e D), e razão de expressão da forma fosforilada/total de FOXO3a (E) e mTOR (F). Na Figura G estão apresentadas imagens representativas de WB das reações de FOXO3a total, P-FOXO3a, mTOR total, P-mTOR e $\alpha$-tubulina (normatizador) $*=P<0,05 ; t$ em $(\mathrm{A})(P=0,07) ; t$ em $(\mathrm{C})(P$ $=0,06) ; \mathrm{N}$ médio $=5$ animais/grupo.

Os níveis de expressão relativa do P-p70S6K não puderam ser calculados em razão de excessivas marcações inespecíficas que prejudicaram as análises. 


\section{DISCUSSÃO}

Alguns estudos têm demonstrado que a reposição de ácidos graxos EPA e de $\omega$-3 auxiliam na prevenção da atrofia muscular associada ao câncer, privação alimentar e septicemia (Smith et al., 2005; Khal \& Tisdale, 2008). Desta forma, procuramos verificar se o $\omega$-3 teria a propriedade de atenuar também a atrofia muscular induzida por glicocorticoides.

Neste estudo observamos que a administração da dexametasona em ratos induziu a significativa perda de peso corporal, atrofia de fibras musculares do tipo IIB e menor quantidade de pequenos movimentos no teste comportamental motor. Ao mesmo tempo, a suplementação concomitante do ácido graxo $\omega$-3 não foi capaz de atenuar a atrofia muscular induzida pela dexametasona. Por outro lado, notamos que a suplementação concomitante do $\omega$-3 causou atrofia muscular também nas fibras do tipo I e IIA, e aumento na expressão de atrogenes, sugerindo que o $\omega-3$ poderia estar potencializando os efeitos colaterais da dexametasona na musculatura esquelética.

Uma das razões que poderiam justificar a falta de um efeito benéfico do $\omega$-3 na atenuação da atrofia muscular em nosso estudo pode estar relacionada com a dosagem e com a absorção intestinal do $\omega$-3 pelos animais do estudo. No entanto, a cromatografia gasosa mostrou um aumento na quantidade de PUFAs e de ácido $\alpha$-linolênico, e diminuição da quantidade de gorduras e ácido araquidônico na musculatura dos animais que receberam o $\omega$-3, indicando que o suplemento administrado via gavagem foi incorporado pelo tecido muscular. Além do mais, outros estudos têm demonstrado a elevação nos níveis de $\omega-3$ no músculo esquelético obtida pela suplementação oral (Soriguer et al., 2000; Le Foll et al., 2007; Abbott et al., 2010).

Outra questão importante que pode ter limitado o efeito do $\omega-3$ em atenuar a atrofia muscular, poderia estar relacionada com a dosagem administrada de dexametasona. Não há na literatura um consenso quanto à dose ideal da dexametasona a ser usada para induzir atrofia muscular. Aparentemente a dose tem sido escolhida empiricamente e tem variado de $0,5 \mathrm{mg} / \mathrm{kg} / \mathrm{dia}$ (Pinheiro et al., 2009) até $11 \mathrm{mg} / \mathrm{kg} / \mathrm{dia}$ (Gounarides et al., 2008). De forma pioneira, Kelly \& Goldspink em 1982, demonstraram ter havido atrofia muscular esquelética com a dosagem de 2,5mg/kg/dia em ratos. Posteriormente, os mesmos autores obtiveram atrofia muscular com o uso da dexametasona com a dosagem de $5 \mathrm{mg} / \mathrm{kg} /$ dia por 5 a 10 dias (Kelly et al., 1986). Tal 
dosagem e período de administração foi similar ao utilizado em nosso estudo. No entanto, acreditamos que estudos futuros poderiam testar os efeitos da dexametasona, e também do $\omega-3$ sob diferentes concentrações.

Todavia, supomos que o $\omega-3$, por si só, poderia ter a capacidade de favorecer a atrofia muscular e/ou atenuar a síntese proteica muscular, por um desequilíbrio de síntese/degradação neste tecido, independente da administração da dexametasona. Os PUFAs, segundo Fiaccavento et al. (2010), seriam capazes de alterar a composição lipídica da membrana celular e a sinalização intracelular influenciando a atividade da via do IGF-1 no músculo esquelético. E segundo Alessi et al. (1996; 1997), a atividade do Akt pode ser modulada tanto controlando diretamente seu estado de fosforilação, quanto pela alteração nos níveis de lipídio que se liga à membrana, como o phosphatidilinositol (PI) 3,4,5 Kinase, que antecede a ativação do Akt. Le Foll et al. (2007), mostraram que ratos alimentados com dieta rica em $\omega-3$ apresentaram reduzida atividade do PI-3K e Akt no músculo esquelético, e com a administração concomitante de dexametasona, a atividade de PI-3K se manteve diminuída porém houve queda significativa da fosforização do Akt. Essa diminuição na atividade de Akt pode resultar em maior atividade de fatores de transcrição como os FOXOs, o que acarreta maior transcrição de enzimas ligadoras E3 envolvidas no processo de atrofia muscular. Isso poderia explicar o fato de que, em nosso estudo, o ganho de peso corporal dos animais do grupo que recebeu apenas $\omega-3$ ter sido 7,2\% menor, em comparação com o grupo controle. Outros estudos já haviam demonstrado previamente a capacidade do $\omega-3 \mathrm{em}$ reduzir o ganho de peso. Sener et al. (2009) observaram que ratos privados de ingestão de $\omega$-3 apresentaram maior ganho de peso que os animais não privados. No estudo de Smith et al. (2004), dentre os grupos de camundongos suplementados com diferentes suplementos, o grupo que recebeu EPA isoladamente foi o que apresentou menor peso corporal. De forma similar, Cintra et al. (2012) observaram que ratos obesos suplementados com $\omega$-3 apresentaram menor ganho de peso corporal. Os autores especularam que o menor ganho de peso poderia ser explicado pela capacidade do EPA/DHA em atenuar significantemente o desenvolvimento de adiposidade induzida por dieta gordurosa e a hipertrofia de células adiposas. Tal efeito seria obtido, em parte, pela maior inibição de lipogênese hepática e da oxidação de ácidos graxos nos tecidos via PPAR $\alpha$ e AMPK (Kunesová et al., 2006; Ruzickova et al., 2004; Kopecky et al., 2009; Kalupahana et al., 2011). 
Outros estudos mostraram que o ácido araquidônico (AA), derivado do $\omega 6$, teria a capacidade de induzir maiores níveis de síntese proteica, através da estimulação da produção de prostaglandina F2 $\alpha$ (PGF2 $\alpha$ ) no músculo esquelético, no entanto, o uso do EPA e DHA em modelo animal mostrou reduzir os níveis normais de PGF2 $\alpha$ em $49 \%$ e $46 \%$, respectivamente, sendo isso explicado pela competição de precursores de $\omega 3$ por enzimas envolvidas na síntese de eicosanoides, que reduz o nível de produção de prostaglandina F2 $\alpha$ (Palmer \& Whale, 1987). Sohal et al. (1992) mostraram efeito similar, com diminuição na produção de PGF2 $\alpha$, em aproximadamente $75 \%$ após suplementação com EPA, além de mostrarem taxa de sintese proteica muscular $20 \%$ menor, representando, segundo os autores, um possível impacto no crescimento e atrofia muscular. Mais recentemente, Fiaccavento et al. (2010) observaram diminuição de $25 \%$ nos níveis de AA, associada a um aumento nos níveis de ALA e EPA no músculo esquelético de hamsters alimentados ad libitum com ração enriquecida com ALA. Tal achado corrobora com o observado nos grupos de animais DX $+\omega 3$ e $\omega 3$ de nosso estudo, em que houve um aumento nas quantidades de ALA, associado a menores níveis de ácido araquidônico (42,12\%) em comparação com o grupo CT. Esse fato poderia explicar um maior impacto sob o trofismo muscular no grupo de associação da dexametasona com o $\omega-3$.

É possível, ainda, especularmos que o $\omega-3$ poderia potencializar os efeitos da dexametasona atuando em nível de receptores de glicocorticoides localizados na fibra muscular. O $\omega-3$, bem como cadeias longas de $\omega-6$, quando associado à membrana celular influencia a função das proteínas e receptores associados à membrana, podendo assim, após o período de suplementação, ter havido uma hipersensibilidade dos receptores de glicocorticoides. Isso pode ocorrer em determinados casos, como na diminuição da massa magra ou no aumento de massa gorda (Singer et al., 2008; Nicolaides et al., 2010). Desta forma, é possível que o consumo prévio e regular de $\omega-3$ pelos animais em nosso estudo tenha influenciado a atividade de receptores de glicocorticoides nas fibras musculares, modulando os efeitos da dexametasona sobre esse tecido.

As alterações comportamentais, observadas em nosso estudo, tais como a diminuição na quantidade de pequenos movimentos nos ratos que receberam a dexametasona (grupos DX e DX $+\omega 3$ ), corroboram com o estudo de Neal et al. (2004), que demonstraram em ratos tratados com dexametasona a ocorrência de menor 
atividade motora em teste de campo aberto e maior tempo para resolução de labirinto. $\mathrm{O}$ mesmo efeito foi observado nos neonatos que receberam a droga, apresentando menor mobilidade em campo fechado e em teste de imersão em piscina (Felszeghy K, 1993).

A atrofia muscular induzida pela dexametasona, específica em fibras do tipo IIB, já havia sido descrita previamente por Prezant et al. (1997), estando a preferência por certos tipos de fibras musculares, como as do tipo IIB e IIX (fibras de contração rápida), provavelmente relacionada com a quantidade de PGC1 $\alpha$ nesse tipo de fibra. O PGC1 $\alpha$ mostra-se elevado em fibras de contração lenta, e está envolvido na regulação do FOXO3a, prevenindo sua ligação com sítio promotor de atrogenes e inibindo a transcrição de atrogina-1/MuRF-1 (Sandri et al., 2006), portanto, prezumindo-se haver menores níveis de PGC1 $\alpha$ em fibras de contração rápida (tipo II), pode se explicar o fato destas fibras serem mais acometidas na atrofia muscular induzida por glicocorticoides, em razão da maior ativação de FOXO3 (Ciciliot et al., 2013).

Foi possível observar, pela análise de expressão relativa de proteínas em nosso estudo, que a expressão de proteínas da via do IGF-1/PI-3 k/Akt/mTOR como o Akt, GSK3 $\beta$ e FOXO3a fosforilados, apresentaram-se significantemente baixos em comparação às suas formas totais no grupo que recebeu a dexametasona. Tal fato é condizentes com demais estudos que mostraram que a dexametasona induz a atrofia muscular por meio de mecanismos gênicos e moleculares envolvidos na degradação proteica, como redução na fosforilação de Akt, GSK3ß, P70S6k e mTOR, que conduzem à redução da síntese proteica e ao aumento da transcrição de atrogenes responsáveis por sinalizar a degradação de proteínas musculares, tais como as miosinas de cadeias leve e pesada (Jones et al., 2010; Eddins et al., 2011; Wu Y et al., 2012).

Observou-se que os animais do grupo $\mathrm{DX}+\omega 3$ apresentaram maior expressão de Akt fosforilado de em relação ao grupo DX. Esse fato que pode sugerir uma atenuação parcial, em níveis proteicos, do efeito inibitório da dexametasona. No entanto, não seria, ainda, capaz de atenuar os danos desta ao tecido muscular esquelético, visto a mensuração da área das fibras a pela expressão de atrogenes, potencializados significantemente.

Observamos, ainda, um aumento da expressão gênica da atrogina-1 e do $M u R F$ 1 no grupo que recebeu dexametasona isoladamente, principalmente nos níveis de expressão da atrogina-1, no entanto com maior significância no grupo que recebeu a dexametasona associada ao $\omega-3$. Tal achado é compatível, do ponto de vista molecular, 
com o que já havíamos observado em relação à atrofia muscular e ao peso dos animais, no qual a associação do $\omega-3$ com a dexametasona aparentemente produziu o agravamento dos efeitos deletérios musculares. Um aumento compatível na expressão protéica do FOXO3a, associado à elevação na expressão gênica de atrogina-1 e $M u R F$ 1 no grupo $\mathrm{DX}+\omega 3$, poderia melhor elucidar o mecanismo que ocasionou a atrofia muscular vista nesse grupo. No entanto, isso não ocorreu, sugerindo que demais mecanismos possam estar envolvidos neste aumento da atrofia muscular observada, como com a ativação de demais FOXOs (FOXO1 e/ou 4), ou pela ativação de demais vias relacionadas com a degradação proteica, como a via da Miostatina/Smad2/3 e Ras/Raf/MEK/ERK.

A miostatina é um forte regulador negativo do crescimento muscular pertencente à via da miostatina/smad2/3, que participa no tecido muscular esquelético inibindo componentes da via do IGF-1 que estão diretamente relacionados com a síntese e degradação proteica. Segundo Gilson et al. (2007) e Schakman et al. (2008) os níveis de miostatina na atrofia muscular induzida por dexametasona encontram-se elevados. Entretanto, estudos mais recentes têm mostrado que a miostatina possui algum grau de importância na regulação de outros processos além da regulação da massa muscular, como a glicólise (Chen $\mathbf{Y}$ et al., 2010), adipogênese (Feldman et al, 2006) e homeostase de cardiomiócitos (Bish et al., 2010). Em nosso estudo, observamos que a expressão de Miostatina no grupo que recebeu apenas dexametasona mostrou-se com tendência de elevação, mas sem significância estatística em relação aos demais grupos. Ao passo que os animais que receberam $\omega-3$ isoladamente, tiveram um aumento significante na expressão de Miostatina, em comparação com o grupo CT. Tal achado corrobora, em parte, com o estudo de Allen et al. (2008) que mostraram maior expressão da Miostatina no músculo tibialis anterior em camundongos que tiveram dieta rica em gordura (saturada e insaturada). Estudos recentes mostraram que a miostatina pode atuar diretamente nos adipócitos, promovendo proliferação ou diferenciação em um mecanismo reverso ao visto no músculo esquelético (Elliott et al., 2012). Hirai et al. (2007) demonstraram que a miostatina age de forma inibitória à diferenciação celular de pré-adipócitos bovinos, enquanto que Zimmers et al. (2002) demonstraram que sua alta expressão em camundongos adultos conduz a diminuição da quantidade de tecido adiposo. Baseado nesses achados, podemos especular que o aumento da expressão da Miostatina, somada à diminuição na expressão de $\operatorname{PGC} 2 \alpha$, poderiam ter influenciado 
uma menor formação de tecido adiposo e síntese protéica nos animais de nosso estudo, estando, portanto, condizente com o menor ganho de peso corporal visto no grupo $\omega 3$. No entanto, não avaliamos a concentração de ácido graxo circulante, ou ainda os níveis de adipogênese.

Wang et al. (2006) mostraram que a dexametasona eleva a expressão da REDD1 no tecido muscular, a qual subsequentemente ativa o complexo TuberinaHamartina resultando em repressão da atividade do mTOR. No entanto, em nosso estudo, não observamos alterações consistentes na expressão do REDD1. Por outro lado, o nível de expressão de $R E D D 2$ para o grupo que recebeu dexametasona mostrouse elevado, mas sem significância estatística.

Observamos redução na expressão gênica da Miogenina nos animais que receberam dexametasona em associação com $\omega$-3, grupo que apresentou maior nível de atrofia muscular, condizendo com demais estudos. Segundo Pereira \& Freire de Carvalho (2011), a dexametasona induz inúmeras condições desfavoráveis à síntese proteica, incluindo a inibição da miogênese, por supressão da Miogenina no músculo esquelético, o que afetaria a miogênese, causando maior atrofia muscular (Schakman et al., 2008). A dexametasona, segundo estudo com células musculares $\mathrm{C} 2 \mathrm{C} 12$, influencia ainda os níveis proteicos de miogenina, reduzindo seus níveis por ubiquitinação através da atrogina-1 (Jogo et al., 2009).

O aumento da expressão de $M y o D$ no grupo $\omega-3$, visto em nosso estudo, corrobora com os achados de Castillero et al. (2009), que encontraram aumento na expressão de $M y o D$ tanto em ratos normais, quanto em ratos artríticos, após administração de EPA. Nesse mesmo estudo, os autores não observaram alterações significativas da expressão da Miogenina com a administração do EPA. Algumas pesquisas mostraram que a atrogina-1 promove a degradação de MyoD (Tintignac et al, 2005; Csibi et al., 2010), corroborando com nossos achados, em que houve queda mais acentuada na expressão gênica de $M y o D$ no grupo DX $+\omega-3$, que mostrou maior expressão de atrogina-1.

A análise da expressão relativa de proteínas relacionadas com a via do IGF1/Akt/mTOR no tecido muscular esquelético mostrou resultado condizente com o estado atrófico muscular apresentado pelo grupo que recebeu a dexametasona, visto pela diminuída fosforilação das proteínas Akt, GSK3- $\beta$ e FOXO3. 
O padrão similar de expressão protéica, observada nas formas fosforiladas e totais das proteínas Akt e GSK3 $\beta$, estudado por nós, corrobora com dados da literatura que mostram uma relação direta entre tais proteínas, com aumento proporcional da fosforilação de GSK3 $\beta$, inibindo-a através da ativação do Akt por fosforilação (Bodine et al., 2001b; Léger et al., 2006; Russell, 2010). O mesmo foi observado com a fosforilação do FOXO3a, que mostrou menores ou maiores indices de fosforilação proporcionalmente à ativação do Akt, dependendo do grupo analisado.

A inibição do FOXO3a por fosforilação é vista em condições normais no músculo esquelético por meio da ativação do Akt pela via do IGF-1. No entanto, sua menor fosforilação acarreta maior degradação proteica, estando esse fator de transcrição relacionado com uma das principais vias de degradação na atrofia induzida por corticoides, o SUP (Sandri et al., 2004). Uma vez ativados, os FOXO's, além de iniciarem a transcrição de atrogenes como a atrogina-1 e MuRF-1, também conduzem, através de interação com o IRS-2 (insulin receptorsubstract-2), à ativação de poteínas que participam de outra via não avaliada em nosso estudo - via Ras/RAf/MEK/ERK que participa, portanto, da atrofia muscular induzida por glicocorticoides (Zheng et al., 2010). Nossos achados de expressão proteica no grupo DX condizem com estudos descritos acima quanto à diminuição da expressão do FOXO3a fosforilado, no entanto, não avaliamos demais FOXOs ou ainda proteínas MEK ou ERK, que possivelmente mostrariam a interação de demais vias no desenvolvimento da atrofia muscular.

Os níveis de expressão de mTOR vistos em nosso estudo não mostraram significância que se relacionasse diretamente com um estado de menor ou maior síntese protéica, no entanto, mostraram-se ligeiramente diminuídos no grupo DX e pouco aumentados no grupo $\omega 3$. Entretanto, demais estudos mostraram que o mTOR atua conjuntamente com outras vias de sinalização além da via do IGF-1/Akt, e está relacionado não somente com a síntese proteica, mas também com muitos outros processos celulares, incluindo a autofagia (Laplante \& Sabatini, 2012; Schiaffino et al., 2013). Afim de determirmos níveis de síntese proteica, teríamos que analisar demais mecanismos ou fatores de iniciação envolvidas na produção de proteínas, como os eIF's (eIF2B, eIF4E), ou ainda fatores de inibição de síntese protéica, como com a marcação do 4EBP1, uma vez não ter sido possível a marcação e análise da proteína P70S6K.

Considerando que os corticosteroides são usados no tratamento de diversas situações médicas, esse estudo mostrou seus potenciais efeitos deletérios sobre a 
musculatura esquelética. Desta forma, a identificação de medicamentos ou suplementos alimentares capazes de atenuar esses efeitos deletérios seria extremamente útil na prática clínica. Por outro lado, esse estudo aponta para um fato importante: suplementos alimentares, que são usualmente considerados benéficos para a saúde de uma forma geral, tal como o ácido graxo Ômega-3, podem, na verdade, interagir com alguns medicamentos, como os glicocorticoides, potencializando seus efeitos colaterais. 


\section{CONCLUSÕES}

1. A dexametasona administrada de forma isolada em ratos, na dosagem de $5 \mathrm{mg} / \mathrm{kg} / \mathrm{dia}$, acarretou perda de peso corporal e muscular, redução da área de secção transversa das fibras musculares do tipo IIB, alterações comportamentais motoras e diminuição da expressão da forma fosforilada de proteínas da via de IGF-1/Akt/mTOR relacionada com a síntese e degradação proteica.

2. O Ômega-3 suplementado de forma isolada em ratos acarretou menor ganho de peso corporal durante o desenvolvimento normal dos animais, diminuição nos níveis de ácido araquidônico com aumento nos níveis de ácido $\alpha$-linolênico muscular, e aumento na expressão gênica de MyoD e Miostatina.

3. A suplementação de Ômega-3 em associação com administração de dexametasona em ratos, não foi capaz de atenuar a redução do peso corporal, a redução da área transversa das fibras musculares, e as alterações comportamentais motoras, causando adicionalmente atrofia das fibras do tipo I e IIA e maior expressão dos atrogenes. 


\section{REFERENCIAS}

Abbott SK, Else PL, Hulbert AJ. Membrane fatty acid composition of rat skeletal muscle is most responsive to the balance of dietary n-3 and n-6 PUFA. Br J Nutr, 2010; Feb;103(4):5229.

Agarkova I, Perriard JC. The M-band: an elastic web that crosslinks thick filaments in the center of the sarcomere. Trends Cell Biol, 2005; Sep;15(9):477-85.

Alessi DR, Andjelkovic M, Caudwell B, Cron P, Morrice N, Cohen P, et al. Mechanism of activation of protein kinase B by insulin and IGF-1. EMBO J, 1996, 15(23), 6541-6551.

Alessi DR, James SR, Downes CP, Holmes AB, Gaffney PR, Reese CB, Cohen P. Characterization of a 3-phosphoinositide-dependent protein kinase which phosphorylates and activates protein kinase Balpha. Curr Biol, 1997 Apr 1;7(4):261-9.

Alheira FV, Brasil MAA. O papel dos glicocorticóides na expressão dos sintomas de humor uma revisão. Rev. psiquiatr. Rio Gd. Sul , 2005; May/Aug, vol.27 no.2.

Allen DL, Cleary AS, Speaker KJ, Lindsay SF, Uyenishi J, Reed JM, Madden MC, Mehan RS. Myostatin, activin receptor IIb, and follistatin-like-3 gene expression are altered in adipose tissue and skeletal muscle of obese mice. Am J Physiol Endocrinol Metab, 2008; May, 294(5):E918-27.

Alves CJ, de Santana LP, dos Santos AJ, de Oliveira GP, Duobles T, Scorisa JM, Martins RS, Maximino JR, Chadi G. Early motor and electrophysiological changes in transgenic mouse model of amyotrophic lateral sclerosis and gender differences on clinical outcome. Brain Res, 2011; Jun 7;1394:90-104.

Birkenkamp KU, Coffer PJ. Regulation of cell survival and proliferation by theFOXO(Forkhead box, class O) subfamily of Forkhead transcription factors. Biochem. Soc. Trans, 2003; 31(Pt 1), 292-297.

Bish LT, Morine KJ, Sleeper MM, Sweeney HL. Myostatin is upregulated following stress in an Erk-dependent manner and negatively regulates cardiomyocyte growth in culture and in a mouse model. PLoS One, 2010 Apr 19;5(4):e10230.

Bligh EG, Dyer WJ. A rapid method of total lipid extraction and purification. Can. J. Biochem. Physiol, 1959; 37: 911-917.

Bodine SC, Latres E, Baumhueter S, Lai VK, Nunez L, Clarke BA, et al. Identification of ubiquitin ligases required for skeletal muscle atrophy. Science, 2001a; 294(5547), 1704-1708.

Bodine SC, Stitt TN, Gonzalez M, Kline WO, Stover GL, Bauerlein R, et al. Akt/mTOR pathway is a crucial regulator of skeletal muscle hypertrophy and can prevent muscle atrophy in vivo. Nat. Cell Biol, 2001b; 3(11), 1014-1019.

Boonyarom O, Inui K. Atrophy and hypertrophy of skeletal muscles: structural and functional aspects. Acta Physiol (Oxf). , 2006; Oct;188(2):77-89. 
Bourre, J.M. Dietary omega-3 Fatty acids and psychiatry: mood, behaviour, stress, depression, dementia and aging. J Nutr Health Aging, 2005;9(1):31-8.

Brooke, M. H, and K. K. Kaiser. Muscle fiber types: how many and what kind?. Archives of Neurology, 23, 1970.

Bushby K, Finkel R, Birnkrant DJ, Case LE, Clemens PR, Cripe L, Kaul A, Kinnett K, McDonald C, Pandya S, Poysky J, Shapiro F, Tomezsko J, Constantin C. Diagnosis and management of Duchenne muscular dystrophy, part 1: diagnosis, and pharmacological and psychosocial management. Lancet Neurol, 2010 Jan;9(1):77-93.

Busquets S, Figueras MT, Fuster G, Almendro V, Moore-Carrasco R, Ametller E, Argiles JM, Lopez-Soriano FJ. Anticachectic effects of formoterol: a drug for potential treatment of muscle wasting. Cancer Res, 2004; 64:6725-6731.

Cai D, Frantz JD, Tawa NEJr, Melendez PA, Oh BC, Lidov HG, Hasselgren PO, Frontera WR, Lee J, Glass DJ, Shoelson SE. IKKbeta/NF-kappaB activation causes severe muscle wasting in mice. Cell, 2004; 119(2):285-98.

Calder, PC. Imunoregulatory and anti-inflamatory effects of n-3 polyunsaturated fatty acids. Braz.J.Med. Biol. Res, 1998; 31:467-90.

Campos Y, Qiu X, Zanoteli E, Moshiach S, Vergani N, Bongiovanni A, Harris AJ, d'Azzo A. Ozz-E3 ubiquitin ligase targets sarcomeric embryonic myosin heavy chain during muscle development. PLoS One., 2010; Mar 24;5(3):e9866.

Castillero E, Martín AI, López-Menduiña M, Villanúa MA, López-Calderón A. Eicosapentaenoic acid attenuates arthritis-induced muscle wasting acting on atrogin-1 and on myogenic regulatory factors. Am J Physiol Regul Integr Comp Physiol, 2009; Nov;297(5):R1322-31.

Chargé SBP, Rudnicki MA. Cellular and molecular regulation of muscle regeneration. Physiol Rev, 2004; 84:209-38.

Chen D, Chen S, Wang W, Liu F, Zhang C, Zheng H. Modulation of satellite cells in rat facial muscle following denervation and delayed reinnervation. Acta Otolaryngol, 2010; Dec;130(12):1411-20.

Chen Y, Ye J, Cao L, Zhang Y, Xia W, Zhu D. Myostatin regulates glucose metabolism via the AMP-activated protein kinase pathway in skeletal muscle cells. Int J Biochem Cell Biol, 2010 Dec;42(12):2072-81.

Ciciliot S, et al. Muscle type and fiber type specificity in muscle wasting. Int J Biochem Cell Biol, 2013.

Ciciliot S, Schiaffino S. Regeneration of mammalian skeletal muscle. Basic mechanisms and clinical implications. Curr Pharm Des, 2010;16(8):906-14.

Cintra DE, Ropelle ER, Moraes JC, Pauli JR, Morari J, Souza CT, Grimaldi R, Stahl M, Carvalheira JB, Saad MJ, Velloso LA. Unsaturated fatty acids revert diet-induced hypothalamic inflammation in obesity. PLoS One, 2012; 7(1):e30571. 
Clemmons, DR. Role of IGF-I in skeletal muscle mass maintenance. Trends Endocrinol Metab, 2009; Sep;20(7):349-56.

Combaret L, Dardevet D, Rieu I, Pouch MN, Bech D, Taillandier D, Grizard J, Attaix D. A leucine-supplemented diet restores the defective postprandial inhibition of proteasomedependent proteolysis in aged rat skeletal muscle. J Physiol, 2005; 569:489-4.

Combaret L, Ralliere C, Taillandier D, Tanaka K, Attaix D. Manipulation of the ubiquitinproteasome pathway in cachexia: pentoxifylline suppresses the activation of $20 \mathrm{~S}$ and $26 \mathrm{~S}$ proteasomes in muscles from tumor-bearing rats. Mol Biol Rep, 1999; 26:95-1.

Combaret L, Tilignac T, Claustre A, Voisin L, Taillandier D, Obled C, Tanaka K, Attaix D. Torbafylline (HWA 448) inhibits enhanced skeletal muscle ubiquitin- proteasome-dependent proteolysis in cancer and septic rats. Biochem J, 2002,361:185-192.

Csibi A, Cornille K, Leibovitch MP, Poupon A, Tintignac LA, Sanchez AM, Leibovitch SA. The translation regulatory subunit eIF3f controls the kinase-dependent mTOR signaling required for muscle differentiation and hypertrophy in mouse. PLoS One, 2010 Feb 1;5(2):e8994.

Cushing, H. The basophil adenoma of the pituitary body and their clinical manifestation. Johns Hopkins Med, 1932; 50, p. 137.

Dasarathy S, Dodig M, Muc SM, Kalhan SC, McCullough AJ. Skeletal muscle atrophy is associated with an increased expression of myostatin and impaired satellite cell function in the portacaval anastamosis rat. Am J Physiol Gastrointest Liver Physiol, 2004; Dec;287(6):G112430.

de Alvaro C, Teruel T, Hernandez R, Lorenzo M. Tumor necrosis factor alpha produces insulin resistance in skeletal muscle by activation of inhibitor kappaB kinase in a p38 MAPKdependent manner. J Biol Chem, 2004; 279(17):17070-8.

Delaunay A, Bromberg KD, Hayashi Y, Mirabella M, Burch D, et al. The ER-Bound RING Finger Protein 5 (RNF5/RMA1) Causes Degenerative Myopathy in Transgenic Mice and Is Deregulated in Inclusion Body Myositis. PLoS ONE, 2008; 3(2): e1609.

Delgado-Lista J, Perez-Martinez P, Lopez-Miranda J, Perez-Jimenez F. Long chain omega-3 fatty acids and cardiovascular disease: a systematic review. Br J Nutr, 2012; Jun;107 Suppl 2:S201-13.

Department of Health. Nutritional aspects of cardiovascular disease. Report of the Cardiovascular Review Group Committee on Medical Aspects of Food Policy. Rep Health Soc Subj (Lond). 1994;46:1-186., 1994; 46:1-186.

Diziezak, J. Fats, oils, fat substitutes. Food Technol, 1989; v.43, p. 66-74.

Dokken BB, Sloniger JA, Henriksen EJ. Acute selective glycogen synthase kinase-3 inhibition enhances insulin signaling in prediabetic insulin-resistant rat skeletal muscle. Am J Physiol Endocrinol Metab, 2005; Jun;288(6). 
Dufner A, Andjelkovic M, Burgering BM, Hemmings BA, Thomas G. Protein kinase B localization and activation differentially affect S6 kinase 1 activity and eukaryotic translation initiation factor 4E-binding protein 1 phosphorylation. Mol. Cell Biol, 1999; 19(6), 4525-4534.

Eddins MJ, Marblestone JG, Suresh Kumar KG, Leach CA, Sterner DE, Mattern MR, Nicholson B. Targeting the ubiquitin E3 ligase MuRF1 to inhibit muscle atrophy. Cell Biochem Biophys, 2011; Jun;60(1-2):113-8.

Elliott B, Renshaw D, Getting S, Mackenzie R. The central role of myostatin in skeletal muscle and whole body homeostasis. Acta Physiol (Oxf), 2012 Jul;205(3):324-40.

Elmore JS, Mottram DS, Enser M, Wood JD. Effect of the polyunsaturated fatty acid composition of beef muscle on the profile of aroma volatiles. J Agric Food Chem, 1999; Apr;47(4):1619-25.

Feldman BJ, Streeper RS, Farese RV Jr, Yamamoto KR. Myostatin modulates adipogenesis to generate adipocytes with favorable metabolic effects. Proc Natl Acad Sci U S A, 2006 Oct 17;103(42):15675-80.

Felszeghy K, Sasvári M, Nyakas C. Behavioral depression: opposite effects of neonatal dexamethasone and ACTH-(4-9) analogue (ORG 2766) treatments in the rat. Horm Behav, 1993; Sep;27(3):380-96.

Fiaccavento R, Carotenuto F, Vecchini A, Binaglia L, Forte G, Capucci E, Maccari AM, Minieri M, Di Nardo P. An omega-3 fatty acid-enriched diet prevents skeletal muscle lesions in a hamster model of dystrophy. Am J Pathol, 2010 Nov;177(5):2176-84.

Fielitz J, Kim M, Shelton JM, Latif S, Spencer JA, Glass DJ, Richardson JA, Bassel-Duby R, Olson EN. Myosin accumulation and striated muscle myopathy result from the loss of muscle RING finger 1 and 3. J Clin Invest, 2007b; 117(9):2486-2495.

Fielitz J, van Rooij E, Spencer JA, Shelton JM, Latif S, van der Nagel R, Bezprozvannaya S, de Windt L, Richardson JA, Bassel-Duby R, Olson EN. Loss of muscle-specific RINGfinger 3 predisposes the heart to cardiac rupture after myocardial infarction. Proc. Natl. Acad. Sci. U. S. A. , 2007a; 104:4377-4382.

Floeter, Mary Kay. Structure and function of muscle fibers and motor units. In Disorders of Voluntary Muscle, Eighth edition, by David Hilton-Jones, Kate Bushby, Robert C. Griggs George Karpati. Cambridge: Cambridge University Press, 2009.

Freeman MP, Hibbeln JR, Wisner KL, Davis JM, Mischoulon D, Peet M, Keck PE Jr, Marangell LB, Richardson AJ, Lake J, Stoll AL. Omega-3 fatty acids: evidence basis for treatment and future research in psychiatry. J Clin Psychiatry, 2006 Dec;67(12):1954-67.

Fujisawa, M.O. dexametasona [bula de remédio]. Campinas, SP: Medley Indústria Farmacêutica Ltda, 2011.

Gilson H, Schakman O, Combaret L, Lause P, Grobet L, Attaix D, Ketelslegers JM, Thissen JP. Myostatin gene deletion prevents glucocorticoid-induced muscle atrophy. Endocrinology, $2007 ; 148(1): 452-60$. 
Glass DJ. Molecular mechanisms modulating muscle mass. Trends Mol. Med, 2003; 9(8), p344350.

Gomes MD, Lecker SH, Jagoe RT, Navon A, Goldberg AL. Atrogin-1, a muscle-specific F-box protein highly expressed during muscle atrophy. Proc. Natl. Acad. Sci. U.S.A. , 2001; 98(25), 14440-14445.

Gordon JN, Trebble TM, Ellis RD, Duncan HD, Johns T, Goggin PM. Thalidomide in the treatment of cancer cachexia: a randomized placebo controlled trial. Gut , 2005; 54:540-545.

Gounarides JS, Korach-André M, Killary K, Argentieri G, Turner O, Laurent D. Effect of dexamethasone on glucose tolerance and fat metabolism in a diet-induced obesity mouse model. Endocrinology, Feb 2008: 149(2):758-66.

Gower WRJr. Mechanism of glucocorticoid action. J Fla Med Assoc, 1993 Oct;80(10):697-70.

Grobet L, Pirottin D, Farnir F, Poncelet D, Royo LJ, Brouwers B, et al. Modulating skeletal muscle mass by postnatal, muscle-specific inactivation of the myostatin gene." Genesis, 2003 Apr; 35(4):227-38.

Gundersen K. Excitation-transcription coupling in skeletal muscle: the molecular pathways of exercise. Biol Rev Camb Philos Soc, 2011; Aug;86(3):564-600.

Guttridge DC, Mayo MW, Madrid LV, Wang CY, Baldwin ASJr. NF-kappaB-induced loss of MyoD messenger RNA: possible role in muscle decay and cachexia. Science, 2000; 289(5488):2293-4.

Guyton AC. Tratado de Fisiologia Médica. In Tratado de Fisiologia Médica, 10 Edição, by M.D. Arthur C. Guyton. Rio de Janeiro: Guanabara Koogan, 2002.

Hasselgren PO, Alamdari N, Aversa Z, Gonnella P, Smith IJ, Tizio S. Corticosteroids and muscle wasting: role of transcription factors, nuclear cofactors, and hyperacetylation. Curr Opin Clin Nutr Metab Care, 2010 Jul;13(4):423-8.

Haugaard SB, Madsbad S, Høy CE, Vaag A. Dietary intervention increases n-3 long-chain polyunsaturated fatty acids in skeletal muscle membrane phospholipids of obese subjects. Implications for insulin sensitivity. Clin Endocrinol (Oxf), 2006; Feb;64(2):169-78.

Haugaard SB, Vaag A, Mu H, Madsbad S. Skeletal muscle structural lipids improve during weight-maintenance after a very low calorie dietary intervention. Lipids Health Dis, 2009; Aug $13 ; 8: 34$.

Hershko A, Ciechanover A. The ubiquitin system. Annu Rev Biochem , 1998; 67:425-79.

Hirai S, Matsumoto H, Hino N, Kawachi H, Matsui $\mathrm{T}$, Yano H. Myostatin inhibits differentiation of bovine preadipocyte. Domest Anim Endocrinol, 2007 Jan;32(1):1-14.

Iverson SJ, Lang SLC, Cooper MH. Comparison of the Bligh and Dyer and Folch methods for total lipid determination in a broad range of marine tissue. Lipids, 2001, 36: 1283-1287. 
Janjoppi L, Katayama MH, Scorza FA, Folgueira MA, Brentani M, Pansani AP, Cavalheiro EA, Arida RM. Expression of vitamin D receptor mRNA in the hippocampal formation of rats submitted to a model of temporal lobe epilepsy induced by pilocarpine. Brain Res Bull , 2008; Jul 30;76(5):480-4.

Jefferson LS, Fabian JR, Kimball SR. Glycogen synthase kinase-3 is the predominant insulinregulated eukaryotic initiation factor 2B kinase in skeletal muscle. Int. J. Biochem. Cell Biol, 1999; 31(1), 191-200.

Jogo M, Shiraishi S, Tamura TA. Identification of MAFbx as a myogenin-engaged F-box protein in SCF ubiquitin ligase. FEBS Lett, 2009; Sep 3;583(17):2715-9.

Jones A, Hwang DJ, Narayanan R, Miller DD, Dalton JT. Effects of a novel selective androgen receptor modulator on dexamethasone-induced and hypogonadism-induced muscle atrophy. Endocrinology , 2010; Aug;151(8):3706-19.

Jones SW, Hill RJ, Krasney PA, O'Conner B, Peirce N, Greenhaff PL. Disuse atrophy and exercise rehabilitation in humans profoundly affects the expression of genes associated with the regulation of skeletal muscle mass. FASEB J, 18, 1025-1027., 2004.

Kalista S, Schakman O, Gilson H, Lause P, Demeulder B, Bertrand L, Pende M, Thissen JP. The type 1 insulin-like growth factor receptor (IGF-IR) pathway is mandatory for the follistatininduced skeletal muscle hypertrophy. Endocrinology, 2012; Jan;153(1):241-53.

Kalupahana NS, Claycombe KJ, Moustaid-Moussa N. (n-3) Fatty acids alleviate adipose tissue inflammation and insulin resistance: mechanistic insights. Adv Nutr, 2011; jul;2(4):304-16.

Kandarian SC, Jackman RW. Intracellular signaling during skeletal muscle atrophy. Muscle Nerve, 2006; 33:155-165.

Kang KS, Wang P, Yamabe N, Fukui M, Jay T, Zhu BT. Docosahexaenoic acid induces apoptosis in MCF-7 cells in vitro and in vivo via reactive oxygen species formation and caspase 8 activation. PLoS One, 2010; Apr 22;5(4):e10296.

Karpati G, Hilton-Jones D, Bushby K, Griggs RC. Disorders of Voluntary Muscle, $8^{\mathrm{a}}$ ed. Cambridge: Cambridge University Press 2009, 2009.

Katiyar S, Liu E, Knutzen CA, Lang ES, Lombardo CR, Sankar S, Toth JI, Petroski MD, Ronai Z, Chiang GG. REDD1, an inhibitor of mTOR signalling, is regulated by the CUL4A-DDB1 ubiquitin ligase. EMBO Rep, 2009; Aug;10(8):866-72.

Kelly FJ, Goldspink DF. The differing responses of four muscle types to dexamethasone treatment in the rat. Biochem J, 1982 Oct 15;208(1):147-51.

Kelly FJ, McGrath JA, Goldspink DF, Cullen MJ. A morphological/biochemical study on the actions of corticosteroids on rat skeletal muscle. Muscle Nerve, 1986 Jan;9(1):1-10.

Khal J, Tisdale MJ. Downregulation of muscle protein degradation in sepsis by eicosapentaenoic acid (EPA). Biochem Biophys Res Commun, 2008; Oct 17;375(2):238-40. 
Komamura K, Shirotani-Ikejima H, Tatsumi R, Tsujita-Kuroda Y, Kitakaze M, Miyatake K, Sunagawa K, Miyata T. Differential gene expression in the rat skeletal and heart muscle in glucocorticoid-induced myopathy: analysis by microarray. Cardiovasc Drugs Ther, 2003; 17:303-10.

Kopecky J, Rossmeisl M, Flachs P, Kuda O, Brauner P, Jilkova Z, Stankova B, Tvrzicka E, Bryhn M. n-3 PUFA: bioavailability and modulation of adipose tissue function. Proc Nutr Soc, 2009; Nov;68(4):361-9.

Kudryashova E, Kramerova I, Spencer MJ. Satellite cell senescence underlies myopathy in a mouse model of limb-girdle muscular dystrophy 2H. J Clin Invest, 2012 May 1;122(5):1764-76.

Kunesová M, Braunerová R, Hlavatý P, Tvrzická E, Stanková B, Skrha J, et al. The influence of n-3 polyunsaturated fatty acids and very low calorie diet during a short-term weight reducing regimen on weight loss and serum fatty acid composition in severely obese women. Physiol Res, 2006; 55(1):63-72.

Laplante M, Sabatini DM. mTOR signaling in growth control and disease. Cell, 2012 Apr 13;149(2):274-93.

Le Foll C, Corporeau C, Le Guen V, Gouygou JP, Berge JP, Delarue J. Long-chain n-3 polyunsaturated fatty acids dissociate phosphorylation of Akt from phosphatidylinositol 3'kinase activity in rats. Am J Physiol Endocrinol Metab, 2007; 292: E1223-E1230.

Léger B, Cartoni R, Praz M, Lamon S, Dériaz O, Crettenand A, et al. Akt signalling through GSK-3beta, mTOR and Foxo1 is involved in human skeletal muscle hypertrophy and atrophy. $J$ Physiol, 2006; Nov 1;576(Pt 3):923-33.

Leonard AE, Pereira SL, Sprecher H, Huang YS. Elongation of long-chain fatty acids. Prog Lipid Res , 2004; Jan;43(1):36-54.

Li H, Kedar V, Zhang C, McDonough H, Arya R, Wang D et al. Atrogin-1/muscle atrophy Fbox inhibits calcineurin-dependent cardiac hypertrophy by participating in an SCF ubiquitin ligase complex. J Clinical Invest, 2004; 114(8): 1058-1071.

Lin PY, Su KP. A meta-analytic review of double-blind, placebo-controlled trials of antidepressant efficacy of omega-3 fatty acids. J Clin Psychiatry, 2007 Jul;68(7):1056-61.

Lokireddy S, McFarlane C, Ge X, Zhang H, Sze SK, Sharma M, et al. Myostatin induces degradation of sarcomeric proteins through a Smad3 signaling mechanism during skeletal muscle wasting. Mol Endocrinol, 2011; Nov;25(11):1936-49.

Magee P, Pearson S, Allen J. The omega-3 fatty acid, eicosapentaenoic acid (EPA), prevents the damaging effects of tumour necrosis factor (TNF)-alpha during murine skeletal muscle cell differentiation. Lipids Health Dis, 2008; 18;7:24.

Mammucari C, Milan G, Romanello V, Masiero E, Rudolf R, Del Piccolo P, et al. FoxO3 controls autophagy in skeletal muscle in vivo. Cell Metab, 2007 Dec;6(6):458-71.

Matsakas A, Patel K. Skeletal muscle fibre plasticity in response to selected environmental and physiological stimuli. Histol Histopathol, 2009; 24: 611-629. 
McElhinny AS, Kakinuma K, Sorimachi H, Labeit S, Gregorio CC. Muscle-specific RING finger-1 interacts with titin to regulate sarcomeric M-line and thick filament structure and may have nuclear functions via its interaction with glucocorticoid modulatory element binding protein-1. J. Cell Biol, 2002;157:125-136.

McFarlane C, Plummer E, Thomas M, Hennebry A, Ashby M, Ling N, et al. Myostatin induces cachexia by activating the ubiquitin proteolytic system through an NF-kappaB-independent, FoxO1-dependent mechanism. J Cell Physiol , 2006; 209(2):501-14.

Medina R, Wing SS, Goldberg AL. Increase in levels of polyubiquitin and proteasome mRNA in skeletal muscle during starvation and denervation atrophy. Biochem J, May 1, 1995; 307 (Pt 3):631-7.

Menezes LG, Sobreira C, Neder L, Rodrigues-Júnior AL, Martinez JAB. Creatine supplementation attenuates corticosteroidinduced muscle wasting and impairment of exercise performance in rats. J Appl Physiol , 2007; 102: 698-703.

Miyazak M, Esser KA. REDD2 is enriched in skeletal muscle and inhibits mTOR signaling in response to leucine and stretch. Am J Physiol Cell Physiol, 2009; Mar;296(3):C583-92.

Moore LM, Fisher AG, Coulson JM, Salmons S, Jarvis JC. Real-time polymerase chain reaction to follow the response of muscle to training. Artif Organs, 2008; Aug;32(8):630-3.

Mordier S, Deval C, Bechet D, Tassa A, Ferrara M. Leucine limitation induces autophagy and activation of lysosome-dependet proteolysis in $\mathrm{C} 2 \mathrm{C} 12$ myotubes through a mammalian target of rapamycin-independent signaling pathway. J Biol Chem, 2000; 275:29900.

Murakami T, Hasegawa K, Yoshinaga M. Rapid induction of REDD1 expression by endurance exercise in rat skeletal muscle. Biochem Biophys Res Commun, 2011; Feb 25;405(4):615-9.

Nader GA. Molecular determinants of skeletal muscle mass: getting the "AKT" together. Int $J$ Biochem Cell Biol. 2005 Oct;37(10):1985-96.

Najbjerg H, Young JF, Bertram HC. NMR-based metabolomics reveals that conjugated double bond content and lipid storage efficiency in HepG2 cells are affected by fatty acid cis/trans configuration and chain length. J Agric Food Chem , 2011; Aug 24;59(16):8994-9000.

Neal CRJr, Weidemann G, Kabbaj M, Vázquez DM. Effect of neonatal dexamethasone exposure on growth and neurological development in the adult rat. Am J Physiol Regul Integr Comp Physiol , 2004; Aug;287(2):R375-85.

Nedergaard A, Karsdal MA, Sun S, Henriksen K. Serological muscle loss biomarkers: an overview of current concepts and future possibilities. J Cachexia Sarcopenia Muscle. 2013 Mar;4(1):1-17.

Nicastro H, Zanchi NE, da Luz CR, de Moraes WM, Ramona P, de Siqueira Filho MA, Chaves DF, Medeiros A, Brum PC, Dardevet D, Lancha AHJr. Effects of leucine supplementation and resistance exercise on dexamethasone-induced muscle atrophy and insulin resistance in rats. Nutrition , 2012; Apr;28(4):465-71. 
Nicolaides NC, Galata Z, Kino T, Chrousos GP, Charmandari E. The human glucocorticoid receptor: molecular basis of biologic function. Steroids , 2010; Jan;75(1):1-12.

Ogilvie RW, Feeback DL. A metachromatic dye-ATPase method for the simultaneous identification of skeletal muscle fiber types I, IIA, IIB and IIC. Stain Technol. 1990;65(5):23141.

Ottenheijm CA, Heunks LM, Dekhuijzen RP. Diaphragm adaptations in patients with COPD. Respir Res , 2008; Jan 24;9:12.

Pallafacchina G, Blaauw B, Schiaffino S. Role of satellite cells in muscle growth and maintenance of muscle mass. Nutr Metab Cardiovasc Dis, 2012 May 21.

Palmer RM, Wahle KW. Protein synthesis and degradation in isolated muscle. Effect of omega 3 and omega 6 fatty acids. Biochem J, 1987 Mar 1;242(2):615-8.

Pereira RM, Freire de Carvalho J. Glucocorticoid-induced myopathy. Joint Bone Spine , 2011; Jan;78(1):41-4.

Pinheiro CH, Sousa Filho WM, Oliveira Neto J, Marinho MdeJ, Motta Neto R, Smith MM, Silva CA. Exercise prevents cardiometabolic alterations induced by chronic use of glucocorticoids. Arq Bras Cardiol , 2009; Oct;93(4):400-8, 392-400.

Pires-Oliveira M, Maragno AL, Parreiras-E-Silva LT, Chiavegatti T, Gomes MD, Godinho RO. Testosterone represses ubiquitin ligases atrogin-1 and Murf-1 expression in an androgensensitive rat skeletal muscle in vivo. J Appl Physiol, 2010; 108: 266-273.

Powell, SR. The ubiquitin-proteasome system in cardiac physiology and pathology. Am. J. Physiol. Heart Circ. Physiol, 2006; 291:H1-H19.

Prezant DJ, Karwa ML, Richner B, Maggiore D, Gentry EI, Cahill J. Gender-specific effects of dexamethasone treatment on rat diaphragm structure and function. J Appl Physiol, 1997; Jan;82(1):125-33.

Qin J, Du R, Yang YQ, Zhang HQ, Li Q, Liu L et al. Dexamethasone-induced skeletal muscle atrophy was associated with upregulation of myostatin promoter activity. Res Vet Sci., 2012; Aug 29.

Qin W, Pan J, Wu Y, Bauman WA, Cardozo C. Protection against dexamethasone-induced muscle atrophy is related to modulation by testosterone of FOXO1 and PGC-1 $\alpha$. Biochem Biophys Res Commun, 2010; Dec 17;403(3-4):473-8.

Ranvier L. De quelques faits relatifs a l'histologie et a la physiologie des muscles stries. Archives de Physiologie normale et Pathologique, 1874, 6; 1-15.

Rebbapragada A, Benchabane H, Wrana JL, Celeste AJ, Attisano L. Myostatin Signals through a Transforming Growth Factor $\beta$-Like Signaling Pathway To Block Adipogenesis. Mol Cell Biol, 2003 October; 23(20): 7230-7242.

Reed UC. Congenital muscular dystrophy, Part II: a review of pathogenesis and therapeutic perspectives. Arq Neuropsiquiatr; 2009, 67(2-A):343-362. 
Reed UC. Doenças neuromusculares (Neuromuscular disorders). J Pediatr (Rio J), 2002; 78 (Supl.1): S89-S103.

Reisner K, Lehtonen M, Storvik M, Jantson T, Lakso M, Callaway JC, Wong G. Trans fat diet causes decreased brood size and shortened lifespan in Caenorhabditis elegans delta-6-desaturase mutant fat-3. J Biochem Mol Toxicol , 2011; Sep-Oct;25(5):269-79

Russell AP. Molecular regulation of skeletal muscle mass. Clin Exp Pharmacol Physiol, 2010; Mar;37(3):378-84.

Ruzickova J, Rossmeisl M, Prazak T, Flachs P, Sponarova J, Veck M, et al. Omega-3 polyunsaturated fatty acids of marine origin reduce dietary obesity in mice by affecting cellularity of adipose tissue. Lipids, 2004; Dec;39(12):1177-85.

Ryall JG, Plant DR, Gregorevic P, Sillence MN, Lynch GS. Beta 2-agonist administration reverses muscle wasting and improves muscle function in aged rats. $J$ Physiol , 2004; 555:175188.

Sandri M, J Lin, Handschin C, Yang W, Arany ZP, Lecker SH, Goldberg AL, Spiegelman BM. PGC-1alpha protects skeletal muscle from atrophy by suppressing FoxO3 action and atrophyspecific gene transcription. Proc Natl Acad Sci U S A, 2006, Oct 31;103(44):16260-5.

Sandri M, Sandri C, Gilbert A, Skurk C, Calabria E, Picard A, et al. Foxo transcription factors induce the atrophyrelated ubiquitin ligase atrogin-1 and cause skeletal muscle atrophy. Cell , 2004; 117(3), 399-412.

Sandri M. Signaling in muscle atrophy and hypertrophy. Physiology Rev, 2008; 23:160-170.

Schachter H, Vajsar J, Zhang W. The role of defective glycosylation in congenital muscular dystrophy. Glycoconj J, 2004, 20(5):291-300.

Schakman O, Gilson H, Kalista S, Thissen JP. Mechanisms of muscle atrophy induced by glucocorticoids. Horm Res, 2009 Nov;72 Suppl 1:36-41.

Schakman O, Gilson H, Thissen JP. Mechanisms of glucocorticoid-induced myopathy. $J$ Endocrinol , 2008; 197:1-10.

Schiaffino S, Dyar KA, Ciciliot S, Blaauw B, Sandri M. Mechanisms regulating skeletal muscle growth and atrophy. FEBS J, 2013.

Schiaffino S, Reggiani C. Fiber types in mammalian skeletal muscles. Physiol Rev, 2011; Oct;91(4):1447-531.

Sener A, Zhang Y, Bulur N, Louchami K, Malaisse WJ, Carpentier YA. The metabolic syndrome of omega3-depleted rats. II. Body weight, adipose tissue mass and glycemic homeostasis. Int J Mol Med, 2009; Jul;24(1):125-9.

Shirai N, Suzuki H, Wada S. Direct methylation from mouse plasma and from liver and brain homogenates. Analytical Biochemistry, 2005, 343: 48-53. 
Simopoulos AP. Omega -3 fatty acids in inflammation an autoimmune diseases. $J$ Am Coll Nutr, $2002 ; 21: 495-505$.

Simopoulos AP. Omega-6/omega-3 essential fatty acids: biological effects. World Rev Nutr Diet, 2009;99:1-16.

Singer P, Shapiro H, Theilla M, Anbar R, Singer J, Cohen J. Anti-inflammatory properties of omega-3 fatty acids in critical illness: novel mechanisms and an integrative perspective. Intensive Care Med, 2008; Sep;34(9):1580-92.

Smith HJ, Greenberg NA, Tisdale MJ. Effect of eicosapentaenoic acid, protein and amino acids on protein synthesis and degradation in skeletal muscle of cachectic mice. Br J Cancer, $2004 \mathrm{Jul}$ 19;91(2):408-12.

Smith HJ, Mukerji P, Tisdale MJ. Attenuation of proteasome-induced proteolysis in skeletal muscle by \{beta\}-hydroxy-\{beta\}-methylbutyrate in cancer-induced muscle loss. Cancer Res, $2005 ; 1 ; 65(1): 277-83$.

Sohal PS, Baracos VE, Clandinin MT. Dietary omega 3 fatty acid alters prostaglandin synthesis, glucose transport and protein turnover in skeletal muscle of healthy and diabetic rats. Biochem $J, 1992$ Sep 1;286 ( Pt 2):405-11.

Soriguer FJ, Tinahones FJ, Monzón A, Pareja A, Rojo-Martínez G, Moreno F, et al. Varying incorporation of fatty acids into phospholipids from muscle, adipose and pancreatic exocrine tissues and thymocytes in adult rats fed with diets rich in different fatty acids. Eur J Epidemiol, 2000; Jun;16(6):585-94.

Soukup T, Smerdu V, Zacharová G. Fiber type composition of unoperated rat soleus and extensor digitorum longus muscles after unilateral isotransplantation of a foreign muscle in long-term experiments. Physiol Res, 2009, 58(2):253-62.

Stewart CE, Rittweger J. Adaptive processes in skeletal muscle: molecular regulators and genetic influences. J Musculoskelet Neuronal Interact, 2006; Jan-Mar;6(1):73-86.

Stitt TN, Drujan D, Clarke BA, Panaro F, Timofeyva Y, Kline WO, et al. The IGF-1/PI3K/Akt pathway prevents expression of muscle atrophy-induced ubiquitin ligases by inhibiting FOXO transcription factors. Mol. Cell , 2004; 14(3), 395-40.

Sun D, Krishnan A, Zaman K, Lawrence R, Bhattacharya A, Fernandes G. Dietary n-3 fatty acids decrease osteoclastogenesis and loss of bone mass in ovariectomized mice. $J$ Bone Miner Res.Jul;18(7):1206-16., 2003.

Surette M. The science behind dietary omega-3 fatty acids. CMAJ , 2008; 15;178(2): 177-180.

Tintignac LA, Lagirand J, Batonnet S, Sirri V, Leibovitch MP, Leibovitch SA. Degradation of MyoD mediated by the SCF (MAFbx) ubiquitin ligase. J Biol Chem, 2005 Jan 28;280(4):284756.

Tisdale MJ. Clinical anticachexia treatments. Nutr Clin Pract, 2006; 21:168-174. 
Van Der Heide LP, Hoekman MF, Smidt MP. The ins and outs of FoxO shuttling: mechanisms of FoxO translocation and transcriptional regulation. Biochem. J , 2004; 380(Pt 2), 297- 309.

Verhees KJ, Schols AM, Kelders MC, Op den Kamp CM, van der Velden JL, Langen RC. Glycogen synthase kinase-3 $\beta$ is required for the induction of skeletal muscle atrophy. Am $J$ Physiol Cell Physiol., 2011; Nov;301(5):C995-C1007.

Voisin L, Breuille D, Combaret L, Pouyet C, Taillandier D, Aurousseau E, et al. Muscle wasting in a rat model of long-lasting sepsis results from the activation of lysosomal, Ca2+activated, and ubiquitin-proteasome proteolytic pathways. J. Clin. Invest , 1996; 97(7), 16101617.

Wang H, Kubica N, Ellisen LW, Jefferson LS, Kimball SR. Dexamethasone represses signaling through the mammalian target of rapamycin in muscle cells by enhancing expression of REDD1. J Biol Chem , 2006; 281:39128-34.

Whitehouse AS, Smith HJ, Drake JL, Tisdale MJ. Mechanism of attenuation of skeletal muscle protein catabolism in cancer cachexia by eicosapentaenoic acid. Cancer Res , 2001; 61:36043609.

Winbanks CE, Weeks KL, Thomson RE, Sepulveda PV, Beyer C, Qian H, et al. Follistatinmediated skeletal muscle hypertrophy is regulated by Smad3 and mTOR independently of myostatin. J Cell Biol, Jun 25;197(7):997-1008 2012.

Wu Y, Zhao W, Zhao J, Zhang Y, Qin W, Pan, J, et al. REDD1 is a major target of testosterone action in preventing dexamethasone-induced muscle loss. Endocrinology, 2010; Mar;151(3):1050-9.

Wyke SM, Russell ST, Tisdale MJ. Induction of proteasome expression in skeletal muscle is attenuated by inhibitors of NF-kappaB activation. Br J Cancer , 2004; 91:1742-1750.

Yimlamai T, Dodd SL, Borst SE, Park S. Clenbuterol induces muscle-specific attenuation of atrophy through effects on the ubiquitin-proteasome pathway. J Appl Physiol , 2005; 99:71-80.

Yoshizawa F, Kido T, Nagasawa T. Stimulative effect of dietary protein on the phosphorylation of p70 S6 kinase in the skeletal muscle and liver of food-deprived rats. Biosci biotechnol biochem , 1999; 63:1803-1805.

Youdim KA, Martin A, Joseph JA. Essential fatty acids and the brain: possible health implications. Int J Dev Neurosci, 2000 Jul-Aug;18(4-5):383-99.

Zhao W, Pan J, Zhao Z, Wu Y, Bauman WA, Cardozo CP. Testosterone protects against dexamethasone-induced muscle atrophy, protein degradation and MAFbx upregulation. $J$ Steroid Biochem Mol Biol, 2008 May;110(1-2):125-9.

Zheng B, Ohkawa S, Li H, Roberts-Wilson TK, Price SR. FOXO3a mediates signaling crosstalk that coordinates ubiquitin and atrogin-1/MAFbx expression during glucocorticoid-induced skeletal muscle atrophy. FASEB J., 2010 Aug;24(8):2660-9. 
Zhu X, Topouzis S, Liang LF, Stotish RL. Myostatin signaling through Smad2, Smad3 and Smad4 is regulated by the inhibitory Smad7 by a negative feedback mechanism. Cytokine, 2004 Jun 21;26(6):262-72.

Zimmers TA, Davies MV, Koniaris LG, Haynes P, Esquela AF, Tomkinson KN, et al. Induction of cachexia in mice by systemically administered myostatin. Science, 2002 May 24; 296(5572):1486-8. 


\section{ANEXOS}

9.1.ANEXO 1 - Carta de aprovação do comitê de ética em pesquisa

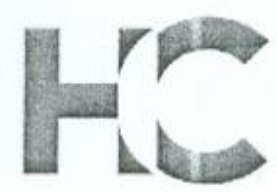

Ao

Departamento de Neurologia

O Presidente da Comissão de Ética para Análise de Projetos de Pesquisa - CAPPesq da Diretoria Clínica do Hospital das Clínicas da Faculdade de Medicina da Universidade de São Paulo, em 24.11.10 tomou conhecimento que o Protocolo de Pesquisa n 1187/09 intitulado: "Efeitos do ácido graxo Omega-3 na prevenção da atrofia muscular induzida pela Dexametasona", aprovado em 09.06.10 será dissertacão de mestrado do aluno ALAN FAPPI, tendo como orientador EDMAR ZANOTELI.

CAPPesq, 25 de novembro de 2010.

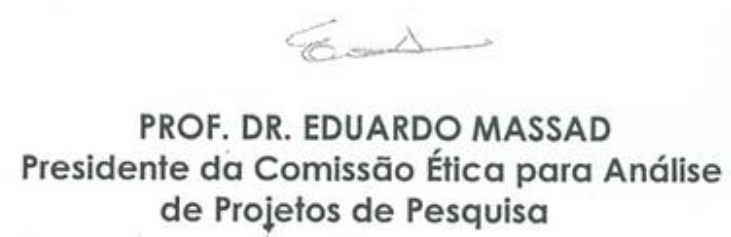

